\title{
Negotiating Human Health in a Rapidly Changing Urban Environment: HIV and AIDS Vulnerabilities among Street Traders in Warwick Junction, Durban, South Africa
}

By May Chazan, B.Sc., B.Ed.

\author{
A thesis submitted to: \\ The Faculty of Graduate Studies and Research \\ In partial fulfillment of the \\ requirements for the degree
}

\begin{abstract}
Masters of Arts
Department of Geography and Environmental Studies

Carleton University
\end{abstract}

(C) May Chazan, 2005 


$\begin{array}{ll}\begin{array}{l}\text { Library and } \\ \text { Archives Canada }\end{array} & \begin{array}{l}\text { Bibliothèque et } \\ \text { Archives Canada }\end{array} \\ \begin{array}{l}\text { Published Heritage } \\ \text { Branch }\end{array} & \begin{array}{l}\text { Direction du } \\ \text { Patrimoine de l'édition }\end{array} \\ \begin{array}{l}\text { 395 Wellington Street } \\ \text { Ottawa ON K1A ON4 }\end{array} & \begin{array}{l}\text { 395, rue Wellington } \\ \text { Ottawa ON K1A ON4 } \\ \text { Canada }\end{array}\end{array}$

Your file Votre référence

ISBN: 0-494-10040-0

Our file Notre référence

ISBN: 0-494-10040-0

NOTICE:

The author has granted a nonexclusive license allowing Library and Archives Canada to reproduce, publish, archive, preserve, conserve, communicate to the public by telecommunication or on the Internet, loan, distribute and sell theses worldwide, for commercial or noncommercial purposes, in microform, paper, electronic and/or any other formats.

The author retains copyright ownership and moral rights in this thesis. Neither the thesis nor substantial extracts from it may be printed or otherwise reproduced without the author's permission.
AVIS:

L'auteur a accordé une licence non exclusive permettant à la Bibliothèque et Archives Canada de reproduire, publier, archiver, sauvegarder, conserver, transmettre au public par télécommunication ou par l'Internet, prêter, distribuer et vendre des thèses partout dans le monde, à des fins commerciales ou autres, sur support microforme, papier, électronique et/ou autres formats.

L'auteur conserve la propriété du droit d'auteur et des droits moraux qui protège cette thèse. $\mathrm{Ni}$ la thèse ni des extraits substantiels de celle-ci ne doivent être imprimés ou autrement reproduits sans son autorisation.
In compliance with the Canadian

Privacy Act some supporting forms may have been removed from this thesis.

While these forms may be included in the document page count, their removal does not represent any loss of content from the thesis.
Conformément à la loi canadienne sur la protection de la vie privée, quelques formulaires secondaires ont été enlevés de cette thèse.

Bien que ces formulaires aient inclus dans la pagination, il n'y aura aucun contenu manquant.

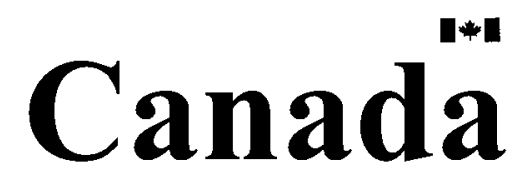




\begin{abstract}
The HIV/ AIDS epidemic is new and growing in South Africa and societal consequences will unfold for decades. This thesis examines vulnerability to infection and impacts among street traders in Warwick Junction, Durban, based primarily on participatory research with traders. At the macro level, it shows traders' vulnerabilities as shaped by historical structures, societal transition, globalization and urbanization, which result in livelihood insecurity and dislocation from their families. At the micro level, traders are experiencing the epidemic differently by age and gender due to uneven socio-economic circumstances. Linking these contexts indicates that institutional intervention could enable traders to respond in ways that mediate the epidemic's effects. This research provides a basis to examine the adequacy of vulnerability concepts, revealing that in order to reduce future tragedy, there is a need to understand the processes that underpin infection and impacts-a re-orientation of vulnerability assessment away from its present outcomes-focus.
\end{abstract}

Key words: vulnerability; HIV/ AIDS; human health; globalization; South Africa 


\section{Acknowledgements}

I would like to extend my sincere thanks to all the women and men in Warwick Junction who entrusted me with their stories and allowed me a glimpse into their lives. I would also like to thank all of the health care providers and traditional healers who participated in this research, and acknowledge the support of the eThekwini Municipality Health Department, the Inner Thekwini Renewal and Urban Management Programme, and the Informal Trade Management Board. I am extremely grateful to Sbo Radebe, Ntombi Thula, Sithle Sithole and Phumzile Cele: as colleagues, research assistants and friends, they have taught me about their country and this research has benefited tremendously from their skills. I value the insights and guidance I received from my three excellent academic advisors. I would like to thank Mike Brklacich, for challenging me and for his consistent support, critical feedback and open-mindedness; Tim Quinlan, for his conceptual contribution to the development of this project; and Alan Whiteside, for his prompt and discerning critique and for genuinely sharing my enthusiasm. I appreciate the useful input offered to me by Fiona Mackenzie, Jeremy Grest, Caroline Skinner, Richard Dobson, Tobias Mkhize and Renaud DePlaen, and the assistance of my colleagues at the Health Economics and HIV/ AIDS Research Division (HEARD) at the University of KwaZulu-Natal (UKZN), especially Obed Qulo, Nkosinathi Ngcobo and Nina Veenstra. Finally, special thanks go out to my Carleton 'support group', especially Melanie Sommerville and Emily Wilson, for their inspiration, commitment, friendship and engagement; to Beverly Kraft and Eric Kokish, for their encouragement and invaluable editorial help; and to Ben Hodson and Lady, for making me laugh, sharing my excitement and feeling my despair. This research was hosted by HEARD and funded by the International Development Research Centre (IDRC) Ecohealth Training Awards. 


\section{Table of Contents}

1.0 Introduction 1

2.0 Conceptual and Methodological Foundations: 8

Negotiating Research in a Cross-Cultural Setting
2.1 Conceptual Starting Points

2.2 Street Traders in Warwick Junction: 16

A Window into Converging Processes of Change

$\begin{array}{ll}2.3 \text { Research Design } & 22\end{array}$

2.3.1 Methodological Framework and Rationale $\quad 23$

$\begin{array}{ll}\text { 2.3.2 Research Process and Analysis } & 25\end{array}$

2.4 Methodological Strengths and Limitations 34

$\begin{array}{ll}2.5 \text { Conclusion } & 35\end{array}$

3.0 The Macro Context of Traders' Vulnerabilities: 38

Converging Processes of Change

3.1 Common Experiences of Change: 39

Key Trends and Characteristics among Traders

3.2 Situating Traders' Experiences amidst Converging Macro Processes 43

3.2.1 South Africa's Transitioning Political Economy (Figure 3a) 44

3.2.2 Transition and Globalization (Figure 3b) 47

3.2.3 Transition and Migration (Figure 3c) $\quad 49$

$\begin{array}{lr}\text { 3.2.4 Enter HIV/ AIDS (Figure 3d) } & 50\end{array}$

3.3 Conclusion 56

4.0 The Micro Context of Traders' Vulnerabilities:

Who, Why, How and What?

4.1 Who among traders is vulnerable to HIV/ AIDS?

4.2 Why are traders vulnerable to HIV and AIDS? 61

4.2.1 The Manifestation of HIV and AIDS $\quad 61$

4.2.2 Perceptions of AIDS and Mixed Messages $\quad 62$

$\begin{array}{ll}\text { 4.2.3 Social Stigma } & 66\end{array}$

4.2.4 Underlying Health Stresses: Livelihood, Mobility, and Access 67

4.3 How are traders vulnerable to HIV and AIDS? 70

4.4 What underlies traders' differentiated vulnerabilities? 76

4.5 Building a Framework of Micro Health Vulnerabilities 82

$\begin{array}{ll}4.6 \text { Conclusion } & 87\end{array}$ 
5.0 At the Core of the Uneven Struggle:

Power, Structure, and Agency

$\begin{array}{ll}5.1 \text { Dimensions of Power } & 90\end{array}$

$\begin{array}{ll}\text { 5.2 Power and Structure } & 92\end{array}$

5.3 Power and Human Agency $\quad 95$

$\begin{array}{ll}5.4 \text { Conclusion } & 96\end{array}$

6.0 Looking Forward: $\quad 98$

A Reorientation of Health and Vulnerability Concepts
6.1 Building a Framework of Comprehensive Health Vulnerabilities

$\begin{array}{ll}\text { 6.1.1 Linking Macro Processes and Micro Vulnerabilities } & 101\end{array}$

(Outer-Inner Ring Interactions)

6.1.2 The Centrality of Human Agency (Middle-Ring Interactions) 104

6.2 Extending Health Vulnerability Concepts amidst HIV/ AIDS and Rapid Change: Beyond Warwick Junction 107

6.2.1 Intersecting Literatures: Extending Vulnerability Dynamics $\quad 107$

6.2.2 Vulnerabilities are embedded in changing social systems 111

6.2.3 Vulnerabilities are differentiated 113

6.2.4 Vulnerabilities are driven by dynamic power relations $\quad 114$

$\begin{array}{ll}\text { 6.2.5 Vulnerabilities are negotiated } & 117\end{array}$

6.2.6 Toward an Interdisciplinary Framework 119

6.2.7 A Reorientation from Outcomes to Processes: 121

Methodological Implications

6.3 Revisiting Warwick Junction: Potential Framework Applications 123

$\begin{array}{ll}6.4 \text { Conclusion } & 127\end{array}$

$\begin{array}{lr}7.0 \text { Summary and Conclusions } & 128\end{array}$

$\begin{array}{ll}7.1 \text { Summary } & 129\end{array}$

$\begin{array}{ll}7.2 \text { Research Contributions } & 131\end{array}$

$\begin{array}{ll}7.2 \text { Conclusion } & 132\end{array}$

$\begin{array}{ll}\text { References } & 137\end{array}$

$\begin{array}{ll}\text { Appendices } & 143\end{array}$ 


\section{List of Tables}

Table 1: Research Framework: Five-Phase Research Process and Outcomes 37

Table 2: 'Othering' among Traders $\quad 59$

Table 3: Scepticism and Differing Perceptions around HIV/ AIDS among Traders 63

Table 4: Underlying Health Stresses for Traders $\quad 69$

Table 5: Differentiated Micro Vulnerabilities $\quad 71$

Table 6: Fear and Inevitability among Young Traders $\quad 71$

Table 7: Intergenerational Silence: The Young-Old Divide 76

Table 8: Factors Underlying Differentiated Vulnerabilities: Gender-Age Trends $\quad 80$

Table 9: Summary of Differentiated Vulnerabilities and Underlying Conditions $\quad 82$

Table 10: Towards an Interdisciplinary Framework of Health Vulnerability $\quad 121$

Table 11: Intervention Strategies at Three Levels 124 


\section{List of Figures}

Figure 1: HIV/ AIDS Epidemic Curves: Infection, Illness, Impacts 14

Figure 2: Map of South Africa and Durban 18

Figure 3: Effects of 4 Macro Processes on the Lives of Warwick Junction Traders 46

Figure 4: Micro Health Vulnerabilities of Warwick Junction Traders 83

Figure 5: Conceptualizing Comprehensive Vulnerabilities

for Warwick Junction Traders

103

Figure 6: Intersecting Literatures -

An Approach to Extending Health Vulnerability Concepts 


\section{List of Appendices}

Appendix A: Schedule of Interviews 143

Appendix B: Stratified Sample of Core Trader Participants 145

Appendix C: Questionnaires for Interviews with Traders 147

Appendix D: Traders' Perceptions of Health as Person-Environment Interactions 153

Appendix E: Core Sample of Traders Differentiated by Age and Gender 154

Appendix F: Reported Impacts of HIV/ AIDS from Interviews with Core 20 Traders, by Age and Gender

Appendix G: Results of Focus Group, AIDS Component (10 December 2004) 156

Appendix H: Biomedical Practitioners' Messages around HIV and AIDS 157

Appendix I: Messages about HIV and AIDS Articulated by Traditional Healers $\quad 158$

Appendix J: Uneven Vulnerabilities Differentiated by Gender and Age 159

Appendix K: Examples of Macro-Micro Interactions Generating Vulnerabilities for

Traders

160

Appendix L: Examples of Inter-Ring Interactions in Figure 5 161 


\section{List of Acronyms and Glossary}

$\begin{array}{ll}\text { ABC } & \text { Abstinence, Be faithful, Condomize } \\ \text { AIDS } & \text { Auto Immune Deficiency Syndrome } \\ \text { ANC } & \text { African National Congress } \\ \text { ARV } & \text { Anti-Retroviral } \\ \text { GEAR } & \text { Growth, Employment and Redistribution } \\ \text { HEARD } & \text { Health Economics and HIV/ AIDS Research Division } \\ \text { HIV } & \text { Human Immunodeficiency Virus } \\ \text { HSRC } & \text { Human Sciences Research Council } \\ \text { IDRC } & \text { International Development Research Centre } \\ \text { IFP } & \text { Inkatha Freedom Party } \\ \text { ITMB } & \text { Informal Trade Management Board } \\ \text { iTrump } & \text { Inner Thekwini Renewal and Urban Management Programme } \\ \text { NGO } & \text { Non Government Organization } \\ \text { RDP } & \text { Reconstruction and Development Programme } \\ \text { SEWU } & \text { Self Employed Women's Union } \\ \text { SAVI } & \text { Southern Africa Vulnerability Initiative } \\ \text { TAC } & \text { Treatment Action Campaign } \\ \text { TB } & \text { Tuberculosis } \\ \text { THC } & \text { Traditional Healers Council } \\ \text { THO } & \text { Traditional Healers Organization } \\ \text { UKZN } & \text { University of KwaZulu-Natal } \\ \text { UDF } & \text { United Democratic Front } \\ \text { WHO } & \text { World Health Organisation } \\ \text { WJURP } & \text { Warwick Junction Urban Renewal Project } \\ & \end{array}$

Bantustan Self-governing tribal homeland under Apartheid

Dagga Marijuana or hashish

Farm Rural area

Forum Traders Against Crime

Fronting Working informally and illegally for another trader in the market

Inyanga Traditional healer

Lobola Bride price

Mealie Corn

Mpempo Traditional incense

Muthi Herbal medicine

Stokvel Informal or co-operative savings scheme

Umdeni Household 


\section{Chapter 1}

\section{Introduction}

Beads of sweat forming on her brow, the 54-year-old Zulu woman turns off her sewing machine and lowers herself painfully onto an upside-down crate. She sews and sells church uniforms amidst the bustle of the Warwick Junction's Berea Railway Station, in the heart of Durban. She supports 18 people on her trading income. As she reflects upon what threatens her health, her story unfolds:

... Our houses were burnt down during the violence, and we were left homeless; we could see it coming from the other side of the river...I moved to Durban in 1986 and started trading in 1991. Most things have improved [since the end of Apartheid], but I am still struggling because I work a lot, and I am not well...

My niece was sick and died last year. I looked after her because nobody else was interested... She didn't say that she had AIDS, but I knew and she knew. My sister's other daughter is presenting with it now... her lips are red with herpes, she's coughing, her tonsils are infected, she has thrush. And another niece, a third one, is also having it. She was pregnant before and the child died, and now she is pregnant again. I am a guardian to all of them; they come to my house and I take care of them. I will be the one to take care of the orphans... None of them will say that they have it... Even the authorities would rather talk about the symptoms but not use the name 'AIDS'.

My main worry is that I won't be able to work, and then what will happen? I am trying to put money away for my kids' education, but I am struggling to pay for food and school uniforms. My church has a 'helping hand' group: each month we contribute 20 Rand, and if there's a death, the money is used to buy food and help the family. But there are funerals every day now. I tell my kids that one day we will have a problem: I will die and they need jobs. But they have stopped looking...

She suffers from hypertension, arthritis and diabetes, but she does not speak about her health in relation to these medical conditions or to her own personal risk of contracting HIV. She views her health in relation to her family, and as intertwined with a 
transitioning government, political violence, urban migration, rising unemployment, the impacts of the AIDS epidemic, and overall impoverishment. Rising unemployment in conjunction with AIDS is leaving her growing numbers to support on a shrinking income; stretched resources are hindering her ability to support and care for sick family members and orphans. Mixed messages from "authorities," stigma, shame and silence are also contributing to her family's vulnerabilities. These converging processes are, for the most part, beyond her control, and she alludes to feelings of powerlessness amongst her children; yet her church group demonstrates continued community strength. This woman's story - with its tragedy and hope-illustrates the complexities and nuances of human vulnerability in Warwick Junction.

In South Africa, a history of colonialism and Apartheid has led to race, class and gender inequalities, fractured family and community structures, and an entrenched system of migrant labour (Sparks 2003). Since the end of Apartheid in 1994, macro-economic 'reform' and globalization have resulted in increased unemployment and a growing gap between rich and poor (Nicholson 2001). Meanwhile, HIV prevalence among women attending antenatal clinics jumped from 0.8 percent in 1990 to 27.9 percent in 2003 (Department of Health 2003). The registered number of adult deaths increased from 272000 in 1998 to 456700 in 2003 (UNAIDS 2003). Post-Apartheid South Africa is facing a new and generalized epidemic - one that is not confined to 'high risk' groupsbut the epidemic is experienced unevenly by region, gender, age, class and race (Gilbert \& Walker 2002). The spread and impacts of HIV/ AIDS appear to be intimately tied to 
South Africa's social history and political economy: an embodiment of historical dispossession and globalization's growing gap (Fassin 2003).

HIV/ AIDS epidemics are "long-wave events" (Barnett \& Whiteside 2002), and while the story of the Zulu seamstress illustrates that the epidemic is already increasing her financial and care-taking burdens, the longer-term effects in South Africa remain to be seen. The Uganda experience suggests that HIV progresses into AIDS over six to eight years, but the full societal impacts of orphaned children, disintegrated households, and fractured communities, only come to light in the decades after infection levels have peaked (ibid.). In South Africa, the epidemic is young and prevalence is rising. Antiretroviral therapies (ARVs), which can extend the lives of people living with HIV for up to six years, are difficult to access for those without private health coverage; public sector treatment 'roll-out' has so far been exceedingly slow (TAC 2005). South Africa's epidemic is like an approaching tidal wave: regardless of even the most successful prevention campaigns, the impacts are looming. But unlike a tidal wave, the consequences of the epidemic will take generations to fully break and an early warning (i.e., rising prevalence) has been sounding for a decade.

Just as a tidal wave may expose the pre-existing impoverishment of people living in marginal coastal housing, so too could rising illness and death reveal and perhaps even accelerate conditions of social and economic insecurity. What can be done so that as the wave breaks those living in low-lying areas are not carried out to sea? While providing universal access to treatment is certainly one part of the solution, the full answer is enormously complex, highly politicized and laden with unknowns. 
This thesis addresses four over-arching limitations that have emerged in HIV/ AIDS research. First, although epidemics do not take place in isolation, little research examines the cumulative and linked impacts of AIDS as it converges with other processes of change (Barnett \& Whiteside 2002). Second, while aggregated data show that infection levels are uneven at the population level, there has been limited study into how the effects of epidemics are experienced and distributed within heterogeneous communities (Craddock 2004). Third, despite growing evidence that HIV/ AIDS epidemics are embedded in societal structures, few studies investigate the political, economic and social drivers of epidemics and their impacts (ibid.). Fourth, very little is known about how individuals and communities are responding to epidemics, or what factors enable and constrain their actions (Barnett \& Whiteside 2002). Collectively, these limitations restrict our understanding of the processes that underlie the spread and impacts of HIV/ AIDS—our understanding of HIV/ AIDS vulnerability.

Indeed, AIDS research has been dominated by biomedical and epidemiological studies, which provide important information on how many people are infected, who, and where; yet, these do not explain what makes different people and groups vulnerable at different times and in different contexts, or how to most effectively intervene (Craddock 2004). While 'vulnerability' is now becoming a common theme among social scientists entering the AIDS field, the concept often lacks precision, and very little conceptual refinement has been based on empirical investigation (Delor \& Huber 2000). These empirical and conceptual limitations impede capacity to address the fundamental processes that have given rise to South Africa's epidemic and will shape its future 
impacts; intensive research is required to unravel the causal processes of vulnerabilities in order to reduce the adversity of the epidemic's outcomes.

The purpose of this thesis is therefore to gain a nuanced understanding of vulnerability to HIV and AIDS: how people and groups are vulnerable, what causes vulnerabilities, and why. HIV/ AIDS vulnerability refers to the underlying processes and conditions that result in different levels of infection, illness and impacts, as well as uneven response possibilities, among individuals and groups. This thesis focuses on one heterogeneous group of people who live and work on the peripheries of South Africa's economy and society: informal street traders in the rapidly changing urban environment of Warwick Junction, Durban.

The vulnerability analysis that follows is based primarily on four months of participatory field research with street traders in Warwick Junction, which took place from September to December 2004. It is thus grounded in traders' own perceptions of the epidemic and the conditions that stress their health. It draws on secondary sources, key informants, health care providers, and field observations to support, contextualize and explain traders' stories.

The assessment begins by examining common experiences in the lives of street traders and situating these within a macro context. It then investigates how traders are affected by the epidemic and what micro conditions shape their health. It next considers the drivers of traders' uneven vulnerabilities and investigates their responses and response options. Finally, it explores the links between macro processes, micro conditions and response capacity and, through this process, develops a framework of 
comprehensive health vulnerability, which provides insights for intervention in Warwick Junction and for vulnerability analysis more broadly.

This thesis is, first and foremost, derived from the experiences of the Zulu seamstress, other traders, health care providers and municipal employees in Warwick Junction. It is also informed by recent developments in HIV/ AIDS, human vulnerability, and globalization research; indeed, a critical examination of these literatures has taken place prior to, alongside, and after the fieldwork in Warwick Junction. The primary research provides a basis from which to begin connecting these disciplines and, ultimately, to examine and challenge the adequacy of current health and vulnerability concepts in addressing the coming impacts of AIDS.

Drawing on key themes from within these literatures, the thesis contends that traders' vulnerabilities existed prior to the epidemic, are generated by uneven power relations, and can be altered. It examines the utility of shifting the current outcomes-focus in AIDS research towards analyses of the underlying processes that underpin infection, illness and cumulative impacts.

The remainder of the thesis is divided into six chapters

- Chapter 2 introduces the conceptual foundations of this analysis, as well as the research site, methodological approach and fieldwork process.

- Chapter 3 sets the macro context of traders' vulnerabilities, examining how societal processes shape traders' common experiences and how these processes interact or converge.

- Chapter 4 sets the micro context, evaluating who among traders is vulnerable to the epidemic, why traders are vulnerable, how they are vulnerable, and what underlies their differentiated vulnerabilities. 
- Chapter 5 investigates the drivers of traders' uneven struggles and the conditions that influence their response options.

- Chapter 6 brings together data from Chapters 3 through 5; it explores how the case study can contribute to the broader development of health and vulnerability concepts, and suggests potential intervention strategies for Warwick Junction traders.

- Chapter 7 provides a summary and conclusions. 


\section{Chapter 2}

\section{Conceptual and Methodological Foundations: Negotiating Research in a Cross-Cultural Setting}

Beneath the crisscross of highway overpasses, Zulu rurality melds itself around thronging scenes of urban South Africa in a junction where 8000 informal traders provide goods and services to some 450000 passers-by each day. Sitting on the sidewalk in this junction, I watched as two women-mother and daughter-mixed rat poison into pails of seeds with their bare hands. The poison increases the value of their seeds; it keeps pests away from growing plants. I asked the mother, a 52-year-old woman who has traded and slept in the market for over 20 years, if she has the power to influence her trading or living conditions. "We believe people can change. We send people; we work through the committees. We work and we hope. Your presence will influence them," she responded. The hopefulness of her words startled me and forced me to scrutinize my own research ethics.

Just down the road, another meeting —one of striking contrast-made me equally aware of my own position. Under a new tin shelter, the bovine head cookers stand on one side of a long line of tables, wielding their axes upon large skulls as they prepare the traditional dish of cow heads and dumplings. On the other side of the tables are their customers: working men, stopping in for lunch. As my assistant approached, an older woman confronted us with hostility: "You're not going to get anything from me. We are angry about the interviews. Asking the same questions and going away, taking information with promises, and nothing happening. I won't talk to you and no one else 
here will talk to you because I say so." The head cookers have recently been moved to this shelter as a means of minimizing blood and refuse on the open sidewalk. As part of a larger urban renewal project in Warwick Junction, this 'upliftment' intervention has attracted much media and research attention, but the head cookers feel unfairly removed from their passing customers. They are struggling more than ever.

Within these scenes and others, the diverse relationships that form the core of this thesis were carefully negotiated. This chapter examines the challenges and rewards of these relationships, the successes and limitations of the process, and the rationale for this approach and field site. It offers insights into research design, methodology, and ethics, and sets the context for the analysis that will follow. The chapter begins with key conceptual starting points and an explanation of why Warwick Junction was selected as the field site. It then outlines the research design and methodology, and provides a detailed reflection on the research process. It ends with an overview of the strengths and limitations of the data produced through this study.

\subsection{Conceptual Starting Points}

This research lies at the intersection of three multi-faceted bodies of literature: the globalization of human systems ${ }^{1}$, human vulnerability to environmental stresses ${ }^{2}$ (including hazards, disasters, and famines research), and HIV/ $\mathrm{AIDS}^{3}$ (drawing from

\footnotetext{
${ }^{1}$ Key readings include McMichael et al 1999; Mittelman 2002; Weisbrot et al 2002.

${ }^{2}$ Key readings include Watts and Bohle 1993; Mustafa 1998; Kelly \& Adger 2000; Cutter et al 2000.

${ }^{3}$ Key readings include Barnett \& Whiteside 2002; Campbell 2003; Kalipeni et al (eds) 2004; Karim \& Karim 2005.
} 
biomedical, epidemiological, public health, health promotion and social science perspectives). The links between socio-environmental change, vulnerability and human health provide a conceptual foundation from which to examine how the rapid rise of South Africa's HIV/ AIDS epidemic is and will be negotiated in local places and among diverse social groups. While this thesis explores these links based primarily on the case study of Warwick Junction traders, the conceptual and empirical components of this research have coincided, and so I begin with the central concepts that form the intellectual basis for this research and research design.

According to the World Health Organization (WHO), and for the purpose of this thesis, human health is a fundamental human right, defined as a "complete state of physical, mental and social well being, not merely the absence of disease" (WHO 1948 in Grad 2002, p 981). Humans negotiate health within complex and dynamic environments, shaped by local and, increasingly, global processes (McMichael \& Beaglehole 2000). Globalization research indicates that these processes - whether incremental or abruptdo not impact all people evenly (Weisbrot et al 2002). Rather, stressors tend to converge on certain places, social groups and economic sectors ( $O^{\prime}$ Brien \& Leichenko 2000), and differential outcomes are often associated with uneven power relations and social inequalities (Mittelman 2002).

This thesis also draws on the concept of 'human vulnerability' in order to examine the processes driving uneven HIV infection and AIDS impacts among street traders in Warwick Junction. There has been a long history of human vulnerability research in relation to environmental stresses, and four recent developments in this field 
are central to understanding how vulnerability is conceptualized in this thesis. First, early research investigated the impacts of socio-environmental stresses on flood-prone communities, but there has now been a significant shift from focusing on impacts to focusing on drivers or root causes of human tragedies (Watts \& Bohle 1993; Brklacich \& Bohle 2004). Second, recent work has documented how humans cope with and adapt to environmental change, and vulnerability is now understood to have a "double structure": impacts depend on "external" exposure to particular stressors or shocks and "internal" capacity to respond, cope or adapt (Chambers 1989; Bohle 2001). Third, evidence suggests that vulnerabilities pre-exist the outcomes of external shocks, and that stressors often expose rather than cause vulnerabilities (Mustafa 1998; Adger 1999). Fourth, efforts are underway to understand how multiple and multi-scale stressors interact and converge, and how vulnerabilities arise within and linked to societal and environmental transformation (O'Brien \& Leichenko 2000; O'Brien 2001).

Vulnerability is also becoming a prevalent theme in AIDS literatures, but this much more recently, and the concept is less well developed in these studies. As Delor and Hubert (2000) explain, "certain difficulties arise when it comes to applying this concept to actual situations." They point out that "work to clarify the concept is thus necessary. Otherwise, the concept of vulnerability runs the risk of losing its heuristic capacity and political and practical relevancy through increasingly frequent but ambiguous use" ( $p$ 1558). The rapid expansion of vulnerability research in this field needs to be matched by similar efforts to refine and define the concept. 
Vulnerability analysis in AIDS research has developed out of biomedical and epidemiological studies of risk. Early research investigated risk of infection based on the assumption that humans act without constraint, leaving largely unexamined how AIDS epidemics are embedded in social structures (Craddock 2004). Evidence shows that interventions based on these rational action models of behaviour change have achieved only limited success (Campbell 2003). Alternative approaches to understanding the epidemic are thus urgently needed.

A small but growing literature now departs from epidemiological and behavioural approaches to look at underlying social vulnerabilities to HIV and AIDS ${ }^{4}$. These studies position human behaviour within social, economic and political structures that limit and shape rational choice (e.g., Delor \& Huber 2000; Barnett \& Whiteside 2002; Gilbert \& Walker 2002; Campbell 2003). In HIV and AIDS in Africa: Beyond Epidemiology, Kalipeni et al (eds. 2004) compile primary research within a "cultural political economy of vulnerability framework." The studies in this volume examine Africa's AIDS epidemics not as multiple instances of individual risk, but rather as deeply embedded in history, geopolitics, global economics, government policies, local institutions and cultural politics (Craddock 2004).

Most social vulnerability research in this field examines why and how epidemics spread, but does not investigate the uneven effects of AIDS-related morbidity and mortality (e.g., Oppong 1998; Kalipeni 2000; Campbell \& MacPhail 2002). Barnett and

\footnotetext{
${ }^{4}$ This is not meant to polarize biomedical and social science approaches, as many physicians and epidemiologists have indeed recognized how vulnerability is embedded in social systems and have undertaken nuanced studies of sexuality (Craddock 2004).
} 
Whiteside (2002) offer a useful set of concepts for expanding current analyses. They distinguish between "susceptibility" as features of a society which make it likely that an epidemic will spread, and "vulnerability" as (closely related) social and economic characteristics which increase the likelihood of adverse consequences resulting from augmented illness and death (i.e., likelihood of impacts). Thus, susceptibility is limited to the likelihood of being infected, while vulnerability is the likelihood of being infected or affected by an epidemic (Barnett $\&$ Whiteside 2002). These concepts are often conflated, and most research currently focuses on susceptibility.

Whiteside (2004) examines the progression of HIV and AIDS with the use of three epidemic curves (see Figure 1). These were developed to demonstrate the time lags from HIV infection to AIDS impacts, but they are also useful for clarifying and extending vulnerability concepts. Figure 1 indicates that vulnerability encompasses the likelihood of infection (first curve), the rate of progression from asymptomatic HIV to full-blown AIDS (second curve), and the likelihood of impacts (third curve).

Of particular importance, the third curve suggests an expansion of vulnerability concepts beyond an individual's likelihood of infection or illness, to encompass effects that are society-wide, such as orphaning and family fracture. It also extends the timeframe over which vulnerabilities need to be assessed, which is key in the South African context. As Whiteside (2004) demonstrates, HIV prevalence is currently high (first curve, point A1) and numbers of AIDS cases are rising (second curve, point B1). However, the time lag between HIV infection and AIDS impacts means that the societal consequences of the epidemic are only beginning to come to light (third curve, point $\mathrm{Cl}$ ). 


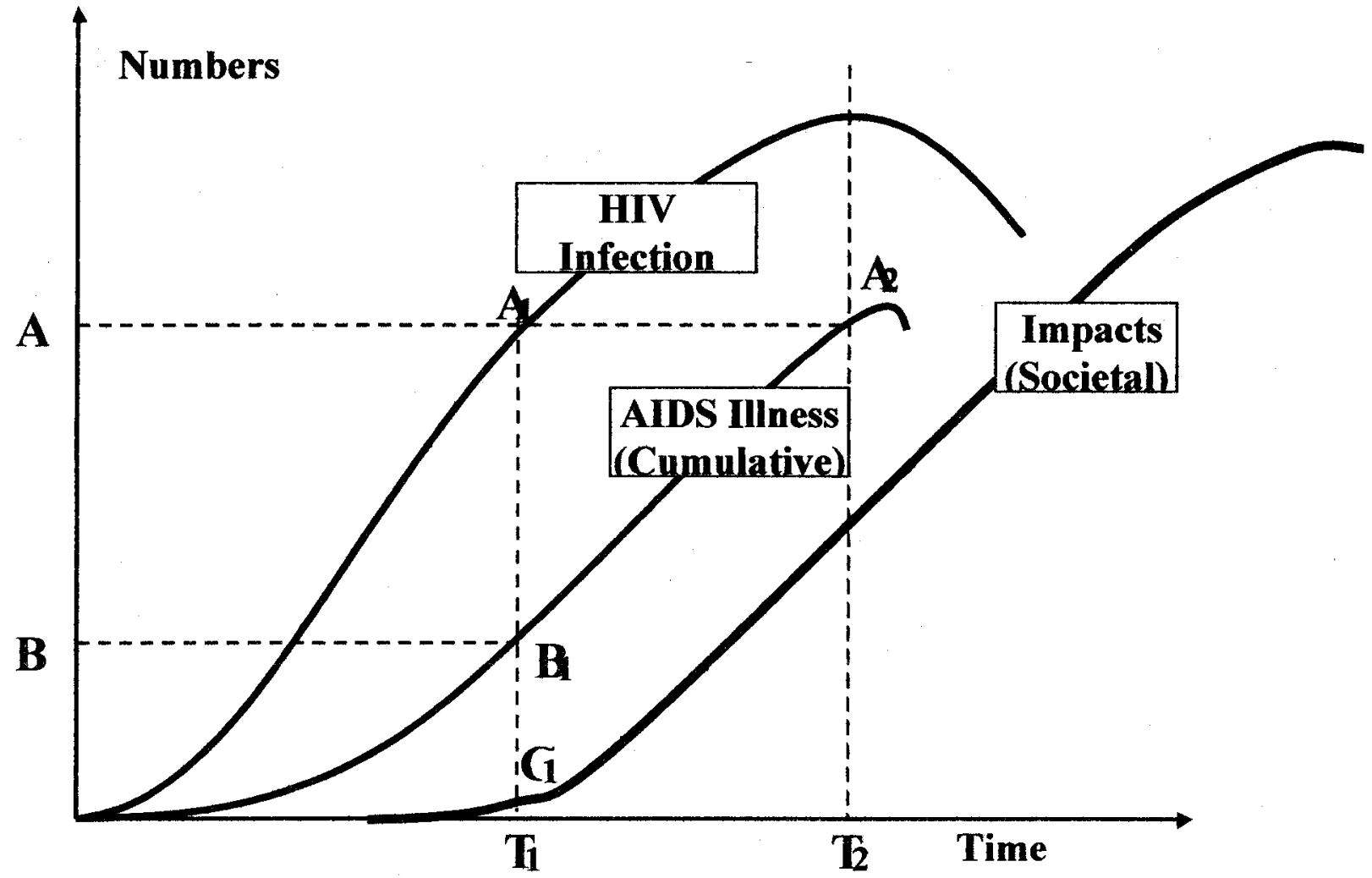

Figure 1: HIV/ AIDS Epidemic Curves: Infection, Illness, Impacts (adapted from Whiteside 2004) 
The third curve is looming and may well present the greatest long-term challenge to wellbeing in South Africa-it is the approaching tidal wave.

Generalized HIV/ AIDS epidemics, such as those faced by much of southern Africa, are new phenomena; they have arisen only in the past two decades. They are also 'long-wave' events that impact populations unevenly, altering demographics as adults die and leave behind the young and the elderly (Barnett \& Whiteside 2002). AIDS is clearly a new and distinct stress to human systems, which may explain why vulnerability concepts in this field are not yet well developed. Overall, current limitations in understanding what causes vulnerabilities within generalized epidemics require attention in order to devise and implement responses.

Drawing from these three research areas--globalization, human vulnerability and HIV/ AIDS - health vulnerability in this study is understood as generated by a series of multi-scale processes that undermines human wellbeing. Moreover, HIV/ AIDS vulnerability is defined as the likelihood of "external" exposure to infection, illness and impacts, and "internal" capacity to respond to the epidemic so as to mitigate adverse consequences. It is shaped by the set of processes that underpins the three curves; the conditions that put some people and groups in harm's way, with no evacuation route, even before the wave hits.

This thesis seeks to understand these underlying processes, recognizing that vulnerabilities are dynamic, uneven and socially generated. The concepts introduced here, linking processes of change, vulnerability and human health, advocate an analysis of systems relationships and the power dynamics driving these relationships. It is 
precisely this sort of examination that follows in Chapters 3 through 5; Chapter 6 then brings together the primary data with vulnerability concepts developed in the AIDS field and elsewhere to expand upon this conceptual analysis. The remainder of this chapter addresses the methodological context of the study, illustrating how the conceptual foundations outlined here have guided the selection of the study site, the methodological approach, and the negotiation of research relationships.

\subsection{Street Traders in Warwick Junction: \\ A Window into Converging Processes of Change}

There are an estimated half-million 'informal' street traders in South Africa and 20000 in Durban; the majority are 'black' and 70 percent are women (Charmes 2003). Street traders provide a window into how societal transformation has come to bear on HIV/ AIDS vulnerabilities, amongst a heterogeneous group of people who, for the most part, have been dispossessed. In post-Apartheid South Africa, globalization, rising unemployment and urbanization have resulted in the 'informalization' of the economy, or the increasing precariousness of many people's livelihoods (Lund 2002). Amidst these changes, the predominantly survivalist nature of 'informal' street trading and traders' low education levels, limited negotiating power, lack of access to resources, and inadequate social protection suggest that this is a disproportionately vulnerable sector of the society (Lee 2004, a). Seventy percent of South Africans working in the 'informal economy' earn less than 1000 Rand per month (Devey et al 2002).

Warwick Junction was chosen as the field site for this study because it is a clearly demarcated locale and a historically charged and rapidly changing urban environment. 
Warwick Junction-also known as the Warwick Avenue Triangle and Grey Street Precinct - is the largest trading and transport hub in Durban, an Indian Ocean port city of just under three million people ${ }^{5}$, in the province of KwaZulu-Natal (see Figure 2). A bus station, train station and several minibus taxi ranks are located in this area, which lies just outside the central business district. Warwick Junction houses the only three formal market buildings in Durban and an estimated 8000 people trade informally on the sidewalks, on highway overpasses, and in the bus, train and taxi termini.

Informal traders sell a range of goods, including fresh produce, prepared foods, alcohol, second hand clothing, electronics, cigarettes, household items and crafts. They also offer services such as hairdressing, shoe repair, tailoring and pay telephones. Others in the area make their living by transporting goods for traders and by collecting and selling recyclables. Warwick Junction is home to the largest muthi (herbal medicine) market in southern Africa; approximately 700 people sell herbal remedies and some are also traditional healers (Dobson 2004, a). Some informal traders have municipal permits and secure trading sites; others trade without permits on the peripheries of the area or as itinerants. While traders reside in the city most of the time (on the streets of Warwick Avenue, in informal settlements, or in the townships), most come from the surrounding rural areas and maintain close ties to their rural homes.

\footnotetext{
${ }^{5}$ In 1999, the crudely projected population figure for the Durban Metropolitan Area was 2.69 million people (Metropolitan Durban 2005). This is the most recent estimate, but Durban is experiencing rapid inmigration and this projection does not account for the impacts of HIV/ AIDS.
} 


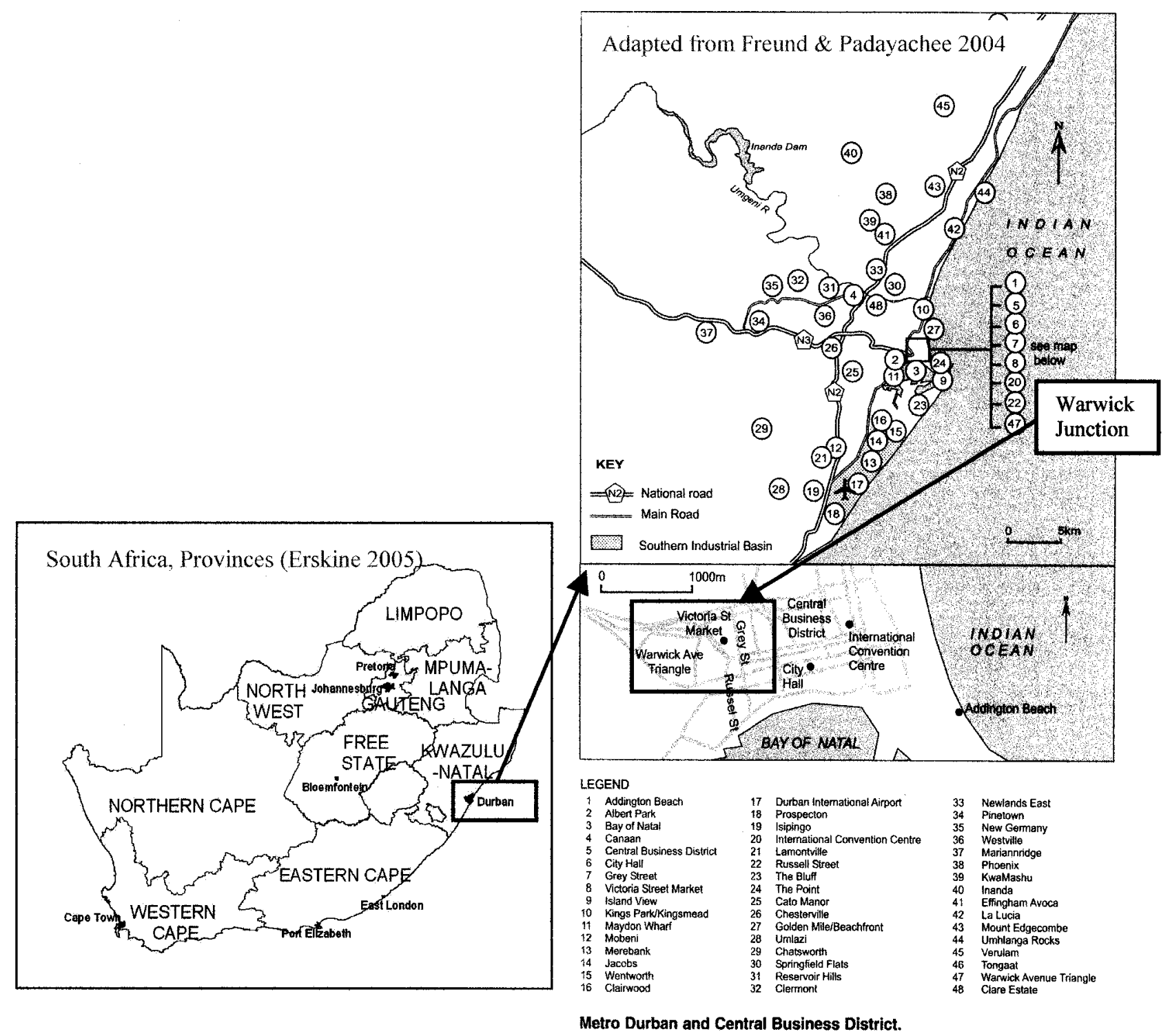

Figure 2: South Africa, Durban and Warwick Junction 
A brief history reveals that this rapidly changing locale and the lives of those trading on its pavements have been shaped by both local historical factors and societal processes more broadly. Warwick Junction is a contested space where different forms of poverty, livelihood, displacement, control and citizenship are constantly being negotiated. From 1900 to the end of the 1930 's, it developed as a vibrant working class neighbourhood and a 'mixed' trading area. However, from the late 1930's until the end of the 1970's, Apartheid legislation was harsh. Under the Group Areas Act, passed in 1950, 'blacks' and 'Indians' were not allowed into the central business district without permission ${ }^{6}$. In the 1960 's, Durban City bylaws comprehensively outlawed trading, labelling traders as illegal intruders. In 1973, the Natal Ordinance (11/1973) was passed, restricting hawking within one hundred meters of any formal business, and outlawing traders from staying in one location for more than 15 minutes (Nesvåg 2002). The 1970's were characterized by forced removals, and some municipal services were discontinued (Grest 2000).

As the Apartheid regime lost power, in the 1980's, repression was replaced with deregulation. The collapse of social control meant that people previously denied access to the city began to stake claims. Minibus taxis "invaded" and Warwick Junction became the site of intense trade and taxi activity (Grest 2000). Formal Apartheid controls were replaced by new forms of informal controls, resulting in arbitrary 'takeovers' of trading areas, extortion, informal supply cartels, price fixing, protection rackets and mafias

\footnotetext{
${ }^{6}$ As a residential area, Warwick Junction resisted the Group Areas Act; it remained non-racial, resisted the imposition of Apartheid, and thus was seen as a politically important area (Grest 2004)
} 
(Nesvåg 2002). Formal traders and residents organized against informal traders and taxis (Grest 2000). Crime and conflict intensified, propelled by political instability and a city council that lacked the legitimacy to regulate trading conditions. The period from 1993 to 1996 was anarchy in Durban's streets (Nesvåg 2002), and with international eyes on the newly democratized nation and globalized economy, fears of repelling investors motivated intervention (Grest 2004).

The Informal Trade Management Board (ITMB) was created by the municipality as a trading committee with whom they could negotiate to regulate the area (Grest 2004). Two years after the transfer of government, in 1996, responsibility for management of the informal economy was decentralized, and Durban adopted a development-oriented approach (Skinner 2004). Under the new constitution, public participation became mandatory for development, and the ITMB became the central negotiating body for traders and an umbrella for other trading committees; however, its role as a 'public' interest group has been questioned because it was put in place by the municipality (Grest 2004). Within the local government, the Informal Trade Department was formed to devise and implement trading legislation (Nesvåg 2002).

Warwick Junction was then chosen as a pilot site for urban renewal because it was seen as the most degraded and derelict part of the city. The project was based on an "area-based management" plan, which was a shift from previous line function operations to a multi-sectoral approach defined according to the precinct. This meant municipal health, informal trade, transport and police departments working together (Dobson 2004a). The Warwick Junction Urban Renewal Project (WJURP) began as a "scrub up" 
in 1996 (ibid.). By 1997, the new muthi market was created on an unused overpass, shelters were built, elevated walkways connecting various market areas were under construction, and a permit system was established (Nesvåg 2002). Warwick Junction was given a public profile and the project administration positioned in a renovated warehouse in the area (Grest 2000). Traders Against Crime, a group of traders also known as the "Forum", came together to fight crime.

In 2001, the pilot project expanded to encompass nine other area-based renewal sites; the WJURP has become the model for a larger Inner Thekwini Renewal and Urban Management Programme (iTrump). An informal economy policy was launched in Durban in 2002, prioritizing the creation properly planned, well-managed markets through the provision of services and infrastructure, the improvement of working conditions, the management of informal trade, and the capacity building of informal trading committees (Lee 2004, a).

The renewal project has improved security and cleanliness in Warwick, and it is once again a vibrant residential and trading area, serviced with two public health clinics, an ambulance depot, churches, schools, non-governmental organizations (NGOs), social centres and a police satellite station (Dobson 2004, a). Warwick Junction was transformed in less that one decade from a public health disaster to the point where it is touted as a tourist attraction; Durban has won international acclaim for the success of this project (Grest 2004). However, the expansion of the project with limited human and financial resources is threatening its sustainability and raising questions around the impacts of state withdrawal from management in Warwick Junction (Grest 2000). 
ITrump increasingly relies on the ITMB, with the closely allied Forum, to solve trading grievances-a sort of "outsourcing" in management (Dobson 2004, b). At the same time, the Self Employed Women's Union (SEWU), an independent traders' organization and the most transparent watchdog body, disbanded in August 2004 due to internal conflict (Skinner 2004). These changes have led to a concentration (and at times abuse) of power among the most prominent trading committees. Furthermore, crime, decay and poverty have not disappeared; nor have the benefits of the project been shared evenly (Lee 2004, a).

In Warwick Junction and beyond, the effects of new liberalized approaches are uneven, and overall conditions for street traders remain poor (Lund 2002). Thus, Warwick Junction has been selected as a "terrain of study which is both the very specific outcome of its own historical development, and also contains elements which are more central to an examination of broader social processes..." (Grest 2000, p2).

\subsection{Research Design}

This study maps out the interactions between these broader societal processes and the local conditions for street traders in Warwick Junction, with the aim of better understanding traders' vulnerabilities to HIV and AIDS. Four research questions are addressed:

1. What macro-level factors are shaping traders' vulnerabilities, and how are these interacting or converging?

2. At the micro-level, why are traders vulnerable to HIV/ AIDS and how are their vulnerabilities differentiated?

3. What drives traders' uneven vulnerabilities and response possibilities? 
4. How does the Warwick Junction case study support, refute or extend current health and vulnerability concepts?

Conceptual work began in September 2003, and fieldwork took place from September 2004 to January 2005 with a follow-up in June $2005^{7}$. The research design had three main components. The first entailed an examination of traders' vulnerabilities through repeated in-depth interviews with a core sample of 20 traders, focus groups and participant observation. The second involved an institutional scan and contextual analysis, including repeated interviews with 13 key informants (municipal employees, trading committee leaders and academics), interviews with 17 health care providers working in Warwick Junction (from public clinics, non-governmental organizations, private practices and traditional healers), attendance at selected conferences, archival research and policy analysis (see Appendix A for a schedule of key informants and health care provider interviews). The final component of the research included critical selfreflection and ongoing conceptual and methodological refinement.

\subsubsection{Methodological Framework and Rationale}

The objectives, conceptual foundations and inherent sensitivities involved in this research lend themselves to an interdisciplinary, participatory and ethnographic methodological framework. The notion that human health is determined by interactions

\footnotetext{
${ }^{7}$ The follow-up took place over four weeks in June 2005 and included: dissemination of findings to traders, health care providers and key informants; re-interviewing traders about changes in their lives and health over the 6-month elapsed period; and assisting HEARD develop a longer-term study in Warwick Junction. The follow-up was undertaken apart from this thesis, and while the findings reinforce and validate the interpretation and analysis, the focus of this document is on the original four months of fieldwork.
} 
between physical, social, emotional, behavioural and ecological factors underpinned this study; thus the investigation moved beyond the boundaries of any one discipline. Interdisciplinarity was achieved through consultation with researchers trained in economics, anthropology, geography, political science, development studies, public health, urban planning and medicine, as well as through a review of secondary materials. The project was also guided by the assumption that power relations are central to human vulnerability. It thus adopted a critical participatory approach, which recognizes research as a political and potentially transformative process--a process that should ultimately benefit participants (Hoggart et al 2002). Participatory strategies involve building trust, establishing partnerships, collaborating in defining and carrying out research, and meaningfully disseminating findings. This approach requires an awareness of the power dynamics inherent in research relationships and the contexts in which information is shared (ibid.). The following activities aimed to maximize participation: collaborating with stakeholders to define research problems and methods; developing relationships with traders through repeated interviews and participation in daily activities; establishing partnerships with the municipality and trading committees through pre- and post-project meetings; and disseminating findings through presentations and reports. This research also contributed to HEARD by training and employing research assistants, sharing process findings with staff, and assisting them in carrying forward this research into a longer-term initiative.

Finally, in order to develop a nuanced picture of what generates vulnerabilities in Warwick Junction, intensive methods (i.e., repeated interviews with a small number of 
traders) were required to probe more deeply into underlying processes than a survey approach targeting a wide population would allow. The study does not aim to make generalizations applicable to all traders, but rather is intended to unravel some of the causal processes of vulnerabilities in this particular sample. The differential nature of vulnerability required that data be collected and analyzed along various axes of social differentiation, including age, gender, trade and social group. Data was scaled down to the individual level; analysis began with an examination of what makes each trader vulnerable, and then identified common patterns and characteristics. Microvulnerabilities were situated within broader processes and conditions by linking the intensive research with the contextual analysis-that is, through global ethnography (Burowoy 2000).

\subsubsection{Research Process and Analysis}

This project was carried out according to a five-phase plan $^{8}$, with the objectives of conceptualizing the research from afar, refining the project focus, gathering preliminary information, conducting intensive research, and feeding back findings to participants (see Table 1 for phased research activities and outcomes). The project's path was, however, far from linear. A detailed reflection reveals the 'messiness' of the research process: the five phases were overlapping and activities from each carried over to guide subsequent directions. The research also required me to continuously confront my own assumptions as a first-time researcher in this cross-cultural context. This section recounts the

\footnotetext{
${ }^{8}$ This is referring only to the main fieldwork and not to the follow-up.
} 
objectives, activities, strengths, challenges and turning points of each phase. It ends with an overview of the research outcomes, data sources and analytical methods.

\section{Phase 1: Conceptualizing the Research from Afar}

In the first phase, I examined how human health and vulnerability have been conceptualized and measured across a number of disciplines. During this time, my relationship with HEARD developed as a result of my collaboration with their project director at an AIDS policy workshop in Canada, and through my supervisor's work with their research director on the Southern Africa Vulnerability Initiative (SAVI). In collaboration with HEARD, and designed to dovetail with SAVI's broader research agenda, I then developed a proposal to undertake fieldwork in Warwick Junction and submitted this for funding to the International Development Research Centre's (IDRC) Ecohealth Training Awards. Prior to leaving for Durban, the proposal was refined through the processes of undergoing Carleton's Ethics Review and attending a training week at the IDRC. The early conceptual work and methodological refinement were instrumental to the subsequent field implementation.

\section{Phase 2: Meeting Stakeholders and Refining the Project Focus in Durban}

The objective of the second phase was to familiarize myself with my field site in order to refine the project focus. Upon arrival in Durban, I held pre-project key informant meetings to discuss potential research questions and methodologies. I sat in queues in the two public health clinics in Warwick, mapped out the different parts of the market, and attended a Traditional Healers Council meeting. Participant observation was critical in this phase, as it provided a window into the conditions of existence in Warwick Junction. 
One early finding was that men dominate the ITMB leadership. I therefore sought to consult with female leaders outside of formal institutions. I was introduced to several influential market women who invited me to participate in their weekly beading group, which I did for three consecutive weeks and intermittently throughout the remainder of my time in Durban. These meetings built trust and served as informal focus groups.

My early experiences guided the project's path. A preliminary scan of available literature revealed that no data exists on the health of traders or on the impacts of AIDS on their lives; the scant materials available were not based on primary research with traders. While I had initially planned to place equal 'weights' on the health care provider, trader and archival components of the research, I refined the primary objective: to document traders' experiences of health and the AIDS epidemic. I would then triangulate traders' stories through interviews or focus groups with key informants and health care providers.

Challenges quickly became apparent. Warwick Junction traders are experiencing research fatigue; many students have conducted research in this area without properly disseminating their findings. As a result, I was met with hesitation from trading committee leaders, some of whom were clearly gatekeepers in the area. Over several meetings, I built relationships and made it clear that I would feed back findings in a culminating presentation for traders, a summary report in isiZulu, and a policy brief for stakeholders.

Furthermore, Warwick Junction's complex division of labour and power became evident in this phase; despite the area's seeming chaos, power operates along multiple 
axes-by gender, age, trade, formality of permit, location of trading site, ethnicity, inclusion in trading committees, traditional hierarchies, and place of origin. I therefore sampled traders according to gender, age and levels of 'inclusion' or 'exclusion' in market structures, focusing predominantly (although not exclusively) on traders who are 'excluded'; that is, those who trade without permits, outside formal spaces, not represented by trading committees, and in less lucrative or socially-recognized trades. The core sample included 20 traders: a cross-section of eight men and 12 women, half younger and half older, and people working in a variety of trades and services (see Appendix B for core participants and sampling criteria).

Finally, my conversations in this phase revealed an extreme sensitivity to speaking about AIDS, and I decided to interview each trader at least twice, in most cases three times, in order to develop relationships in which open discussions were likely to ensue. Preliminary interviews focused on issues of livelihood, health, security and service access, touching on AIDS only briefly and toward the very end (see Appendix $\mathrm{C}$ for interview questionnaires).

\section{Phase 3: Building Trust and Gathering Preliminary Information}

The objectives of the third phase were to build rapport with and gather preliminary information from traders, and to begin meetings with health care providers. On HEARD's recommendation, I hired and trained two research assistants- - one man (Sbo) and one woman (Ntombi)-to assist with interviews with traders. Interviews took place in isiZulu at traders' sites, guided by semi-structured questionnaires with flexible and open-ended questions. We were met with hesitation and hostility on a few occasions 
(and in three instances refused interviews), but most traders welcomed us and we became accustomed to sitting on the sidewalk and huddling together for privacy. I alternated interviewing in tandem with each assistant. Audio-taping was impossible amidst the bustle of the market, so I scribed as they facilitated and translated the discussions.

Where I experienced more difficulty was in accessing health care professionals. The under-resourced reality of the public health system in South Africa meant that health care providers could generally afford no more than 15 minutes. In addition, inyangas (traditional healers) treated me with scepticism, as many worried about intellectual property rights.

Another challenge was reconciling the diverse messages and constant warnings I received from certain colleagues about spending time in this high-crime area. On my first day in the market, my colleague was robbed of his cell phone. In my next two solo visits, I witnessed violence in the taxi ranks and a carjacking; I grew accustomed to a certain level of verbal harassment. I was reminded of the dangers on a daily basis.

However, as I became more comfortable and projected a sense of confidence, the verbal harassment diminished, and as people came to know me, I was afforded some protection. Younger male participants occasionally appeared by my side if they thought I needed assistance, and older women came to my defence if I was rudely approached during our interviews. The physical security threat-though never completely erased from my mind---was gradually replaced with emotional intensity. I found myself in tears as the seamstress from the beginning of Chapter 1 told us about her nieces who are dying 
and her daughter who was raped in the market. On another occasion, I witnessed a young man die of illness in the scorching heat, on the pavement outside the clinic.

My experiences also challenged my preconceived assumptions and led me to constantly re-negotiate my roles as researcher, foreigner, student and tourist. I was initially concerned with how people would react to me--white, female, Canadian. I assumed that my research assistants, being Zulu and from Durban, would be comfortable in the market and offer me protection. But I was mistaken: Ntombi was nervous to walk around this area and I was told by some traders that I am "not really white" because I am Canadian. Despite my early self-consciousness, my position soon became blurred.

I was aware of my changing relationships with Sbo, Ntombi and our participants, and the learning that took place in this phase was as much about my own condition as it was about traders' lives. I was, as Fine (1994) describes, consciously "working the hyphen" between "Self-Other:"

Self and Other are knottily entangled. This relationship, as lived between researchers and informants, is typically obscured in social science texts, protecting privilege, securing distance... When we opt, instead, to engage in social struggle with those who have been exploited and subjugated, we work the hyphen, revealing far more about ourselves, and far more about the structures of Othering. (Fine 1994, p72)

As I shared tears with participants, the boundaries were displaced; this blur deepened my understanding of Warwick Junction, street trading, vulnerability and AIDS.

\section{Phase 4: Conducting Intensive Research}

Based on our preliminary findings, our second round of interviews with traders probed more deeply into experiences of Apartheid, democracy, urbanization, the renewal 
project and AIDS. In this phase, traders were much more forthcoming - a testament to the decision to conduct repeated interviews.

Despite this methodological success, this phase was not without challenges. By far the biggest obstacle was that Ntombi resigned from the project before the second round of trading interviews. She secured full time work and, while I was thrilled for her, the way forward quickly became strewn with roadblocks. In a three-week period, I interviewed, hired and trained three women, and each quit the project after only a few days. I was told that the research was "too dangerous" and "too uncomfortable." In this same period, Sbo encountered family-related stress and had to take time off work. In addition to time lost to hiring and training, I was concerned with maintaining consistency in the interviews. Fortunately, my decision to be a part of each interview meant that we were still able to track down participants, and by the end of this phase, I hired an excellent female assistant (Sihle) who saw the main fieldwork through to completion.

And challenges do provide opportunities. The challenge of repeatedly losing my assistants allowed me to spend time in Warwick Junction on my own. I visited traders casually and participated in market activities. This required that I learn some isiZulu. Traders were impressed and mildly amused by my struggle to speak the language; older women began feeding me at every opportunity.

As these relationships continued to transform, I re-scrutinized my own motivations and ethics. I was concerned with taking up traders' time and food. I began giving out fruit and bread after each interview, although I did not give these gifts directly following the interviews because I did not want them to come across as a form of 
payment. When traders expressed a need for information, I did my best to assist: I obtained information on legal aid for one participant and on immigration standards for another.

\section{Phase 5: Feeding Back to Participants and Stakeholders}

The final fieldwork phase was spent feeding back results and cross-validating interpretations. We revisited the majority of traders to verify the information recorded previously and to map out their households and life history timelines. I returned to several stakeholders, including all those with whom I had held pre-project meetings, to feed back and triangulate traders' stories. I also presented methodological reflections for my colleagues at HEARD and UKZN, and spent several weeks gathering archival information.

In addition, we held a feedback focus group for traders and other stakeholders to discuss the preliminary findings. I worked with one of my isiZulu-speaking colleagues from HEARD to support Sbo and Sihle as facilitators. Nine participants attended, six of whom were traders - it was a small but productive group, and many traders felt validated by the presence of an environmental health officer from the municipality. The day started with a presentation given by Sbo, then went into breakout sessions for men and women, and culminated with a larger group discussion led by Sihle. There was a marked difference in participation when men and women were asked to discuss together and apart: the women who were silent in the larger group were active in debate in the breakout session. Overall, the process of opening this dialogue was both powerful and 
productive; traders engaged and developed a sense of cohesion around issues of health and AIDS.

\section{Data Sources, Outcomes and Analyses}

Analysis took place throughout all of the phases of the research, as interconnected with the research process itself. After each day of fieldwork, I typed interview transcripts and logged emerging trends, observations, issues and my own shifting roles. At the end of each phase, I reviewed transcripts with my assistants and used flip charts to map out themes and conceptual considerations.

Once back in Canada, I undertook a systematic analysis, concentrating primarily on the data produced with the core sample of 20 traders. This analysis included:

- Creating diagrammatic mind maps of the causes of vulnerability for each trader;

- Identifying common and contrasting themes and issues among the sample, and coding each transcripts accordingly;

- Refining key issues and themes through the coding process, and creating tables and charts to analyze these issues and themes by trader; and

- Identifying key axes of differentiation from the charts-in this case age and gender-and comparing pertinent issues within the sample.

I then analyzed interviews with health care providers, comparing issues and discourses between biomedical practitioners, inyangas, and traders. I drew on key informant interviews and secondary materials to contextualize and explain other data. I also revisited earlier conceptual work, noting where the fieldwork linked with other health and vulnerability models. 
The outcomes of this research are three-fold. First, process outcomes include building relationships between HEARD and Carleton, developing trust with stakeholders and traders, building capacity among research assistants, opening a dialogue between traders, and developing my own research skills and critical reflexivity. Second, the research generated a variety of data, such as transcripts from interviews with traders, key informants, and health practitioners, as well as archival data, field notes and logs. Third, the empirical work provided a basis from which to analyze and refine health and vulnerability concepts and assessment methodologies; several research tools and concepts were developed through the ongoing and culminating analyses.

Finally, traders' identities have been kept confidential, and thus all personal identifiers have been removed from interview transcripts; traders are referred to in the thesis by trade, gender and age. Health care providers, traditional healers and key informants were offered a choice between being identified by name and position or by occupation, and are thus referred to accordingly.

\subsection{Methodological Strengths and Limitations}

Undertaking participatory research within the time frame allocated for this study was extremely challenging. A four-month period in Durban and Warwick Junction meant focusing on building relationships and conducting interviews; the facilitation of communications between stakeholder groups and support of traders in collecting, analyzing and acting upon the research were not developed to the same extend. Unlike 
previous research in Warwick Junction, however, I did return to follow up on the project and disseminate the findings.

My inability to speak isiZulu posed another significant barrier, and my reliance on multiple in situ translators raises questions about the consistency and validity of my data. However, I have maximized potential for validity by checking back with participants to ensure accuracy. I have also triangulated the data among a number of different sources. Moreover, rather than claiming to accurately 'represent' traders' voices or uncover the 'truth' of their experiences, I have remained critical of the context in which knowledge was produced.

The main strength of the fieldwork, I believe, was my own openness, empathy, caring and determination; I allowed the study to evolve as an iterative process and remained critical of my own roles and assumptions. I have continuously called into question how my own and participant positionality, circumstance and discourses shaped not only my research process, but also the interpretations and conclusions that follow.

\subsection{Conclusion}

At its core, this research entailed cautious, caring and critical negotiations of diverse relationships—-from the seed seller and bovine head cooker at the start of this chapter, to colleagues at HEARD, research assistants, a women's beading group, government officials, traditional healers, and beyond. This chapter outlined how these relationships were selected, developed, maintained and interpreted, offering 
methodological insights with broader applications. It examined and evaluated the study's interdisciplinary, participatory, ethnographic approach.

This chapter also positioned the study at the intersection of globalization, human vulnerability, and HIV/ AIDS research, demonstrating how these literatures provide conceptual tools with which to examine vulnerability to HIV/ AIDS in a context of rapid change. It introduced street traders in Warwick Junction as a strategic case study: a window into how converging processes have come to bear on a group of people living and working on South Africa's peripheries.

The following chapters map out street traders' vulnerabilities to South Africa's new and growing epidemic: the macro context, the micro context, and their uneven struggles. This vulnerability analysis extends the conceptual and methodological foundations introduced in this chapter. 
Table 1 -- Research Framework: Five-Phase Research Process and Outcomes

\begin{tabular}{|c|c|c|c|c|c|c|}
\hline $\begin{array}{l}\text { OUTCOMES/ } \\
\text { DATA } \\
\text { SOURCES }\end{array}$ & $\begin{array}{l}\text { 1. Conceptualizing } \\
\text { the research from } \\
\text { afar }\end{array}$ & $\begin{array}{l}\text { 2. Refining the } \\
\text { project focus with } \\
\text { stakeholders }\end{array}$ & $\begin{array}{l}\text { 3. Building trust \& } \\
\text { gathering preliminary } \\
\text { information }\end{array}$ & $\begin{array}{l}\text { 4. Conducting } \\
\text { intensive research }\end{array}$ & $\begin{array}{l}\text { 5. Feeding back to } \\
\text { participants and } \\
\text { stakeholders }\end{array}$ & $\begin{array}{l}\text { Post fieldwork } \\
\text { analysis }\end{array}$ \\
\hline $\begin{array}{l}\text { Research } \\
\text { tools, } \\
\text { analyses, \& } \\
\text { conceptual } \\
\text { refinement }\end{array}$ & $\begin{array}{l}{ }^{*} \text { Literature analysis } \\
\text { on health \& } \\
\text { vulnerability } \\
\text { concepts } \\
{ }^{*} \text { Developing } \\
\text { research proposal } \\
{ }^{*} \text { Ethics review- } \\
\text { refining } \\
\text { methodology }\end{array}$ & $\begin{array}{l}\text { * Refining research } \\
\text { objectives, methods } \\
\text { * Devising sampling } \\
\text { strategy } \\
\text { * Developing } \\
\text { Questionnaire } \\
\text { Round } 1 \text { with } \\
\text { traders }\end{array}$ & $\begin{array}{l}\text { * Interim analysis } \\
\text { * Piloting interview } \\
\text { * Translating } \\
\text { questionnaire } \\
{ }^{*} \text { Ethics review with } \\
\text { health department- } \\
\text { methodological } \\
\text { refinement }\end{array}$ & $\begin{array}{l}\text { * Interim analysis, } \\
\text { conceptual check- } \\
\text { back } \\
\text { * Developing } \\
\text { Questionnaire Round } \\
2 \text { with traders }\end{array}$ & $\begin{array}{l}\text { * Interim analysis, } \\
\text { conceptual check-back } \\
\text { * Presentation for } \\
\text { HEARD and other } \\
\text { researchers } \\
{ }^{*} \text { Culminating session } \\
\text { for traders and } \\
\text { stakeholders }\end{array}$ & $\begin{array}{l}\text { * Coding \& } \\
\text { charting, } \\
\text { comparisons } \\
\text { within/ between } \\
\text { participant groups } \\
\text { * Revisiting/ } \\
\text { extending concepts } \\
\text { *Writing/ } \\
\text { presenting thesis, } \\
\text { technical report, } \\
\text { journal article }\end{array}$ \\
\hline $\begin{array}{l}\text { Process } \\
\text { outcomes: } \\
\text { field notes } \\
\text { and reflexive } \\
\text { log }\end{array}$ & $\begin{array}{l}\text { *Establishing } \\
\text { relationships with } \\
\text { HEARD and IDRC } \\
\text { * IDRC Ecohealth } \\
\text { Training Week; } \\
\text { linking with } \\
\text { international } \\
\text { researchers }\end{array}$ & $\begin{array}{l}\text { * Building trust with } \\
\text { gatekeepers } \\
{ }^{*} \text { Establishing } \\
\text { relations with } \\
\text { iTRUMP } \\
\text { * Linking with other } \\
\text { researchers } \\
{ }^{*} \text { Critical reflection }\end{array}$ & $\begin{array}{l}{ }^{*} \text { Hiring and training } \\
\text { research assistants } \\
{ }^{*} \text { Building trust with } \\
\text { traders } \\
{ }^{*} \text { Establishing } \\
\text { relationship with health } \\
\text { department } \\
{ }^{*} \text { Critical self reflection }\end{array}$ & $\begin{array}{l}\text { * Research assistant } \\
\text { hiring and training } \\
{ }^{*} \text { Critical self } \\
\text { refection } \\
{ }^{*} \text { Linking with other } \\
\text { researchers }\end{array}$ & $\begin{array}{l}\text { * Supporting assistants to } \\
\text { facilitate focus group } \\
\text { * Opening dialogue } \\
\text { amongst traders } \\
\text { * Begin discussion with } \\
\text { HEARD regarding } \\
\text { follow-up \& continuation } \\
\text { of project }\end{array}$ & $\begin{array}{l}{ }^{*} \text { Continued work } \\
\text { with HEARD } \\
\text { towards follow-up } \\
\text { research } \\
\text { * Dissemination in } \\
\text { Durban }\end{array}$ \\
\hline $\begin{array}{l}\text { Traders: } \\
\text { interviews/ } \\
\text { focus group/ } \\
\text { research log }\end{array}$ & & $\begin{array}{l}\text { * Participant } \\
\text { observation in } \\
\text { Warwick Junction }\end{array}$ & $\begin{array}{l}\text { * Round } 1 \text { of interviews } \\
\text { * Participant observation } \\
\& \text { field reflections }\end{array}$ & $\begin{array}{l}\text { * Round } 2 \text { interviews } \\
\text { * Participant } \\
\text { observation, casual } \\
\text { visits, reflections }\end{array}$ & $\begin{array}{l}\text { * Round } 3 \text { interviews, } \\
\text { household mapping, } \\
\text { check-back with traders } \\
\text { * Community focus } \\
\text { group, feedback }\end{array}$ & \\
\hline $\begin{array}{l}\text { Key } \\
\text { informants: } \\
\text { interviews }\end{array}$ & & $\begin{array}{l}\text { * Pre-project } \\
\text { meetings with key } \\
\text { informants }\end{array}$ & & & $\begin{array}{l}\text { * Post-project key } \\
\text { informant interviews }\end{array}$ & \\
\hline $\begin{array}{l}\text { Health care } \\
\text { providers: } \\
\text { interviews/ } \\
\text { focus group }\end{array}$ & & & $\begin{array}{l}\text { * Interviews with clinic } \\
\text { managers and traditional } \\
\text { healers }\end{array}$ & $\begin{array}{l}\text { * Interviews with } \\
\text { counsellors, NGO's, } \\
\text { pharmacists \& } \\
\text { private doctors }\end{array}$ & $\begin{array}{l}\text { * Feedback meeting with } \\
\text { municipal health } \\
\text { department }\end{array}$ & \\
\hline Archival data & $\begin{array}{l}* \text { Background } \\
\text { research on AIDS \& } \\
\text { political economy of } \\
\text { South Africa }\end{array}$ & $\begin{array}{l}\text { * Preliminary scan } \\
\text { of grey literature, } \\
\text { policy analysis }\end{array}$ & & & $\begin{array}{l}\text { * Archival research, } \\
\text { published \& unpublished } \\
\text { documents }\end{array}$ & \\
\hline
\end{tabular}




\section{Chapter 3}

\section{The Macro Context of Traders' Vulnerabilities: Converging Processes of Change}

Swarms of commuters make their way along the maze of elevated walkways, from the dimly lit train station to the bustling taxi ranks outside. The Berea Railway Bridge is a clamouring hub of activity. Those who have managed to obtain trading permits here are the lucky ones. They tell of battles to legalize trading in the station and years of police beatings and arrests prior to their victory. Yet, even with the improved trading conditions, many remain stressed by South Africa's rising unemployment and their displacement from home:

In the days of Apartheid, we ran between the railway police and the city police, each unable to arrest us in the domain of the other. I have traded in Durban since 1973, but I still belong at home on the farm ${ }^{9}$. I only come here to work because there is no other choice. (Sunglasses \& accessories trader)

Others still cannot access permits; they trade on the bridge as itinerants, frequently fleeing security personnel and enduring harassment. They do not have employment opportunities elsewhere. One itinerant trader reflects on his experience of South Africa's government transition:

There are still no jobs. The employment picture isn't any better. I have friends who are qualified engineers who are selling sweets in the street. There's better housing; I have seen improvements there. And grants are coming slowly... But a lot of people are still suffering. Twenty or 30 years down the line, let's hope that things really get better. (Itinerant trader, candy bars)

The Apartheid experience is branded in the consciousness of all traders, but equally engrained is the ongoing economic hardship that, for many, characterizes the 
post-Apartheid period. Unemployment is central to traders' lives; it is their primary motivation for trading in Warwick Junction and one reason why "a lot of people are still suffering". Indeed, 10 years after the end of Apartheid, the struggle continues for many street traders in South Africa's rapidly changing urban areas.

This chapter introduces the macro context of traders' vulnerabilities; it outlines the processes and outcomes of South Africa's rapid change. It begins with an overview of participants' common experiences, which demonstrate the convergence of four processes: South Africa's transitioning political economy, globalization, increased population mobility and the HIV/ AIDS epidemic. Drawing on secondary sources, the chapter then undertakes a historical analysis that situates traders' struggles within these four macro changes.

\subsection{Common Experiences of Change: Key Trends and Characteristics among Traders}

There have been no changes. I'm tired of sitting here with no job. The government has done nothing, and I heard that the sick grant will be stopped... There was fighting, houses were burnt down and the government is not doing anything. People came to put our names on a list, but nothing has happened. There has been no compensation... I voted before but I won't again. (Mpempo ${ }^{10}$ seller)

While the heterogeneity among participants will become clear in later chapters, Warwick traders share certain similar experiences and their stories tell of a number of important commonalties. What emerges is that change is the norm in traders' lives; moreover, ongoing changes within traders' households, workplaces and communities are

\footnotetext{
9 'Farm' is a colloquial term that refers to rural area; it does not assume agricultural uses.

${ }^{10}$ Mpempo is traditional incense.
} 
enmeshed in broader societal processes, including the transitioning government, rising unemployment, migration, and HIV/ AIDS.

Participants divulged mixed feelings about the government transition. Some feel that their lives have improved considerably: they are afforded more rights, some now have access to basic services (e.g., water and electricity) and improved infrastructure (e.g., roads), and a few are accessing newly instated social transfers. Yet, frustration and disillusionment abound. The assertion that "there has been no compensation" epitomizes a common sentiment. Disappointment and "broken promises" strongly colour traders" relations to local government: "The city promised to provide accommodation but so far has not kept to this promise" (Dlamini, M. 2004).

Their disillusionment is compounded by the fact that the economic stresses they faced under Apartheid have continued-albeit through new processes--into the postApartheid era. They continue to struggle economically, and some emphasized that their financial situations are getting worse. Participants reported that trading is becoming less profitable as more people become unemployed and flock to the city. Many described the market as "saturated:" too many people trading and not enough customers.

Young traders expressed frustration and resignation at the lack of employment, and young men in particular revealed a sense of hopelessness for the future. Participants frequently remarked that young people moving to the city are "reckless," and that alcohol and drug abuse is increasingly common: "Young women coming to the city drink a lot, and drug themselves with dagga ${ }^{\prime \prime}$. I see this in Mayville in the taverns; it's happening a 
lot" (Trolley pusher, fruit). Many suggested that this risk taking is directly related to unemployment and bleak economic opportunities.

In addition, migration and urbanization has accelerated for traders through the transition and post-Apartheid era as a result of changing political and economic conditions. Of the 20 traders interviewed in the core sample, only one is originally from Durban. One is from Zanzibar, Tanzania, and has no contact with his home. The remaining 18 come from surrounding rural areas (mostly in KwaZulu-Natal with a few from the Eastern Cape), and most maintain close ties with their homes, visiting regularly and sending back money and goods (see Figure 2). Their primary reason for moving to the city and for beginning to trade is unemployment within their families. The second (and only other) reason cited for moving is political violence. "Faction fighting," which took place during the transition of government from the mid-1980's to the mid-1990's in the rural parts of KwaZulu-Natal, impacted the lives of many traders; many had close family members killed and their houses burnt down.

Traders also discussed a recent surge in young adult deaths and an increased frequency of funerals: "Funerals are happening at home every day now. It's no longer only on Saturday that we have funerals, it's every day of the week" (Sunglasses \& accessories trader). Illness, death and orphans, together with urban migration and unemployment, have led to one experience shared by almost every participant: growing

\footnotetext{
${ }^{11}$ Dagga is the isiZulu word for marijuana or hashish. It is considered to have spiritual and medicinal properties.
} 
numbers are being supported on shrinking household incomes. Households ${ }^{12}$ tend to be spread in three or more locations, and their structures are increasingly fluid to accommodate rising unemployment and mortality.

With resources stretched, many traders are faced with a serious dilemma. They believe that their own insecurity results from their limited education and training, and yet, within their families, youngsters are leaving school because households cannot absorb the cost of school fees, uniforms, and supporting non-working youth. They are striving to create opportunities for younger generations, but their diminishing incomes are forcing their children out of schooling prematurely.

Within Warwick Junction, traders reported a change in the threats to their security. Those who traded in Durban prior to the end of Apartheid, through the transition period, and prior to the renewal project offered their personal histories of the area. These mirror the history of Warwick Junction outlined in Chapter 2; they spoke of intense police harassment during Apartheid, followed by a period of chaos and high crime, and finally a significant decrease in violence ${ }^{13}$. Many are now concerned with the changing roles of the Forum: "The Forum has stopped being concerned with crime now [since 2002] and just harass traders at their tables. They are being a threat... it 's all favouritism and corruption" (Sunglasses and accessories trader). Allegations against the

\footnotetext{
12 'Households' are defined according to traders (umdeni in isiZulu). A household encompasses a combination of kin relations, resource sharing, and symbolic (if not physical) connection to a common place marked by the house structure. It does not exist in one location; it is constantly adjusting to pressures and challenges. This definition challenges the current definition of a household as a cohesive social unit in which members share nightly meals and sleep in the same physical house structure (Hosegood \& Solarsh 2004).
} 
ITMB and the Forum of extortion, bribery, harassment, assault, unfair allocation and removal of trading space, and intimidation came through clearly from many participants. Some fear for their lives if they are overheard talking about it and feel they have nowhere to voice complaints; they view the committees as closely tied to the municipality and police.

A theme emerges from within traders' common experiences: change means a continuous replacing of one struggle for another. Their struggles are simultaneously material, as growing households confront shrinking incomes, social, as urbanity confronts rurality, and symbolic, as hopes confront realities.

\subsection{Situating Traders' Experiences amidst Converging Macro Processes}

Since 1982 I have been trading here and in the bus station. Before we were scared, abused. People were stealing from us, and we were always running from the police. Now we're not scared; things are better. But in terms of making profits, nothing has changed... My daughter has TB and 3 months ago was admitted to the hospital... My eldest son has lost a lot of weight, but he's not saying he's sick... I have a project going on at home to build another room; I'm worried about dying and my kids having nowhere to stay. (Mat seller)

The end of Apartheid has meant not only political transition, but also rapid and far-reaching social, economic and demographic transformation. The trends above suggest that four interacting processes are shaping the vulnerabilities of many in Warwick Junction: (1) the transitioning political economy of South Africa, (2) globalization (with subsequent rising unemployment), (3) increased population mobility and (4) the new HIV/ AIDS epidemic. Figure 3 depicts traders' experiences at the centre of these four

\footnotetext{
${ }^{13}$ However, many traders have witnessed or experienced recent crime: two showed scars from recent stabbings; one told about her daughter being raped in the market; one described a recent taxi shootout;
} 
macro changes; it provides a guide with which to examine the dynamics of their vulnerabilities.

\subsubsection{South Africa's Transitioning Political Economy: Figure 3a}

Apartheid had its roots deep in South Africa's colonial history, but the legislated discrimination began with the Afrikaner National Party taking power in 1948. Every South African was classified into one of four 'race' groups: 'white', 'coloured' (mixed race), 'Asian/ Indian' and 'black'. Black people were the most restricted: they were excluded from quality education and many forms of employment, they could not move about the country freely, and they were segregated in where they could live. Under Apartheid, each tribal group had its own homeland-a self-governing territory or Bantustan. Black people were forced into these crowded and impoverished Bantustans, and men migrated to urban areas to work in white-owned factories and mines. Apartheid means 'separateness'; this was social engineering on a grand scale (Welsh 2000).

In 1976, youth in the Johannesburg township of Soweto rallied in opposition to being taught in Afrikaans. Over the next 14 years - as the wheels of transition were set in motion-the National Party government became increasingly beleaguered. In 1984, the United Democratic Front (UDF), a coalition of opposition groups, was formed. The townships became more and more ungovernable, and the economy was under huge pressure from foreign sanctions. Through the 1980's, the Inkatha Freedom Party (IFP), which ruled in the homeland of KwaZulu, was engaged in conflict with the UDF over control of parts of the state (Bonnin et al 1996). This led to political violence, which 
continued to the 1994 election and only gradually petered out afterwards. The violence was consistently highest in KwaZulu-Natal (Freund 1996). As illustrated by traders, the conflict resulted in much killing and destruction, and led to waves of refugees fleeing to the urban areas, which the Apartheid State was then powerless to prevent.

Political gains toward the transition were made during this period of intense conflict. Through the late $1980 \mathrm{~s}$, clandestine meetings were held between Nelson Mandela and the government and between the African National Congress (ANC) and groups of Afrikaners. In 1990, political parties were unbanned and political prisoners freed (Sparks 2003). Three years of tense negotiations followed, with more political violence, until in 1994, the country went to the polls to elect the first democratic government-a sweeping victory nationally for the ANC, with KwaZulu-Natal held by the IFP (Morrell 1996).

Over the past 10 years, South Africa has been transformed from an oppressive and racist political regime, to a democratic state with one of the most progressive constitutions in the world (Sparks 2003). This transformation has raised hopes for millions of South Africans that wealth and opportunities would be more equitably distributed among future generations. Ten years in, the project of democracy has achieved many successes, including improved access to basic services, social transfers, judicial transparency, and the growth of civil society. 


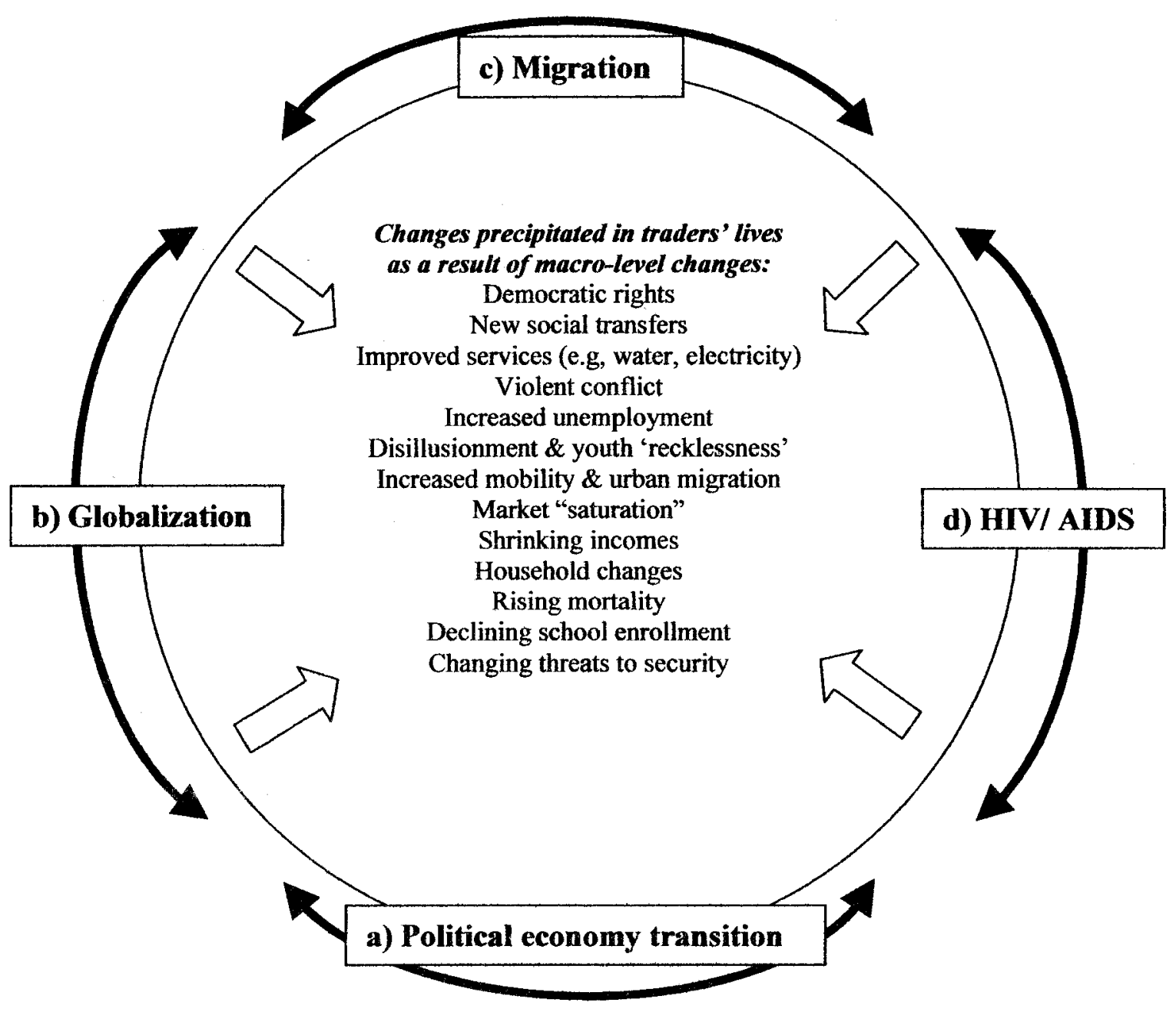

Figure 3: Changes in the Lives of Warwick Junction Traders Precipitating from Four Macro Processes: Political Economy Transition, Globalization, Migration and HIV/ AIDS 


\subsubsection{Transition and Globalization: Figure $3 b$}

A number of processes have converged with South Africa's democratization, and indeed have served to constrain the transition's promising potential for some people. South Africa's first democratic election took place just three years after the collapse of the Soviet Union - an era in which neoliberal economics were gaining global hegemony. Under external and internal pressures to open South Africa's previously protected economy to global markets, the new South African government abandoned its redistributive economic policies in favour of attracting foreign direct investment and encouraging free market growth (Nicholson 2001).

In 1996, the Reconstruction and Development Programme (RDP), which promised to redistribute land and provide housing, water, electricity, health care and education to all, was replaced by a policy of Growth, Employment and Redistribution (GEAR). GEAR has been described as "an unvarnished free-market programme, directly in line with the neo-liberal agenda, or what is known as the 'Washington consensus'; a combination of relaxed exchange rates, privatisation, fiscal discipline and collaboration with the private sector to produce export-driven growth" (Sparks 2003, p 193). The prevailing hope was that national economic growth would 'trickle down' to uplift the millions of black, coloured and Indian South Africans disadvantaged by years of exclusive educational and employment policies.

Unfortunately, the 'trickle down' has not yet materialized for most, and the transition to democracy has been bittersweet. Prior to the 1994 election, the economy was declining and unemployment rising; the end of price protection for white commercial 
farmers put many thousands of black labourers out of employment and there was very little new foreign investment. Removal of protective tariffs on manufactured goods (in line with the international General Agreement on Trades and Tariffs) resulted in declines in manufacturing sectors and factory closures (Nicholson 2001). While South Africa's economy has continued to grow (albeit more slowly than initial GEAR predictions), growth has taken place in less labour-intensive and higher-skilled positions; this is "jobless growth," meaning economic growth with fewer people employed (ibid.).

There are a number of key features of the post-Apartheid political economy related to globalization: "The first is weak economic growth and investment response. The second is the persistence of high unemployment rates and even a significant increase in unemployment. The third is the country's high level of both income and spatial inequality" (Naude 2004 p 47). The income gap between rich and poor has grown, and from 1996 to 1999 unemployment jumped from 1.3 to 5.8 million people, with the greatest impacts on black South Africans and in particular black women (Nicholson 2001). Unemployment rates have reached 30 percent for men and 43 percent for women (ibid.). Indeed, "the harsh reality of globalization, of competitive participation in the new worldwide marketplace, is that it leads to increased unemployment and pressure on wages" (Sparks 2003, p 26).

In South Africa, globalization has taken place amidst a labour force that has been kept out of education and training, and thus does not have the skills to compete in the new global labour market. Informal traders would be among those facing this lack of employment opportunity, and this is the most pervasive stress for participants in this 
study.

Furthermore, the growth of street trading in South Africa mirrors a global trend towards informalization-a trend towards increasingly precarious livelihoods and declining responsibility of states or private sector to provide social protection (Lund 2002). Economic liberalization underlies the deregulation of the informal economy and the belief that informal work is a solution to unemployment ${ }^{14}$. Many traders have no access to any social benefits and thus fear falling ill or not being able to work.

Even before considering the impacts of AIDS, we must recognize that globalization and economic 'reform' are creating tremendous hardship for much of the population, street traders included. Poverty and inequality institutionalized under Apartheid have remained entrenched. Traders have few resources and diminishing safety nets upon which to draw when and if they are faced with shocks or longer term stresses. This may well explain their disillusionment with South Africa's democratization.

\subsubsection{Transition and Migration: Figure 3c}

With the transition from Apartheid came the collapse of state control over where people could live. This, together with rising unemployment and political violence, led to a mass influx into the urban areas. The urban population of South Africa jumped from $48 \%$ of the total in 1980 to $58 \%$ in 2002 (World Bank 2005). Likewise, the number of informal traders in the Central Business District of Durban rose from 200 in 1984, to 800

\footnotetext{
${ }^{14}$ The current withdrawal of state from the Warwick Junction Project is also in line with a neoliberal agenda. The changes in security threats reported by traders are likely enmeshed in related institutional changes; declines in violent crime came about through increased political stability and civil society mobilization (i.e., the formation of Traders Against Crime), and the subsequent management outsourcing explains the concentration of power within trading committees.
} 
in 1990, and then sky-rocketed to 19800 in 1997 (Nesvåg 2002)-hence the "saturation" of the Warwick market described by participants.

As traders recounted, the collapse of state control led to chaos in South Africa's cities, with crime surging in the early 1990's (Nesvåg 2002). Sexual violence has reportedly increased as well (Whiteside \& Sunter 2000). Rapid urbanization has led to the development of informal (peri) urban squatter settlements, and as Sparks (2003) notes:

Life in these communities is tough. The crime rate is high, and predatory slumlords preside over the allocation of living space and exact tribute from the inhabitants. Turf wars break out between rival gangs. The fabric of traditional African social systems, with its extended family and age group networks was badly shredded years ago by the migrant labour system and disruption of tribal life; now it is under further assault with this massive urbanisation and the alienation that goes with it. (p 50)

This "alienation" in conjunction with high levels of poverty and unemployment, which are understood to undermine youth power (Campbell \& MacPhail 2002), could explain the "recklessness" and alcohol abuse reported by traders. In addition, the fracture of families resulting from the Apartheid migrant labour system has had profound impacts on gender relations, on the construction of gender identities, and on constructions of masculinity in particular (Campbell 2003).

\subsubsection{Enter HIV/ AIDS: Figure 3d}

HIV entered South Africa amidst this historical legacy of family fragmentation, gender inequality and poverty, and at a time when unemployment and population mobility were increasing. The virus came into the country in the late 1980 s and took hold in the early 1990s. Increased mobility and the opening up of South Africa's borders to its 
neighbouring countries played a role in allowing HIV into the country. Migration created a crucible for transmission; migrant labourers came to areas where conditions encouraged sexual 'mixing' and multiple partnering. Infected men then returned to their home communities where local epidemics were established (Whiteside \& Sunter 2000). Many of the exiles and guerrilla fighters returning to South Africa in the early 1990s came from bases in countries where HIV/ AIDS epidemics were entrenched (ibid.). Furthermore, intense (and increasing) poverty has generated circumstances in which women are more likely to enter into transactional sexual relations and men may turn to risky sexual practices as a means of coping with the harsh realities of their lives (Campbell 2004). South Africa is a fertile ground for HIV transmission.

The first ante-natal survey ${ }^{15}$ was carried out in 1990 and found a prevalence of 0.8 percent. At the time of the first election, in 1994, HIV prevalence stood at 7.6 percent; by 2003, the national antenatal prevalence was up to 27.9 percent (Department of Health 2003). The number of registered adult deaths has risen from 272000 in 1998 to 456700 in 2003 (UNAIDS 2003). The HIV/ AIDS epidemic explains why traders are beginning to see funerals every day - but the crucial point is that death rates are still rising. There was virtually no HIV in South Africa prior to 1990 (Karim 1999); this epidemic is new and growing, and while HIV prevalence is rising, full-blown AIDS cases and longer-term impacts are yet to be felt.

\footnotetext{
${ }^{15}$ Blood samples taken from pregnant women attending public ante-natal clinics for a range of routine tests were used in this survey. The samples were unlinked and anonymous. Ante-natal surveys have taken place every year since 1990; the samples exclude women accessing private health care.
} 
A closer examination of the available data indicates that infection levels are not uniform. The epidemic is marked by large regional variations; KwaZulu-Natal has consistently shown the highest prevalence in the country, jumping from 1.61 percent to in 1990 to 37.5 percent in $2003^{16}$ (Department of Health 2003). The epidemic is also experienced unevenly by gender, race, age, and socio-economic status (Gilbert \& Walker 2002). The Human Sciences Research Council (HSRC) and Mandela Foundation conducted a population-based survey with a random sample of households across South Africa in 2002; this showed the highest levels of infection at 24 years for women and 32 years for men (Gouws \& Karim 2005). Young women are more likely to be infected and, because HIV is a lifetime condition, they carry the burden of infection forward as they age. A survey in Hlabisa (rural KwaZulu-Natal) found 6.9 percent of the 20 to 24 age group of women were infected in 1992. Ten years later, 38.4 percent of this cohort (then aged 30 to 34 ) was infected. In 2001, the 20 to 24 female cohort had a prevalence of 50.8 percent (Gouws and Karim 2005). Women are infected younger than men and, in total, more women than men are infected. In 2003, an estimated 5.6 million people were HIVpositive: 3.1 million women, 2.4 million men and 100000 children (Department of Health 2003).

The course of the epidemic has been shaped by inconsistent, controversial and negligent national responses. Political leaders have put forth mixed messages about the

\footnotetext{
${ }^{16}$ Data are collected at the clinic level but not made available in disaggregated form. In the absence of data, this thesis assumes that the profile of HIV infection among traders in Warwick Junction is at least the same if not worse than in the rest of the province; the majority of traders are women and migrants.
} 
existence and causes of AIDS, and the government has been exceedingly slow to provide public access to ARVs (TAC 2005).

At the time of the first election, a "brilliant national AIDS plan was in place, but it was not implemented because the government was taken up with other things" (Whiteside 2005). The epidemic was simmering at a point when democracy, economic growth and basic services took priority:

The new democratic government was faced with huge challenges of building a new society and undertaking to deliver essential services. Its efforts were predicated on a constitution born of a human rights ethos. Upon assuming the mantle of authority, the new government started its efforts with good intentions and well-developed plans. However, this did not extend to the critical need to implement anti-retroviral prophylaxis or treatment (Deane 2005 p 539).

By the time of the second election in 1998, when Mandela stepped down and Mbeki was elected, the epidemic was in full force. In 1999, Mbeki came across a "dissident" website that indicated an alternative to the belief that HIV is a harmful virus that causes AIDS. Later that year, he convened a Presidential Panel, which included an equal number of "AIDS dissidents" from outside South Africa and mainstream scientists from within the country. Their task was to investigate the evolution of the syndrome and the efficacy of anti-retroviral therapies, but the panel was unable to reach agreement. With pressure rising, Mbeki withdrew from the debate, but allowed his Minister of Health to remain engaged (Whiteside 2005).

The ANC has since been involved in a number of scandals and controversies, including:

- Supporting and funding "bogus" (and sometimes lethal) AIDS 'cures', such as an industrial solvent and a coal-based derivative; 
- Questioning the existence and causes of AIDS;

- Refuting the 2000 Medical Research Council data that indicated a steep increase in young adult mortality and named AIDS as the leading cause of death;

- Questioning the efficacy and safety of ARV prophylaxis and treatment (and refusing, until compelled, to provide drugs for rape survivors, prevention of mother-to-child transmission and AIDS treatment), with particular scepticism for drugs developed by multinational pharmaceutical companies; and

- Polarizing the debate over whether medical therapy or proper nutrition is required to treat HIV (Deane 2005).

Yet, just as the government has failed in prevention and treatment, South Africa has adopted a rights-based constitution and civil society groups have mobilized around the 'right to health'. The most powerful lobby, the Treatment Action Campaign (TAC), has undertaken three unprecedented actions in their rally for accessible AIDS treatment. First, in 2002, TAC took the government to court to demand Nevirapine for prevention of mother-to-child transmission on the basis that access to this medication is women's constitutional right; TAC won. Second, in 2003, TAC went to court in conjunction with the government to demand lower cost ARVs from pharmaceutical companies; the case was won when pharmaceutical companies withdrew. Third, in late 2003, TAC instigated mass civil action, demanding a treatment 'roll-out' that would make ARVs accessible through the public health system. The government responded with a plan to treat 53000 people by April 2004, just after the third national election (Whiteside 2005).

However, at the time of the election, the number of people on treatment was in the hundreds rather than thousands, and it is still nowhere close to the original targets. Of the 24900 patients targeted for treatment in KwaZulu-Natal by February 2004, only 3000 
were receiving ARVs (TAC 2005). Thus, people who cannot afford private health care or who do not have 'medical aid' (private health insurance) still do not have access-these are people with few resources and insecure livelihoods, such as informal street traders in Warwick Junction.

Health care in South Africa is funded through the central government, but the provinces are responsible for health care delivery and the ARV roll-out. EThekwini (Durban) Municipality also plays a role in heath care delivery through city-run public clinics and a municipal health department (which includes the AIDS Training, Information and Counselling Branch). While national-level responses have so far been inadequate, decentralization may create opportunities for provincial and local governments to develop HIV/ AIDS programs for traders; yet none currently exist in Durban (Lee 2004, b).

The HIV/ AIDS epidemic is new and uneven in South Africa, with the full impacts yet to unfold. HIV entered the country amidst a history of inequality and a sea of change. Government response was then (and continues to be) inadequate and misguided. Indeed, despite the first-rate private health care available to some, many do not have access to ARV therapies. The lack of access is compounded by confusing and debilitating messages from political leaders.

\subsection{Conclusion}

Economic 'reform' and globalization shape the post-Apartheid experience in South Africa, and for many street traders these have meant declining employment 
opportunities and deepening poverty. Economic and political change have instigated (or accelerated) a cycle of oscillating urban-rural migration for many traders, and thus a life of living apart from their families. These stresses are creating a climate of disillusionment, despite the myriad of positive changes that are underway. The HIV/ AIDS epidemic has entered into this context-there was virtually no HIV in South Africa 15 years ago.

Participants describe their lives as a series of struggles—over livelihoods, rights, security, health and' power. These struggles are both the legacy of Apartheid and the outcomes of globalization, urbanization and HIV/ AIDS. It is within these rapidly changing macro conditions that participants are living with and responding to the realities of the epidemic. Traders are struggling now, even before the full impacts of AIDS have emerged. With the macro pieces now in place, Chapter 4 turns to an examination of how vulnerabilities to the epidemic are generated, experienced and negotiated among traders-the micro context. 


\section{Chapter 4}

The Micro Context of Traders' Vulnerabilities:

Who, Why, How and What?

The taxi ranks in Warwick Junction are worlds unto themselves. Hundreds of minibus taxis filled well beyond capacity rock with Zulu hip-hop as they zip in and out of crowded metal shelters. Underneath, commuters come and go, drivers holler at harried passengers, youngsters congregate around billiard tables, and men armed with machine guns keep the peace as they stand guard over drivers' precious spaces. Young people find opportunities in these hubs, selling food and drinks to the thousands who pass through each day.

On one occasion, I asked a young man selling chips what he thought would affect his health most over the next five years. He replied quickly and quietly: "HIV/ AIDS will be the biggest threat in the next five years-not to me, but other people will be having it." Neither my research assistant nor I had yet asked him anything about the epidemic. We tried to probe deeper into his response, but he changed the subject abruptly.

In another encounter, just outside the herbal market, a 21-year-old woman sat on the sidewalk roasting mealies over a small fire in the lid of a metal garbage bin. Cars whizzing by on one side and pedestrians pushing along on the other, I asked her when the 
last time a family member was ill. Staring at the ground, she whispered:

My brother died three months ago, he was 32. He was weak and lost a lot of weight. We were told he had TB and he was given treatment, but it didn't help. He was treated at the clinic and stayed at the farm.... Then he came to Durban, and my sister and I looked after him. I took him to the clinic and I took him to the hospital, but the queues were too long and they requested that a family member stay with him for the treatment. But we couldn't take time off work... I looked after my brother, using gloves because of his abscesses. We didn't know for sure he had it, but I suspect it was AIDS.

The participants in this study were not asked, nor did any disclose, their HIV status, and like the young man in the taxi rank, many distanced themselves from their own personal risk of infection. Yet, I only had to listen to their stories to get a sense of how deeply the epidemic is implicated in their lives. The mealie cooker's experience is illustrative. She was faced with caring for a sick brother amidst a culture of fear and silence; he never told her whether he was infected, but she knew. She took precautions to prevent becoming infected herself. She was required to take time away from her tenuous work to care for him, but she was unable to access the necessary health care.

This chapter examines the micro contexts of traders' vulnerabilities to HIV and AIDS. It is structured around four questions: (1) Who among traders is vulnerable? (2) Why are traders vulnerable? (3) How are traders vulnerable? (4) What underlies their differentiated vulnerabilities? While Chapter 3 depicted traders' experiences as shaped by common macro processes, this chapter reveals that vulnerabilities are differentiated at the micro level, as a result of social and economic conditions that are distinct by age and gender. It demonstrates that vulnerabilities result from interacting social, economic, political, ecological and individual factors that stress traders' health and wellbeing. The chapter ends by piecing together the local conditions that underpin traders' likelihood of 
infection, illness and broader AIDS impacts to develop a framework of their micro vulnerabilities.

\subsection{Who among traders is vulnerable to HIV/ AIDS?}

It's affecting me and my whole community. It doesn't affect only one family or person. Neighbours are getting sick and children are being left alone, and we have to take care of each other. (Mealie cooker)

One of the aims of the fieldwork in Warwick Junction was to understand who among traders is likely to be infected or affected by the epidemic (Barnett \& Whiteside 2002). Many traders initially described HIV/ AIDS as a problem of poor decision-making on the part of individuals and cast the epidemic as something that affects 'others' (see Table 2a). "I'm aware of this problem, even at home people are disappearing - at a distance I can see this problem," explained an older woman who collects and sells recyclable cardboard. 'Othering' often emerged in conversations with older women, many of whom view HIV/ AIDS as a disease of youth caused by young people's weaknesses: 'I won't get it, it's a kiddy's disease... [Children need to learn] how to behave, how to protect themselves" (Chicken seller).

Table 2: 'Othering' among Traders

\begin{tabular}{|l|l|}
\hline Themessage & Traders' perceptions of HIV/ AIDS \\
\hline $\begin{array}{l}\text { a) Poor decisions by } \\
\text { individuals }\end{array}$ & $\begin{array}{l}\text { "The only way to stop it is for each person to look after them self" (Hairdresser) } \\
\text { "Solutions come from individuals" (Cardboard collector) } \\
\text { "People who get AIDS do because they don't like themselves" (Trolley pusher, } \\
\text { fruit) }\end{array}$ \\
\hline b) A disease of youth & $\begin{array}{l}\text { "The problem with young people is that they can't suppress their feelings. If } \\
\text { they could only forget about sex and abstain, they wouldn't be having this } \\
\text { problem. This generation has a strong sex drive." (Seamstress, church uniforms) } \\
\text { "Youth are not the same as in yesteryears. There are fewer virgins. People } \\
\text { have sex earlier. Young people have become too permissive and weak." (Ma } \\
\text { Dlamini) } \\
\text { "We try to advise young traders that we're here to sell stuff not to sell our } \\
\text { bodies, but we all need money. Young people don't see things like us. We're } \\
\text { committed to our families back home, but young girls are looking for } \\
\text { boyfriends and are looking for money." (Mat seller) }\end{array}$ \\
\hline
\end{tabular}


With repeated conversations, however, it became clear that vulnerability to HIV and AIDS is not an individual issue and the consequences are not limited to youth. The effects of the epidemic on traders are pervasive: all 20 interviewed have been or are personally affected. Many have cared for people sick with AIDS, taken in orphans, felt the financial burden, and watched friends, customers and community members die. Half of the traders in the core sample have lost close family members to (suspected) AIDSrelated illnesses. Three quarters have noticed symptoms among traders and customers in Warwick Junction; they revealed a pattern: people are "disappearing" before they become ill, returning to the rural areas or informal settlements, and dying in silence. They described the epidemic with grief and helplessness. Impacts among traders are the norm, not the exception; the answer to who among traders is vulnerable is evident: everyone.

Nevertheless, part of what perpetuates the 'othering' is a tendency to conceptualize vulnerability solely as a likelihood of infection and to categorize people into 'risk' groups. When asked if the epidemic is affecting traders, for example, Sister Dudu, the director of Lifeline Voluntary Counselling and Testing Centre for HIV/ AIDS in Warwick Junction, explained, "most of the traders we are seeing are negative... I think it's because of the age of people we are seeing; we'd have a very different picture if young traders were coming in here." Limiting vulnerability to likelihood of infection misses the effects of the epidemic on those who are not personally infected and may serve to keep the epidemic at a distance. This 'othering' phenomenon has been reported elsewhere, and placing people in 'risk' groups is often part of the distancing process 
(Delor \& Hubert 2000); ultimately these views impact why and how traders are vulnerable.

\subsection{Why are traders vulnerable to HIV and AIDS?}

The macro causes of traders' vulnerabilities were examined in Chapter 3, but the question of why traders are vulnerable is more complex still. At the micro level, traders' vulnerabilities are caused by the manifestation of the disease, their perceptions of the causes and prevention of AIDS, stigma, poverty and livelihood insecurity, dislocation from family, and lack of access to services, information and resources. The factors detailed below are not all relevant to each trader at all times, but together they depict why many traders are vulnerable.

\subsubsection{The Manifestation of HIV and AIDS}

Traders know AIDS by its symptoms (e.g., thrush, skin lesions, TB, pneumonia, weight loss and diarrhea), by the fact that young people who should be healthy become sick and cannot recover, and by its mysterious and chronic evolution. Transmission of HIV is biologically determined ${ }^{17}$, but the likelihood of transmission is driven by the convergence of a number of physical, behavioural, social and economic conditions. Once infected, HIV suppresses the immune system, but this is insidious; most people in South Africa live with the virus for six to eight years before physical symptoms begin to appear. Secondary illnesses then take hold, manifesting as respiratory infections, skin lesions, and other ailments. As the immune system weakens, these illnesses become more severe. The 
insidiousness of this progression makes it possible to focus on the symptoms and to discount that HIV might underlie these chronic infections; in many cases, it makes it possible for traders to attribute their own or their family members' illnesses to 'other' causes.

Furthermore, wellbeing for people living with HIV depends on their overall physical health status, as well as emotional state, social support, and access to treatment and care. The impacts of the epidemic on individual traders, their families and their communities depend on their capacities to care for people falling ill, to support those who can no longer work, and to parent orphaned children. Meanwhile, resources are increasingly spent on care and treating secondary infections. The slow and debilitating progression of HIV/ AIDS makes it impoverishing for those most heavily impacted.

Thus, two aspects of this syndrome's manifestation contribute to traders' vulnerabilities: its inconspicuous expression and its slow, resource-depleting evolution.

\subsubsection{Perceptions of AIDS and Mixed Messages}

People are pointing fingers, saying 'you brought this, you brought this'... I don't want to bother talking about this-it's there to kill. By the time you know you're positive, you get sick... I don't believe there's something like AIDS. Where is this thing coming from? Why is there no cure? If a person gets malaria, they say it's AIDS. If they get TB, they say it's AIDS. If the three of us go and get tested and they come back in two weeks and say you have it and you two don't, how do I know they're telling the truth? How do I know they didn't mix up the blood? Can I watch? (Cigarette seller)

There is no clear truth about the existence, causes, prevention or treatment of AIDS among traders (see Table 3). It was not uncommon for the same person to doubt

\footnotetext{
${ }^{17} \mathrm{HIV}$ is transmitted primarily through heterosexual intercourse in South Africa (Whiteside \& Sunter 2000).
} 
the existence of AIDS in one conversation and to speak about the importance of ARV's and condoms in the next. How traders perceive the problem conditions how they prevent and respond to it. It is unlikely that an individual who believes that condoms are infected with HIV, for example, will choose this mode of prevention. But why the scepticism?

Table 3: Scepticism and Differing Perceptions around HIV/ AIDS among Traders "I've not seen anyone affected, I have not been affected, my family is not affected. I'm not worried
about it" (Seed seller, mother)
"We talk about [AIDS]; there's a rumour that it can be spread through the wind, so we worry about it
on windy days." (Mpempo seller)
"Maybe if we had better work and we worked a lot then we would think less about women"
(hairdresser)
"I don't know, I don't think [condoms work] because a lot of people are dying. If condoms work, why
are so many people dying?" (Chicken seller)
"Condoms don't offer protection, they are not strong if they are the free ones. The ones they give out
for free break." (Hairdresser)
"Condoms are the cause of more troubles and can cause HIV by leaking or overflowing, and
sometimes people cut holes in them. Using condoms is pointless." (Bovine head cooker)
"South Africans are scared to talk about it and they need to be educated about condoms. There are all
kinds of misconceptions, like that condoms have the virus in them, that the lubricant is actually HIV,
so they are scared to use them" (Hairdresser)
"I protect myself and my family using muthi. I trust muthi more than condoms" (Muthi seller)

According to Tobias Mkhize, an environmental health officer who works closely with informal traders, "you need to understand AIDS both in terms of the clinic and traditional medicine" $(2004$, a). As has been noted with other populations elsewhere in South Africa (Campbell 2004), traders seek health care from both biomedical professionals and traditional healers, and most move between these without tension. Out of 20 traders, 13 use muthi, visit traditional healers, or rely on "God and ancestors" to remain healthy or treat illness; however, only one out of these 13 relies solely on traditional medicine. In the culminating focus group, there was consensus that there is a role for traditional healers to play in treating HIV/ AIDS and other illnesses. As one young man explains: "At home I used inyangas, but when I'm sick here I have no time to 
see inyangas so I just go to the clinics or hospitals... If I get sick [with HIV], I'll go back to the farm and use traditional treatments. That's what I trust because I grew up with it since I was young" (Trolley pusher, fruit).

The scepticism expressed by traders is mirrored in the messages articulated by health care providers. There is no unified biomedical or traditional discourse. Messages are mixed within and between these two epistemes; assertions coming out of each are at times contradictory and at other times overlapping.

The most pervasive biomedical AIDS campaign in South Africa, and the message recited most often by traders, is prevention through ' $\mathrm{ABC}$ '_-'abstinence', 'be faithful' and 'condomize', in that order. Yet, ' $\mathrm{ABC}$ ' is gender-biased and has not effectively prevented the spread of HIV: 'abstinence' is unrealistic in marriage, co-habitation, and situations of sexual violence; it does not help to 'be faithful' if one's partner is not doing the same; and many women feel unable to 'condomize'. In the absence of accessible ARV therapies, the biomedical mantra for those infected is to 'live positively': eat well, avoid alcohol, exercise, and take immune system boosters. Both of these messages target individuals' behaviours but do not address the broader impacts of the epidemic. At best, ' $\mathrm{ABC}$ ' is only a partial solution, defined from a rather narrow behavioural perspective; it overlooks the complexities of social relations, the uneven constraints on people's actions, and the broader consequences of AIDS. These dominant messages do not match how traders are experiencing the epidemic.

Like traders, the municipality, province and many biomedical practitioners see a role for traditional healers in prevention and treatment. Some healers are now legally 
certified $^{18}$ and the municipality is working with them to promote 'ABC'. Many of the counsellors interviewed recommend traditional treatments to people who are HIVpositive- mostly as immune boosters-because ARV treatments are not accessible (see Appendix $\mathrm{H}$ for examples of messages from biomedical practitioners). There have also been interventions to reduce the HIV risk inherent in some traditional treatments: "especially important has been letting inyangas know that they can be contributing to the epidemic through scarification, and they need to use sterile razors" (Mkhize 2004, a). Efforts are underway to monitor and scientifically test traditional remedies (ibid.).

But there are significant discursive obstacles to this 'partnership'. Traditional medicine does not conceptualize disease as caused by pathogens to be treated with empirically tested medications. Rather, illness results from spiritual misalignment and treatments are handed to healers by their ancestors. The result is healers, much like biomedical practitioners and traders, piece together elements from various discourses: "I'm about to start on a new medication. It involves doing cuts and after the treatment you don't get the virus again. I don't know how long the treatment will prevent the virus from coming back. Treatments are given to me from my ancestors. They show me the treatment and I don't doubt them. The treatments don't need to be tested" (Inyanga \#2). The inyangas interviewed expressed a range of views: some claim to eradicate the virus,

\footnotetext{
${ }^{18}$ The municipality and the province are now working with the Traditional Healers Council (THC) to certify inyangas as health care providers. Other traditional healers associations, including the Traditional Healers Organization (THO), are seen by some as a threat to efforts to formalize traditional medicines. Most inyangas continue to operate outside any association and without certification (Mkhize 2004, b).
} 
some preach ' $\mathrm{ABC}$ ', some are treating the symptoms, some believe AIDS is a conspiracy, and some doubt its existence (see Appendix I).

Traders' differing perceptions heighten their vulnerabilities and are influenced by the multiple and dynamic perspectives articulated by those sanctioned to provide health care. The messages that come across most strongly are narrow and do not account for traders' complex social relations. This is compounded by the mixed messages and inconsistent political leadership discussed in Chapter 3.

\subsubsection{Social Stigma}

I would prefer if I got infected today and was killed tomorrow-then I wouldn't have to live with the stigma. (Trolley pusher, fruit)

While every participant is personally affected by the epidemic, most denounced their own vulnerabilities and many questioned the existence of AIDS. The social stigma attached to HIV and AIDS is likely contributing to the 'othering' and scepticism discussed above. Traders view the epidemic with disgrace: “[Traders] don't have AIDS. They know about HIV and AIDS. They sleep on the streets but they are proud people, they protect themselves, they are not dirty" (beading group). This culture of shame largely results from a belief that sexuality is taboo or tainted: "None of them will disclose that they have it. I think it's because of the stigma and in African culture it's associated with sexual intercourse, which is taboo" (Seamstress, church uniforms).

Consequently, traders described a debilitating silence that constrains them from getting tested, obtaining treatment and accessing social support. One older woman explained: "The government needs to support people to disclose so they don't infect 
others and so we can support them. It really has to start at home. We don't say when our kids have it. We all need to talk about it" (Mat seller). The overwhelming stigma attached to HIV/ AIDS increases traders' vulnerabilities.

\subsubsection{Underlying Health Stresses: Livelihood, Mobility and Access}

I walk to the Durban bus station at night because I don't make enough money even to take a taxi. Some days I don't make a cent. Sometimes I sell only one mat per week: 35 Rand per week. And I try to send it home... Where we are sleeping is crowded and not comfortable. If anyone gets an infectious disease, all of us get it. Like scabies, we all suffer from scabies. Living conditions are bad. There are water shortages. We have toilets, but they are in bad condition. We sleep on the pavement. (Mat seller)

Clearly, the impoverishing nature of AIDS, the mixed messages, and the intense stigma require an understanding of vulnerability that looks beyond HIV/ AIDS as an isolated medical issue; indeed, this discussion of why traders are vulnerable points to a number of complex social and economic causes. Such a shift in understanding HIV/ AIDS is consistent with traders' perceptions of health more generally. Traders perceive their health not merely in biomedical terms - as the absence of disease- but rather as conditioned by interactions between themselves and their environments. They understand themselves as physical, spiritual and emotional beings, and view their environments as including physical and social conditions in their work and living places. ${ }^{19}$

This was evident in the culminating focus group, where traders ranked their top three health priorities as (1) livelihood insecurity and poverty, (2) mobility and

\footnotetext{
${ }^{19}$ Appendix D provides examples of how traders, at specific times, describe their health concerns as different dimensions of person-environment interactions. Furthermore, many describe chronic illnesses as linked to environmental conditions: hypertension to financial stress, arthritis to uncomfortable working conditions, seizures to political violence, and TB to dust. While there is no universal perception of 'self', 'environment', or 'health' among traders, understanding health vulnerabilities requires a multidimensional approach. This perception of health is supported by Campbell (2004).
} 
dislocation from family, and (3) lack of access to information, resources and services.

The discussion also portrayed these key health conditions as affecting traders'

vulnerabilities to HIV and AIDS. A summary, as outlined with the facilitators of the

focus group, is as follows:

\section{Poverty and livelihood insecurity}

Traders' vulnerabilities are generated by lack of affordable housing, impoverished working environments, lack of access to water, poor sanitation and pest control, and lack of social security. They report a concentration of power amongst certain trading committee members, which recently has become a threat to the livelihoods of some. Together, these conditions of poverty and livelihood insecurity make it difficult for them to take time off work, access health care, care for sick family members, and absorb the costs of funerals, orphans and adult family members who are unable to work. Intense poverty is also associated with risky sexual activity.

\section{Mobility and dislocation from families}

Most traders in Warwick Junction maintain close ties to their farms. Their incomes often support large numbers, with households spread over three or more locations. Being displaced from family creates tremendous stress, and in the context of the epidemic, traders' mobility makes it difficult to care for sick family members. In addition, many traders worry about not having adequate social support were they to fall ill.

\section{Lack of access to information, services and resources}

Traders are not accessing public clinics in Warwick Junction; they feel they cannot take the time away from their sites to sit in clinic queues, and many report being turned away from clinics for not having addresses in Durban ${ }^{20}$. They do not have health insurance, which means that anti-retroviral therapies are currently inaccessible. They face a severe lack of access to information, both on HIV/ AIDS and on how to apply for social transfers, loans and municipal housing.

Interviews with individual traders, health care providers and key informants reinforced that livelihood insecurity, mobility and lack of access stress traders' health (see Table 4). Overall, social and economic factors have emerged as health priorities for 
traders, with environmental, biomedical, psychological and spiritual conditions

intertwined within these issues. These multidimensional health conditions underlie

traders' vulnerabilities to HIV and AIDS.

Table 4: Underlying Health Stresses for Traders

\begin{tabular}{|c|c|c|}
\hline $\begin{array}{l}\text { a) Health } \\
\text { priorities, } \\
\text { as per focus } \\
\text { group }\end{array}$ & $\begin{array}{l}\text { b) Supporting evidence from traders' } \\
\text { interviews }\end{array}$ & $\begin{array}{l}\text { c) Supporting evidence from health care } \\
\text { providers and key informants }\end{array}$ \\
\hline $\begin{array}{l}\text { 1. Livelihood } \\
\text { insecurity and } \\
\text { poverty }\end{array}$ & $\begin{array}{l}\text { "If they stop me from selling here, we'll } \\
\text { all starve." (Mat seller) } \\
\text { "My top health concern? Financial } \\
\text { problems stress me out." (Seamstress, } \\
\text { pinafores) } \\
\text { "Even when I'm sick I come to work. I } \\
\text { haven't been sick enough to take time } \\
\text { off work... there's no one here to look } \\
\text { after my stuff." (Mat seller) }\end{array}$ & $\begin{array}{l}\text { "The biggest threat to the health of muthi } \\
\text { traders is living conditions, lack of } \\
\text { accommodation, exhaustion from sleeping } \\
\text { on the streets..." (Ma Dlamini) } \\
\text { "Financial problems; they are traveling long } \\
\text { distances to and from work, they don't have } \\
\text { proper residences." (Inyanga \#2) } \\
\text { "Water all over, garbage dumped in the } \\
\text { streets, poor sanitation." (Counsellor \#3) }\end{array}$ \\
\hline $\begin{array}{l}\text { 2. Mobility, } \\
\text { dislocation and } \\
\text { family-related } \\
\text { stress }\end{array}$ & $\begin{array}{l}\text { "My children depend on me, they will } \\
\text { suffer if I die." (Seed seller, mother) } \\
\text { "There are stress-related effects, like I'm } \\
\text { worried because I don't know what's } \\
\text { happening at home." (Mat_seller) }\end{array}$ & $\begin{array}{l}\text { "Hypertension amongst the older women } \\
\text { because of stress. Many have three to five } \\
\text { children, no husbands, and they are the } \\
\text { breadwinners. They have no money to send } \\
\text { their kids to school." (Sr. Dudu) } \\
\text { "They work very hard and send all their } \\
\text { money home for their children to go to } \\
\text { school." (Ma Khawula) }\end{array}$ \\
\hline $\begin{array}{l}\text { 3. Lack of } \\
\text { access to } \\
\text { information, } \\
\text { resources and } \\
\text { services }\end{array}$ & $\begin{array}{l}\text { "I went to the clinic here last year when } \\
\text { I was pregnant because I needed to see a } \\
\text { doctor. They wouldn't take me. They } \\
\text { said I had to go back to where I am } \\
\text { from. I don't have an address in } \\
\text { Durban." (Seed seller, daughter) } \\
\text { "There is a real lack of information } \\
\text { because we don't get it here in the } \\
\text { market, we're not at home long enough, } \\
\text { we're not in the township." (Seed seller, } \\
\text { mother) }\end{array}$ & $\begin{array}{l}\text { "One of the big problems is that when } \\
\text { traders go to the Lancer's clinic they are } \\
\text { told they have to go to their home clinic... } \\
\text { this is a stupid law." (Sr. Dudu) } \\
\text { "I've never seen anything for traders to } \\
\text { teach them about AIDS or to bring them } \\
\text { into the clinic." (Counsellor \#5) } \\
\text { "The problems they are facing is that they } \\
\text { don't have access to loans from the } \\
\text { government. They need loans to grow their } \\
\text { businesses." (Inyanga \#3) }\end{array}$ \\
\hline
\end{tabular}

Why are traders vulnerable to HIV and AIDS? At the micro-level, traders'

vulnerabilities are linked with their own perceptions of the epidemic, the social stigma,

${ }^{20}$ The clinic managers in Warwick Junction insisted that they do not turn anyone away. This contradiction requires further investigation but is beyond the scope of this thesis. 
the impoverishing nature of AIDS, and the broader social, economic, spiritual and ecological conditions in which they live and work. These factors intersect and interact in complex ways, and in so doing, they contribute to the effects traders are experiencing now and will likely experience as the epidemic progresses. Having introduced each of these factors, Section 4.5 will examine their interconnections.

\subsection{How are traders vulnerable to HIV and AIDS?}

I am a guardian to all of them; they come to my house and I take care of them. I will be the one to take care of the arphans. All of this really stresses me. (Seamstress, church uniforms)

We have seen that traders share certain common social and economic conditions, yet within this group, how traders are vulnerable and what impacts they bear are not uniform. Vulnerabilities were expressed differently by various subgroups within the core sample as a result of social and economic characteristics that are distinct by age and gender. Examining how traders are vulnerable adds another level of nuance to the macro and micro causes of traders' vulnerabilities.

Table 5 documents key concerns of traders by age and gender, illustrating the differentiation of their vulnerabilities at the micro level. It depicts two clear trends, which are examined in more detail below. First, younger traders share pervasive fears of infection, and these fears are shaped by gender relations and gender-specific circumstances. Second, older traders are vulnerable to the impacts of the epidemic, with older women experiencing disproportionate social, economic and emotional stresses.

\footnotetext{
${ }^{21}$ However, several visits to this trader revealed that she does in fact leave her mats in the care of two other women who work in her trading block when she must be away.
} 
Table 5: Differentiated Micro Vulnerabilities ${ }^{22}$

\begin{tabular}{|l|l|l|}
\hline & Men & Women \\
\hline Younger & $\begin{array}{l}\text { Fear of infection } \\
\text { Stigma } \\
\text { Lack of social support } \\
\text { Lack of access to services } \\
\text { Losing customers to HIV/ AIDS }\end{array}$ & $\begin{array}{l}\text { Fear of infection } \\
\text { Fear of dying and leaving behind young children } \\
\text { Difficulties negotiating sexual practices } \\
\text { Feelings of powerlessness } \\
\text { Stigma }\end{array}$ \\
\hline Older & $\begin{array}{l}\text { Losing friends and community } \\
\text { members } \\
\text { Losing customers to HIV/ AIDS } \\
\text { Worries about children } \\
\text { Financial strain of orphans }\end{array}$ & $\begin{array}{l}\text { Burden of caring for sick family members } \\
\text { Financial strain of supporting sick family } \\
\text { members and orphans } \\
\text { Emotional stress } \\
\text { Lack of communication with younger family } \\
\text { members }\end{array}$ \\
\hline
\end{tabular}

Younger traders are highly fearful of becoming infected and they expressed a shared sense of anxiety and inevitability (see Table 6). They raised concerns about how they would access treatment, care and support if they were to fall ill. Most would return home to their families, but they worry about the lack of livelihood opportunities and health services in the rural areas. Some felt it would be difficult to disclose an HIVpositive status to their families because of the stigma attached to the virus.

\section{Table 6: Fear and Inevitability among Young Traders}

"My parents are very strict and I don't know if they would accept if a family member had it. They
don't talk about sex." (Mealie cooker)
"Sometimes I think about getting tested, but then I get too scared." (Barrow boy)
"I'm worried about HIV. I would love to know. But it's not curable, so what's the point [of getting
tested]?" (Mealie cooker)
"I'm keeping some money to deal with it when it comes." (Trolley pusher, fruit)

Social and economic stresses, gender relations and broader social norms underlie young traders' fears, and these reveal important gender differences. Young women are afraid of dying and leaving behind their children: "in the next five years I could die, and

\footnotetext{
${ }^{22}$ Table 5 draws on the data in Appendices E-G. Appendix E shows the core sample of traders divided into four groups based on age and gender. Appendix $F$ provides an analysis of vulnerabilities, by age and gender. Appendix G documents the results of the AIDS component of the culminating focus group, as recorded by research assistants.
} 
who will look after the kids?" (Mealie cooker). They worry that their families will not be able to support them if they get sick and that resources would be stretched too thinly to properly look after their children. All six of the young women were concerned with the stigma they or their children would face if they were to present with symptoms.

Fear of infection among young women goes beyond caring for their families, as they often feel powerless to prevent the disease. While four out of the six believed that condoms are effective, at the time of the interviews, only one was using them consistently and this only in the previous six months since the birth of her child. A young woman cooking curries explained: "I feel threatened but I'm not protecting myself... I don't use condoms. My boyfriend doesn't want to and he says he doesn't have another girlfriend." Another young woman clearly described her sense of powerlessness:

[My boyfriend and I] talk about it, but we are from the rural areas where we believe in having one man. If our man gets someone on that side while we are on this side, we have no control over that... I'm scared of it. I talked to my boyfriend about it but now he doesn't trust me and doesn't want me to sell here in the market. He thinks I have someone here. I can't protect myself from this. (Shoe seller)

All the women in the study claimed to be monogamous: "being faithful" is their primary defence against infection. Indeed, their partners are unwilling to use condoms, and thus they rationalize that "being faithful" is adequate. This would be the case if their partners were monogamous as well, but most suspected this to be unlikely. 
By contrast, younger men seem to have more control over their sexual practices ${ }^{23}$. All claimed to use condoms sometimes and to "turn women away" who are not willing to do the same. However, the interviews showed inconsistencies. Men shared the attitude that condoms are not necessary in marital relationships and many stressed (or boasted) that they have multiple partners. The unevenness in attitudes highlights gender dynamics in which men appear to have more choice than do women, both in individual negotiations of sexual behaviour and in social norms that make it more acceptable for them to have multiple partners.

Yet, these projected attitudes stand in direct contrast to young men's unanimous fears of getting tested or becoming ill. Young men are worried about living with the stigma and many felt they would not have access to social support if they got sick. This widely-voiced lack of support was expressed starkly by one young man: "I don't know what I'd do. No one would be able to take care of me. I don't have anywhere to go. I might kill myself" (Hairdresser).

Young men portrayed an overall sense of anomie. They reported not having economic opportunities; as noted in the last chapter, they spoke about partaking in risky behaviours because they feel hopeless about the future. The young hairdresser's explanation of what would make it easier for him to deal with the epidemic is revealing: "if I could find a nice job and work, because if you have a nice job and work, then you have a future, and you have money to help your brothers and sisters, and you could have

\footnotetext{
${ }^{23}$ Sexuality consists of complex emotions, relationships and actions, which are linked to constructions of masculinity, femininity and gender relations. Discussions around sexual practices are not intended to reduce sexuality to isolated or quantifiable behaviours (Campbell 2004).
} 
a wife." The lack of employment and support, together, underpin young men's vulnerabilities.

Although attitudes, concerns, projected sense of control, and reported practices are contrasting between men and women, fear of infection plays deeply into all young traders' psyches. There is universal anxiety and inevitability among young traders, but these fears are shaped by social and economic circumstances that are gender-specific.

Where younger traders discussed their own personal fears of infection, older traders were concerned with the impacts they are experiencing and will face in the future. Older men reported losing friends, community members, and customers, and they were worried about their children. They are feeling the financial strain of orphans in their home communities:

It's affecting me a lot. I know a lot of people who have passed away because of it and it's still going to be there until the government makes a real plan for treatment. Most cases are from the rural area... Orphans are a problem because all the families are poor. Kids are being taken by relatives. (Sunglasses and accessories trader)

A key finding is that, of the four groups of traders, older women are experiencing disproportionate effects of the epidemic. The story of the seamstress from Chapter 1, a 52-year-old woman who is taking care of three sick nieces amongst her 18 dependents, illustrates the distinct and profound vulnerabilities of older women.

Older women are bearing the brunt of the social and care-taking burdens of the epidemic in their families. Two thirds of those interviewed have taken care of, or are caring for, family members or neighbours sick with AIDS-related illnesses, and in most cases, these women have nursed several people in this situation. By contrast, only one 
third of the younger women, one quarter of the younger men, and none of the older men have cared for a relative whom they suspect had HIV.

The economic impacts of AIDS on already-stretched incomes of older women are of paramount concern. As outlined in the last chapter, these women are supporting growing numbers on shrinking incomes. On top of this, the epidemic is having significant financial impacts on two thirds of the older women, and half are looking after orphans. They worry about future financial implications, including the cost of funerals, orphans, treatment and care (both of HIV and of secondary illnesses), and time off work.

Furthermore, the emotional toll of the epidemic is not to be under-estimated: helplessness, fear, worry, and despair overshadowed conversations about HIV/ AIDS among all traders. In the case of older women, they are extremely worried about their children, even if they are not currently sick. Difficulties communicating about the epidemic within families are compounding their stresses, and a debilitating intergenerational silence impacts both younger and older traders (see Table 7). The older woman selling mats expressed her frustration and powerlessness:

If they would listen, people wouldn't be dying this way, at this rate. They don't believe it kills, they don't believe it will happen to them, or they don't think the person they're with has AIDS. I'm talking about it because it is something that's happening to me. I am talking about my kids. I take them to the clinic; I take home condoms. They don't listen, though, they are still taking risks... I suspect my son has it ... How are we supposed to help if he won't get tested? (Mat seller)

These emotional impacts reinforce the economic burdens, especially when a longer-term perspective is considered. The pressures of being the primary breadwinners and caregivers deepen the effects of the epidemic on older women in Warwick Junction. 
Heightening these consequences are their fears that they could succumb to personal illnesses that would diminish their capacities to provide support and care. Indeed, all of the older women in this study suffer from (largely untreated) chronic illnesses such as diabetes, arthritis and hypertension.

\section{Table 7: Intergenerational Silence: The Young-Old Divide}

"I can't talk to my children about this, or about sex. It's taboo. It's better if someone else talks to the children. That's the way we grew up." (Cardboard collector)

"I don't talk about it with my mother, she is too old." (Curry cooker)

"This is the hardest thing. People need to create support, but the main problem that we're facing is that people will not disclose. For the young ones it's not easy to tell the old ones, for the old ones it's not easy to tell the young ones." (Counsellor \#4)

How, then, are traders vulnerable to HIV and AIDS? Traders are feeling an increased burden of care, financial stresses, emotional trauma, and distressing fears for the future; HIV/ AIDS is augmenting pre-existing stresses in their lives. However, different traders are vulnerable in different ways, with trends emerging along age and gender axes. There is a clear gender dimension to the burden of care, with impacts falling disproportionately on older women, while young people share an acute fear of infection.

\subsection{What underlies traders' differentiated vulnerabilities?}

I'm part of the committee. On the committee I think everybody's satisfied... but not everybody can be satisfied in this world. (Cigarette seller)

Traders are clearly not all vulnerable to the epidemic to the same extent or in the same way, and the discussion above portrays several age and gender distinctions that emerge at this micro scale. An even closer examination of age and gender relations (see Table 8 for a summary, Appendix $J$ for a full analysis) reveals that many social and 
economic factors underlie traders' differentiated vulnerabilities, with three of particular importance: (1) division of family responsibilities, (2) distribution of resources, assets and capital, and (3) level of livelihood security and political voice. Women reported the greatest family responsibilities and the least access to resources. Meanwhile, young traders reported the least security over their trading spaces and the most exclusion from trading committees. In light of the contrasting experiences of the epidemic described above, this section examines these underlying conditions in more detail.

There are striking contrasts in family responsibilities between the four groups of participants. Young men are responsible for themselves, while young women are responsible for their children, parents and siblings. Older men and younger women have similar financial responsibilities, but young women are simultaneously responsible for childcare. Older women have the greatest level of family responsibility, supporting children, partners, grandchildren, extended family, and community members. Women bear a double burden - financial and care - and this starts younger than men and increases with age. The differentiated effects of HIV/ AIDS on traders reflect this double burden.

According to Richard Dobson, one of the lead planners of the Warwick Junction Urban Renewal Project, "you need to be careful with assumptions around marginalization. For some, having access to space to trade has really changed their lives... People selling things like cigarettes actually make a lot of money; this is lucrative". He explained that "the key is to look at access to capital. Men are in the higher income and more secure trades because they have greater access to loans through private 
and informal networks" (Dobson 2004, a). Dobson's words depict the second condition underlying uneven vulnerabilities: gendered access to resources.

Indeed, men in this study reported more access to capital and education than did women. None of the women felt that their incomes are adequate to meet their needs, while half of the men expressed that their businesses are lucrative enough to accumulate some savings. Uneven access to capital, education and income, together with the disproportionate family responsibilities, result in women having fewer opportunities to move beyond survivalist trading.

Together, uneven family responsibilities and resource access may lead to differing levels of social security, and here three examples emerge:

- Men and women described differences in their insurance and savings plans, which influence how they can respond to health stresses and longer-term AIDS impacts. Men have more formal savings and insurance (i.e., from banks or insurance companies), while women are involved in various co-operative savings and informal insurance schemes $\left(\right.$ stokvels $^{24}$ ), becoming more common as they age. It is likely that added responsibility has led women to enter into informal social security schemes.

- Women explained that their social security is linked to access to their family homes. Three older women whose houses were burnt down in the political violence of the 1980s and 1990s spoke emotionally about their subsequent loss of belonging and security. Four of the six older women discussed with great urgency their desires to build or extend their houses before they die, as security for their families. The family house is an asset and a symbol of security for them; those who have lost theirs in the faction fighting feel most vulnerable. This gendered urgency around the family home may also be associated with women's double burden of responsibility.

\footnotetext{
${ }^{24}$ Traders describe stokvels as co-operative savings whereby a group of people make financial contributions and each individual can claim their share either at a specific time or when a crisis arises. In some plans, members put money together and use the savings towards shared food, school fees or school uniforms. Traders also invest in informal funeral coverage.
} 
- The stories of two young women who have lost their parents illustrate how uneven entitlements and access underlie their vulnerabilities. In both cases, older brothers now control their family homes. The pinafore seamstress, who lives with her partner and child in the city, expressed: "I have to save money because if I ever get sick I will need to go home, but I will need money to see a doctor, to get help. Even though I am not welcome, I would have to go back there because I have no other choice." The young woman who sells shoes resents handing her earnings over to her brother and not having access to any family savings. The agegender vulnerabilities of these women are related to inheritance practices where property is passed down to the eldest male sibling.

These three examples indicate an overall trend whereby many women are living with greater family responsibilities and less access to resources than their male counterparts; they have more claims on their time and fewer safety nets. These distinct roles, rights and responsibilities bear on their vulnerabilities to the epidemic.

The third underlying factor-livelihood insecurity - is clearly a pervasive stress among traders and, as discussed in the last chapter, one that is made worse by growing unemployment and informalization. In Warwick Junction, livelihood security is related to the security of trading spaces and political voice within trading committees. These too have distinct age and gender dimensions.

Younger people have less access to secure spaces than do older traders. All of the young traders in this study work for someone else or as itinerants, none have permits, and all are subject to various forms of control. The 'trolley pushers', for example, have obtained their illegal spaces through personal networks; their trolleys are owned and 
governed by informal managers. The woman cooking curries is 'fronting, ${ }^{25}$ for a trader

inside the market. She told how the Forum and police harass curb-side cookers, and how

committees impose price controls on her. The woman selling pinafores works in her

boyfriend's space and would like to obtain her own permit in order to gain independence

from him. By contrast, all of the older traders work for themselves and most have

permits.

\section{Table 8: Factors Underlying Differentiated Vulnerabilities: Gender-Age Trends}

\begin{tabular}{|l|l|}
\hline $\begin{array}{l}\text { Underlying health } \\
\text { conditions }\end{array}$ & Gender-age trends within core sample \\
\hline $\begin{array}{l}\text { Family and social } \\
\text { responsibilities }\end{array}$ & $\begin{array}{l}\text { Women experience a double burden of responsibility: financial and care. } \\
\text { Family responsibility starts younger for women and increases with age. }\end{array}$ \\
\hline $\begin{array}{l}\text { Social security and } \\
\text { support }\end{array}$ & $\begin{array}{l}\text { Loss of parents \& strained relations with older male siblings over access to family } \\
\text { home/ resources may increase vulnerability for younger women. } \\
\text { For older women, house as asset \& symbol; building house as security for family. } \\
\text { Older men have more formal insurance and savings; women have informal } \\
\text { schemes. }\end{array}$ \\
\hline $\begin{array}{l}\text { Social \& economic } \\
\text { opportunities }\end{array}$ & $\begin{array}{l}\text { Young men have more access to family assets than young women. } \\
\text { Men have more access to capital and education. } \\
\text { Older men accumulating most profits from trading. } \\
\text { Lack of access to capital, with greater family responsibilities, suggests that women } \\
\text { have fewer chances for advancement than men. }\end{array}$ \\
\hline $\begin{array}{l}\text { Livelihood security } \\
\text { Access to services } \\
\& \text { information }\end{array}$ & $\begin{array}{l}\text { Young people \& women in least secure trades. } \\
\text { needs lack adequate representation. }\end{array}$ \\
\hline Health \& illness & $\begin{array}{l}\text { Women discuss barriers to accessing services and information; men do not. } \\
\text { Older women carry a disproportionate burden of disease. } \\
\text { Women exposed to more workplace health threats. } \\
\text { Women report missing more work due to illness (or illness of a child). }\end{array}$ \\
\hline
\end{tabular}

${ }^{25}$ 'Fronting' refers to selling outside for traders operating within the market. This is considered to be a management nuisance because 'fronters' do not adhere to space demarcations and create competition for those abiding by such structures (Mkhize 2004, a). 
Patrick Mcnube, the Area Manager for the Warwick Junction Project, explains that not all traders are represented by the ITMB, which is the main negotiating body for traders and acts an umbrella for a number of smaller street committees:

The ITMB only represents actual traders. Barrow boys, cardboard collectors, and the likes are on their own. The barrow boys have their own supervisors elected in the rural areas; these are ethnic, traditional leaders. If they get complaints back home, then the barrow boys can be suspended. Trolley pushers are on their own too, because they are seen as a threat to people trading at tables. There's animosity, so they don't belong to the ITMB. They are mostly fronting. The hairdressers too are mostly foreigners, some legal and some illegal, and they're not represented. (Mcnube 2004)

Youth are over-represented in these peripheral trades. Many feel they cannot report grievances because they are trading illegally. Leaving their spaces means risking their livelihoods, and they have few opportunities to voice their concerns. Their exclusion is likely augmenting the 'young-old' divide around HIV/ AIDS, as older traders in leadership positions are not communicating with younger traders about their shared experiences and anxieties. In addition, the lack of political voice and exclusion even from informal work may be contributing to young people's feelings of hopelessness.

Furthermore, representation of women in the ITMB is "starting to adjust, but it is still male-dominated" (Dobson 2004, a). Women's unequal voice in negotiations could partially explain the gender insensitivity of many trading bylaws (Lee 2004, a) and their difficulties accessing information. Under-representation may also contribute to women's uneven exposure to workplace health hazards, such as pesticides, unsafe cooking equipment and animal refuse; many do not have the means or the time to organize and lobby for better conditions. This is made worse by the closure of SEWU. 
What underlies traders' differentiated vulnerabilities? Traders' vulnerabilities to the epidemic depict broader age and gender divisions in their lives, particularly differences in family responsibilities, access to resources and livelihood security. This supports the finding that pre-existing structures shape the ways in which traders are experiencing and will respond to HIV and AIDS. Table 9 summarizes how vulnerabilities and underlying conditions are differentiated by age and gender.

Table 9: Summary of Differentiated Vulnerabilities and Underlying Conditions

\begin{tabular}{|c|c|}
\hline Uneven Effects of HIV/ AIDS & Uneven Underlying Conditions \\
\hline $\begin{array}{l}\text { - Older women are bearing a disproportionate } \\
\text { burden of family impacts: care, financial, } \\
\text { emotional } \\
\text { - Younger traders share pervasive fears and } \\
\text { sense of inevitability, differentiated by gender } \\
\text { - Young women feel powerless to prevent } \\
\text { infection and are worried about young children, } \\
\text { social stigma } \\
\text { - Young men afraid of stigma, lack of social } \\
\text { support, economic insecurity }\end{array}$ & $\begin{array}{l}\text { Women bear a double burden of family } \\
\text { responsibility; it starts younger than men and } \\
\text { increases with age. } \\
\text { Women have less access to resources and } \\
\text { assets than do men, and are less socially } \\
\text { secure } \\
\text { Young people are excluded from formal } \\
\text { employment and the market } \\
\text { Women and younger traders are lacking } \\
\text { representation and voice in Warwick } \\
\text { Junction }\end{array}$ \\
\hline
\end{tabular}

\subsection{Building a Framework of Micro Health Vulnerabilities}

Building on traders' perceptions of health as conditioned by person-environment interactions, this section compiles the data presented throughout this chapter-who, why, how and what-to develop a framework of micro health vulnerabilities (see Figure 4). The data in this chapter indicate that at the micro level, health is about how individual traders interact with their living and workplace environments and with their local political economy and social contexts; this supports notions of multidimensional "health 
determinants" (WHO 2003) and "global ecological" models of health (Forget \& Lebel 2001). While the who, why, how and what of traders' vulnerabilities have so far been analyzed separately, Figure 4 groups the key health conditions that have emerged from the fieldwork and provides a guide to examine how the interactions among these factors can heighten traders' vulnerabilities. Interviews with traders also showed that the relative importance of each component of this framework to their health varies from person to person, and over time.

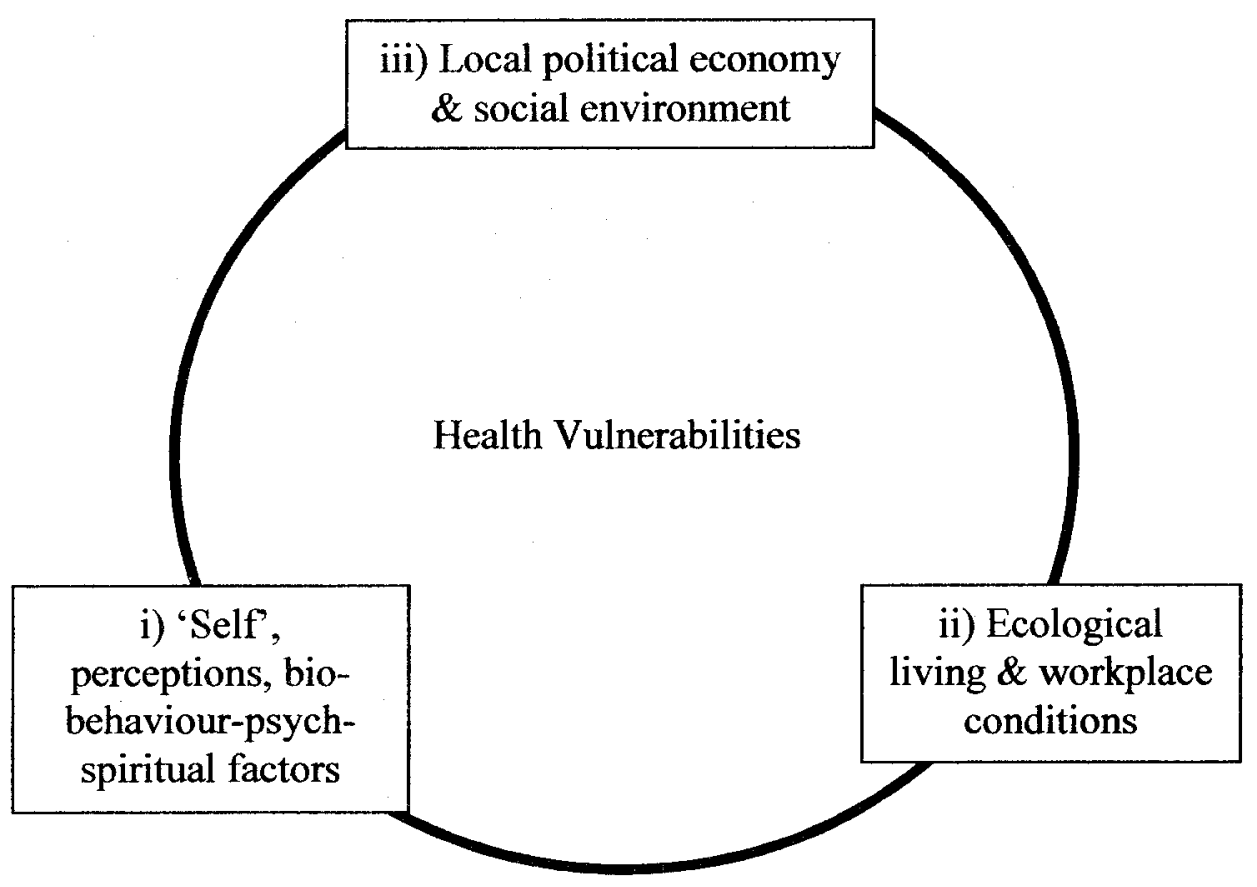

Figure 4: Conceptualizing Micro Health Vulnerabilities for Warwick Junction Traders 
Each of the three components represented in Figure 4 is complex in its own right. The individual biological, behavioural, spiritual and psychological 'self' (Figure 4i) involves the cumulative picture of traders' individual medical histories, immune system functioning (nutritional status, untreated illnesses), gender, age, sexual behaviours, substance use, stress levels, perceptions, sense of belonging, spiritual wellbeing and selfesteem. Equally complex and dynamic are their ecological workplace and living conditions (Figure 4ii), such as water quality, housing quality, workplace safety (open fires, stray bullets, handling of pesticides), shelter, sanitation, waste disposal and pest control. Finally, the local political economy and social context (Figure 4iii) includes livelihood security, income, social security, education level, social support, mobility, family responsibilities, security, gender norms, stigma, and access to services, information, and resources, among others.

The story of the older woman selling seeds illustrates how, in late 2004, many conditions came together to impact her health, and thus how the three components of Figure 4 are interactive and mutually reinforcing. This woman sleeps on the streets of Warwick Junction to save on housing and transportation, so that she can send more money home to support her extended family. From Figure 4, it is this woman's social and economic conditions, and in particular her family responsibility, that necessitate her sleeping on the streets (i.e., Figure 4iii). This arrangement leaves her exposed to numerous environmental workplace and living hazards (Figure 4ii) resulting from inadequate municipal services (e.g., she voiced concerns over insufficient waste disposal, pest infestations, lack of water, unsanitary or inaccessible toilets, and lack of shelter). She 
is also exposed to dust, exhaust, sun, heat and rain, and she handles pesticides with unprotected skin (Figure 4ii). One of many health consequences of sleeping in Warwick Junction is that she lacks a place to cook her nightly meals and so depends on dangerous, makeshift fires. These socio-economic and ecological conditions (i.e., Figure 4iii \& Figure 4ii respectively) recently manifested in one serious impact on her health: she showed a burn scar that runs the entire length of her arm (Figure 4i). She had to take three months off work because of this injury, which further stressed her livelihood and her family's wellbeing (Figure 4iii).

In complex and overlapping ways, each of the categories in Figure 4, their interactions, and their cumulative effects are associated with vulnerability to infection, illness and impacts. An exhaustive examination of these linkages is beyond the scope of this thesis, but certain key connections are illustrated below.

Biological, behavioural, emotional, and spiritual factors (Figure 4i) impact traders' vulnerabilities to the epidemic in a number of ways. In terms of vulnerability to infection, all traders in the sample are sexually active, but most do not use condoms consistently. Level of immune functioning influences the rate at which HIV progresses to AIDS; if traders are or become HIV-positive, their reported untreated illnesses may accelerate the onset of symptoms and hinder their recovery from secondary illnesses. Many also live with high personal stress, which could make them less able to cope with their own or their family members' illnesses. 
Ecological conditions (Figure 4ii) interact with biological and behavioural determinants (Figure 4i). Poor living and working conditions-low water quality, lack of sanitation, poor waste disposal and inadequate pest control-weaken immune functioning (even without HIV present) and may accelerate illness among those living with HIV. In addition, intestinal infections and skin lesions are common among people living with HIV, and thus if traders are (or become) infected, then insufficient water and sanitation may impede their responses, increase complications, and make living with the disease even more painful and degrading.

A number of social and economic conditions (Figure 4iii) underpin vulnerability to infection. For instance, gender relations often prevent women from using condoms, and many traders suggested that economic insecurity is driving risky sexual behaviours: "It affects traders because they are so poor. I can call a woman in here any time and she needs money so badly... They don't have sex for money, but they will go with anyone who has a place to stay or can give them things. Anyone who has even a little bit of money" (Hairdresser). Lack of access to health services causes traders to go untreated for illnesses, including sexually transmitted infections, which also increases their likelihood of contracting HIV (Whiteside \& Sunter 2000).

Furthermore, social and economic conditions (Figure 4iii) hinder traders' capacities to respond to the epidemic, and thus increase their vulnerabilities to illness and impacts. Traders do not have access to ARVs and most cannot afford treatment for secondary infections; this means an accelerated progression from HIV to AIDS. The social stigma, difficulties taking time off work, and overall livelihood insecurity stress 
those caring for sick family members. Meanwhile, most traders do not have savings from which to draw if they or their family members fall ill. Chronic poverty makes it hard for them to deal with the shocks of losing an income-earning household member, funeral expenses and taking in orphans. Given the impoverishing nature of AIDS, this cycle has the potential to become a downward spiral of poverty driving transmission of HIV and the epidemic deepening poverty.

\subsection{Conclusion}

At the micro level, traders' vulnerabilities to the epidemic result from the impoverishing nature of AIDS, mixed messages, stigma, livelihood insecurity, mobility, and lack of access to services, information and resources. Collectively, these findings indicate that AIDS is not merely a medical issue and it cannot be examined in isolation. Traders' health depends on their individual interactions with their physical, social and political environments. Indeed, this chapter demonstrates that their vulnerabilities to HIV and AIDS are interwoven with social relations, livelihoods, ecological conditions, emotional support, and the linkages between these factors.

Traders' vulnerabilities are furthermore differentiated by age and gender, influenced by uneven levels of family responsibility, access to resources and livelihood security. Young traders fear infection: for young women it is fear for their children and inability to negotiate safe sex that dominates, while for young men the lack of livelihood options and social support colour their view of the future and sway their behaviours. Older men are affected as members of their communities die, but this chapter has revealed that older women are bearing the responsibility. The epidemic is augmenting 
pre-existing vulnerabilities in their lives; they are caring for the sick and orphaned, and many are the primary income earners in their families. Chapter 5 picks up on this differentiation and looks into core of the uneven struggle. 


\section{Chapter 5}

\section{At the Core of the Uneven Struggle: Power, Structure and Agency}

Inside the Warwick Junction Project Office, a colourfully refurbished warehouse in the heart of Warwick Junction, laminated news clippings depicting the victories of the renewal project line the walls and 'before and after' photographs decorate the space with a sense of pride. Richard Dobson, one of the leaders of the Warwick Project, is someone who has fought long and hard for those struggling to secure livelihoods in this postApartheid inner city. On one occasion, I asked him who has benefited most from the renewal and who the least:

There is a gendered division of labour... This is a macro question. Women are the back stop providers. They take care of the needs of the family; they have to bring in money. Women are survivalists. It's hard to know, but it may be that they do the worst jobs out of desperation, or that they see the gaps where men don't want to do the work and they dig out their own niches. (Dobson 2004, a)

Emmanuel Dlamini, president of the ITMB and another prominent character in Warwick Junction, frequents the Office as well. On another occasion, I asked him the same question: who has benefited most from the renewal and who the least?

There's a big problem with our young people. They feel like they don't have access to higher education. They drop out of school. There's a loss of hope, and so they are turning to street trading. But this is causing conflict with the elders who are established and who control the space. The lack of space and opportunities for these young people makes them transient. They become the trolley pushers (Dlamini, E. 2004).

Both men highlight the dynamics between Warwick Junction and the broader political economy; their reflections reinforce the age and gender divisions revealed in Chapter 4 and offer further insights into the uneven struggles faced by traders. 
Constraints resulting from differing family responsibilities and livelihood opportunities, as well as feelings of powerlessness, intermingle with politically charged structures in Warwick Junction to marginalize many traders, especially women and youth. Yet, amidst these structures, traders continue to act.

This chapter builds from the differentiated vulnerabilities discussed in the last chapter and shows how power lies at the core of traders' uneven struggles ${ }^{26}$. It demonstrates that traders' vulnerabilities to HIV and AIDS are a series of negotiations between structure and agency - negotiations governed by psychosocial and politicaleconomic dimensions of power operating at multiple scales.

\subsection{Dimensions of Power}

We don't have power. There's nothing we can do. We need an old age pension, or maybe a loaf of bread and some beans. (Chicken seller)

Relations of power figure prominently in the conditions that shape traders' health and generate their vulnerabilities to HIV and AIDS. Nowhere is this more apparent than in the emotional effects of the epidemic on women. As seen in Chapter 4, young women feel very little power to prevent becoming infected; most feel unable to negotiate condom use and thus they portray the epidemic as uncontrollable. Older women expressed anxiety over the inter-generational silence and their inabilities to protect their children.

Young men's vulnerabilities are equally linked with power, although the manifestations are more subtle. They claimed to have more control over condom use and

\footnotetext{
${ }^{26}$ This thesis is informed by a Foucaultian conceptualization of power as operating continuously in all interactions, and as always met with resistance; power is thus dynamic and constituted as it is enacted or exerted (Foucault 1980).
} 
many stressed that they have multiple sexual partners; yet, despite this seeming power, they expressed an equal sense of foreboding and inevitability. They reported engaging in risky behaviours as compensation for their economic insecurities and feelings of alienation $^{27}$.

Traders' vulnerabilities are thus interwoven with power relations, which are both psychosocial and political-economic in nature. The psychosocial dimension involves traders' personal sense of control over their life conditions and feelings of efficacy; this includes their expressions of inevitability, hopelessness and uncontrollability towards the epidemic and the future. The political-economic dimension involves command over resources, enfranchisement, entitlements, and level of political, social and economic opportunities. This speaks to the three factors underlying traders' differentiated vulnerabilities, as noted in Chapter 4: division of family responsibilities, access to resources, and livelihood security/ political representation.

Furthermore, for many traders, psychosocial forms of power are embedded within political-economic power. The chicken seller's comment above- that power is about having a pension and food-illustrates the connections between these two dimensions; until her basic needs are met, there is very little she can do to affect change. Financial insecurity fuels her feelings of powerlessness. Dlamini's comment at the opening of this

\footnotetext{
${ }^{27}$ Campbell (2004) suggests that constructions of masculinity which give men unequal social power and frame male multiple partnering as a social norm are largely "coping mechanisms" on the part of men faced with inescapable dangers. Feeling unable to provide for their families or pay lobola (bride price) undermines masculinity, and a general lack of support and sense of hopelessness is associated with risktaking behaviour and risky sexual activity (Campbell 2004).
} 
chapter demonstrates this as well: lack of employment opportunities and exclusion from market structures drive young traders' feelings of hopelessness.

Traders' uneven vulnerabilities to HIV and AIDS are thus intertwined with the political economy, and particularly with relations of power that operate through class, gender, age and race structures ${ }^{28}$. Traders internalize these structural vulnerabilities into their feelings of personal control and constructions of intimacy. This supports the assertion in the last chapter that biomedical and behavioural interventions, which target individual actions (e.g., 'ABC'), are at best partial solutions. Such approaches overlook the structural drivers of uneven HIV infection and AIDS impacts.

\subsection{Power and Structure}

"How can women secure an income when they so often have to hand their money over to men? There's a continual drain." (Dobson 2004, a)

Power relations are operating through structures at many scales to shape traders' vulnerabilities. Most evidently, these relations operate at the macro level, within Warwick Junction and in traders' households. This section examines how power is exerted and experienced at each of these scales, and how dynamics at the three levels are mutually reinforcing.

At the macro level, power is exerted through access to social, economic and political opportunities. At this scale, traders, as a group, have very little control over the

\footnotetext{
28 At the macro-level we saw that traders are constrained by class, race and gender structures laid down by Apartheid, while at the micro-level, race and class are more homogeneous among traders, and thus age and gender stand out as key structures. Given South Africa's colonial history, it is impossible to fully disentangle race, class, gender and sexuality (McClintock 1995).
} 
societal processes that impact their lives, such as rising unemployment, globalization, urbanization, and the ARV roll-out. Their social and economic opportunities are constrained by historical exclusion from education and employment, as discussed in Chapter 3. They feel shut out of the workforce and do not have adequate social protection. Despite many positive changes in their society (e.g., the granting of political rights, social transfers and basic services), many are disillusioned with the new democracy and some feel that poverty is worsening. Dlamini's insight into why young people are "turning to street trading" speaks to this dispossession and its effects on health. Rising unemployment and lack of access to education draw young people into precarious work, which impacts their physical health, generates feelings of hopelessness, perpetuates risk-taking, and fuels disillusionment.

Within Warwick Junction, power is exerted through trading space security and representation in negotiating bodies, as discussed in Chapter 4. At this smaller scale, the differentiation within the sample of traders becomes more pronounced. Older people clearly control the allocation of space in the market, while young traders have little access and minimal institutional protection. Power dynamics operating in the market govern the security of women and young traders to leave their spaces and their freedom from harassment. This has consequences for accessing health care, taking time off for illness, and caring for family members.

At the household level, power manifests as control over resources and decisionmaking. Although women in this study assume disproportionate family and financial responsibilities, men are reported to control family resources and have greater access to 
family assets in almost every case. This "continual drain," as Dobson refers to it, is made worse by women's burden of care. Household dynamics implicate livelihood and health: women take more time away from work due to illness and care-taking responsibilities.

The power dynamics operating at these three scales interact and serve to entrench traders' structural vulnerabilities. For example, household structures-with women as the "back stop providers" - shape or reinforce the political economy of Warwick Junction and the division of trades; women do the worst jobs at least partially because immense family responsibility leaves them no other choice. Likewise, household dynamics are shaped by macro structures; as discussed in Chapter 3, household gender relations are constructed within a historical legacy of family fragmentation and gender inequality. Conditions where men lived away from home and women were dependent on them for remittances have had lasting impacts on gender roles, responsibilities and control over resources (Campbell 2003).

Thus, power operates at many levels to shape the conditions that govern traders' health, livelihoods and security. These conditions include their social responsibilities and their access to resources, trading spaces, health care, education and social support. Traders' highly and unevenly constrained environments make them differentially vulnerable to HIV and AIDS. 


\subsection{Power and Human Agency}

A group of us got together to deal with the deaths. If somebody loses a child, we contribute 300 Rand to the family. If it's a main family member, we contribute 700 Rand. (Mat seller)

Even within highly constrained environments, however, traders act; they are neither passive nor powerless. Inasmuch as their stories provide insights into the structural causes of vulnerability, they also reflect agency, strength and resilience. Traders are social actors, but their actions are limited by uneven levels of political, economic, and psychosocial power, as outlined above.

The woman selling seeds explained: "women sleep together in big numbers, there are too many of us to count. We do not let men come near; we beat up any man who comes near." The woman selling mats revealed: "we put money aside every month in our small group, and this goes towards food, school fees, school uniforms." Upon being forcibly removed from his itinerant space, the man selling candy bars on the Berea Bridge asserted: "I'll just need to locate another space; I'll just put a box there and trade."

Traders respond to the conditions that threaten their health. The acts of migrating to Durban and beginning to trade, for most traders, were reactions to increasing financial stress in their households. Increased household fluidity is a response to political violence, unemployment and rising adult mortality. While traders' precarious livelihoods and stretched incomes pose significant health threats, many enter informal social security schemes. Young people who are shut out of formal employment and permitted trading spaces are eking out livelihoods as trolley pushers. Disillusionment is met with alcohol 
abuse, "recklessness" and disengagement from political processes. The formation of Traders Against Crime was a community response to crime in the area. SEWU was formed to counter the under-representation of women and lack of transparency of the ITMB. These responses may reduce or perpetuate vulnerabilities; in either case, traders are social actors--they act individually and collectively ${ }^{29}$.

But they can only act within their means. Being the "back stop providers" means that incomes must go to supporting extended household members. Not having access to resources can exacerbate the stress of personal or family illness. Lack of representation can limit negotiation for improved conditions and rights. The strength it takes for these men and women to survive and support their families should not be underestimated. However, just as power relations influence traders' health conditions, they also undermine their response possibilities.

\subsection{Conclusion}

At the core of traders' uneven struggles is a web of political, economic and psychosocial power operating within traders' households, in Warwick Junction, and in the society at large. While Chapter 4 demonstrated that many traders view the epidemic as unstoppable and uncontrollable, this chapter illustrates how these feelings are embedded in broader issues of social, historical and economic dispossession. Indeed, traders' vulnerabilities are deeply rooted in class, race, gender and age structures. These

\footnotetext{
${ }^{29}$ Responses are also taking place at the institutional level: the renewal was a response to urban decay; social transfers are a response to poverty and inequality; the ARV roll-out is a response to AIDS and civil society pressure. Institutional responses are important because they frame the response options available to traders. The focus of this discussion is on individual and community level responses, but the key role of institutional agency will be addressed in Chapter 6 .
} 
structures are internalized as psychological attributes and manifest in perceptions of personal empowerment and constructions of gender identities.

Dobson's quandary at the beginning of this chapter-of whether women "do the worst jobs out of desperation" or whether "they dig out their own niches" -captures the age-old 'structure-agency' debate that is clearly pivotal to understanding vulnerability. This chapter has grappled with this debate, and evidence suggests that the answer is both: traders' vulnerabilities are negotiated as an interaction between social and economic structures and human agency. They demonstrate remarkable strength and resilience, and yet they act within highly constrained environments. 


\section{Chapter 6}

\section{Looking Forward:}

\section{A Reorientation of Health Vulnerability Concepts}

Rain in Warwick Junction means clogged drains: gutters running with filmy water, rotting produce, waves of muck dredged up with each passing car. These are relatively quiet moments in the market. Nearing the end of my time in Durban, I sat sharing an umbrella in a third interview with the older woman who sells seeds and sleeps in the market. This time I asked her how "the story of Warwick Junction" has affected her health:

I have been right here in Warwick Junction for twenty years. Things were difficult back then. The bad days were the 1980's. I remember once the police took my child and I had to run after them to get her back. They stole our food and would throw it away, and they'd kick us and beat us. We were running all the time ...

The police stopped, but then there was a lot of crime in the 1990's. It was very bad in those days: stealing, stabbings, mugging, people beaten up right in front of us. Especially white people and Indian people were victims. People had their chains ripped right off of their necks.

... We put a stop to it because criminals were chasing away our good customers. We elected a forum. We made examples of the criminals we caught. Now there is no crime in the area... you just have to scream and people will come from all over ... Recently there was a white man chasing a thief. The thief was cut up in pieces, demolished. He was handed over to the police in pieces...

The development has improved my health and selling to a certain extent. I am more secure. I don't just set up and then have to run. I have fewer palpitations; there's less harassment and it's less stressful. I still need a proper place to do washing, and I am tired. But I am much more together mentally now. Back then I was not normal; I was falling apart from the harassment.

This is a common story, and yet it is revealing. It depicts a strong woman who has remained in a precarious socio-economic and physical space for most of her adult life. It 
demonstrates that the space is dynamic - changing as a result of different policing approaches and trader initiatives - and that her vulnerability is intertwined with its changing conditions. It shows that she views her health not in terms of illnesses, but in terms of emotional wellbeing, freedom from harassment, and overall security. It also illustrates how this woman joined with others to challenge the crime that threatened her livelihood.

We know from previous chapters that while better working conditions have reportedly improved this woman's health, a new stress has recently entered her life: AIDS. She is vulnerable because of her immense family responsibilities, and she is just beginning to feel the effects.

Her story ties together four central themes from this research: (1) traders' vulnerabilities are embedded in dynamic social systems; (2) different stresses arise as traders interact with their changing environments at different times and in different contexts; (3) their wellbeing depends on their power to control and respond to these changing stresses; and (4) interventions can reduce their vulnerabilities. This chapter revisits and expands upon these themes and, like this woman's story, demonstrates how they come together and interact. Based on the information presented in Chapters 3 through 5, it builds a framework of health vulnerabilities for Warwick Junction traders. It then illustrates how these themes could extend health vulnerability concepts more broadly by drawing on the conceptual foundations introduced in Chapter 2 .

Through this process, this chapter addresses the overarching rationale for this thesis: empirical and conceptual limitations in AIDS research restrict our understanding 
of vulnerability to HIV/ AIDS and thus impede our capacity to intervene in the processes that will shape the future impacts of the epidemic.

\subsection{Building a Framework of Comprehensive Health Vulnerabilities for Warwick Junction Traders}

Chapters 3 through 5 analyzed, from a variety of angles, how traders are vulnerable to HIV and AIDS, what causes their vulnerabilities and why. Chapter 3 portrayed traders' vulnerabilities as enmeshed in historical structures and four processes of macro-level change: the transitioning political economy, globalization, increased population mobility, and the new HIV/ AIDS epidemic (see Figure 3). Chapter 4 depicted traders' vulnerabilities as resulting from their individual interactions with differing socioeconomic and ecological conditions (see Figure 4). While the macro and micro contexts of traders' vulnerabilities were examined separately in Chapters 3 and 4, this section explores the linkages between macro processes and micro conditions. What emerges is that response capacity and underlying power relations-as articulated in Chapter 5mediate the impacts of macro and micro stressors.

The framework developed in this section is represented by three concentric rings (see Figure 5). The complexities of each ring have been explored already: the outer ring represents the changing macro context (Chapter 3), the inner ring represents traders' micro health conditions (Chapter 4), and the middle ring represents uneven power relations and response options (Chapter 5). Figure 5 illustrates the dynamics between macro changes, micro vulnerabilities and human agency: the connections between the three rings. This section links macro and micro processes (i.e., outer and inner rings), and 
then demonstrates how institutional, community and individual responses can mitigate the impacts of the epidemic (i.e., interactions with the middle ring).

\subsubsection{Linking Macro Processes and Micro Vulnerabilities: Outer-Inner Ring Interactions}

While Chapter 3 depicted macro changes as generating common conditions (most often stresses) for traders, a closer examination of the micro context indicated that the same societal processes could be experienced differently. Traders' experiences are conditioned by the interactions between macro changes and their uneven micro circumstances, and the differentiated vulnerabilities discussed in Chapter 4 highlight these links. Two examples are illustrative $\mathrm{e}^{30}$.

First, young men's vulnerabilities are shaped by their lack of livelihood options, which is tied to rising unemployment levels and minimal education and training opportunities. These circumstances are influenced by exclusion from education and employment and by macro-economic 'reform' and globalization (Figure 5a \& 5b). At the micro level, these processes are generating feelings of hopelessness, with implications for constructions of masculinity and risk-taking behaviours (Figure 5i). Young men also report inadequate social support and a sense of anomie in the city (Figure 5 iii \& 5i), which are linked to their displacement from home and to increased mobility and urbanization more broadly (Figure 5c). HIV/ AIDS has entered into this environment, and the hopelessness, risk-taking and alienation reported by young male traders increases

\footnotetext{
${ }^{30}$ These two examples were selected because they clearly illustrate how the same macro processes interact with contrasting micro conditions to result in differentiated vulnerabilities. Appendix $\mathrm{K}$ provides further examples of macro-micro linkages, taking each of the four outer-ring processes as entry points.
} 
their likelihood of infection; their vulnerabilities are a result of the converging macro and micro processes that were in motion prior to the epidemic.

Second, older women are affected by a lack of rural livelihood options. They are feeling the effects of rising unemployment in their families, where they are often the only income earners. They are also stressed by dislocation from their families and the difficulties of caring for their children in the rural areas from the city. They too are negotiating the macro stresses of rising unemployment and urban migration (Figure 5, outer ring). Moreover, these stresses are being made worse by AIDS, as they assume responsibility for orphans and sick family members. Their vulnerabilities have resulted from a combination of these macro processes and their distinct micro conditions, particularly their disproportionate family responsibilities (Figure 5iii). This manifests not as an increased likelihood of infection, but as an increased burden of care.

Linking the macro and micro contexts of traders' vulnerabilities in this way demonstrates that traders' vulnerabilities are intertwined with underlying social systems, which are influenced by interacting macro and micro processes. In addition, HIV/ AIDS, a new societal stressor in South Africa, is experienced differently by different traders. The differentiation of traders' vulnerabilities further suggests that this framework is not a one-size-fits-all model; rather, the 'weights' attributed to any particular ring, or component within a ring in Figure 5, varies from trader to trader, and over time. 


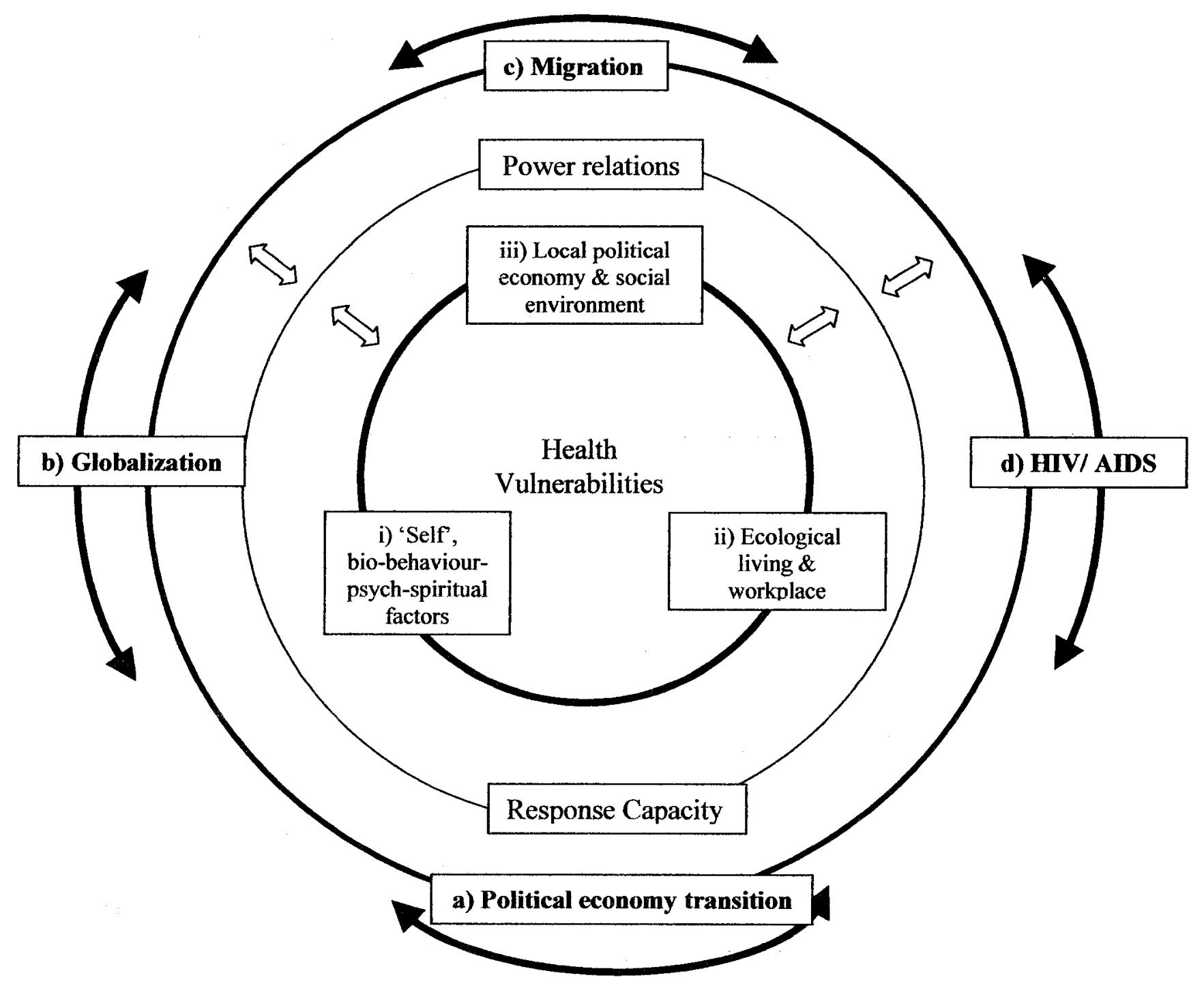

Figure 5: Conceptualizing Comprehensive Health Vulnerabilities for Warwick Junction Traders 


\subsubsection{The Centrality of Human Agency: Middle-Ring Interactions}

Chapter 5 revealed that traders are not passive in their experiences of either macro processes or micro health conditions. As represented by the middle ring of Figure 5, their uneven vulnerabilities are not driven merely by external events, but also by their unequal capacities to respond to existing pressures and new shocks. The interactions between the three rings highlight how human agency mediates the outcomes of macro and micro processes.

The last chapter showed that traders respond to the stresses in their lives. Many women have joined stokvels, for instance, which provide them with resources if and when a family member dies. These actions (middle ring) could soften the shocks they bear from the epidemic (outer ring), including the cost of funerals and taking in orphans.

Discerning how traders respond, and what conditions affect their behaviours, is therefore critical to understanding their vulnerabilities. This implies an examination of how macro and micro processes combine to influence traders' actions. The following two examples illustrate these relationships (see Appendix L for additional examples):

- At the micro level, traders express a lack of clear truth about the epidemic (Figure $5 i)$. This is partially due to inadequate and misguided macro-level leadership (Figure 5a \& 5d). These macro and micro factors come together to impact traders' responses (middle ring): some claim not to use condoms because they are sceptical about the existence or prevention of AIDS.

- Older women explain that until their basic needs and the needs of their families are met (Figure 5i-iii), they feel no power to affect any short- or longer-term change. This survivalist condition, which is made worse by rising unemployment (Figure 5a \& 5b), feeds back upon their actions (middle ring). It hinders them from taking time off work to access health care, information, training and other services. 
Macro and micro processes clearly influence traders' response possibilities, and as such the outer and inner rings of Figure 5 come together to shape the middle ring.

These two examples also reveal that traders' health vulnerabilities are affected by institutional actions, which mediate their response options. In the first case, national (institutional) responses to the epidemic - the mixed messages, the lack of leadership, the slow public-sector ARV roll-out—are contributing to local discourses of scepticism, shame and inevitability. These discourses partially impede traders from testing for HIV, accessing social support, acquiring ARV treatments, and in some cases, adopting preventive practices. In the second case, women are struggling to meet their basic needs and this limits their power. Yet, newly instituted social transfers (an institutional response) are helping to meet the basic needs of some women and thus expanding their response capacities.

Traders' actions are at the moment highly restricted, as discussed in Chapter 5. But this research has also shown that these constraints are changing. Traders' actions are affected by their rapidly changing environments; the middle ring, like outer and inner rings, is dynamic. Indeed, the transitioning political economy means women and youth are now migrating alongside men: they are no longer confined to impoverished Bantustans. Gender and age dynamics are changing in the market as a result, and with women and youth in income generating positions (even positions as tenuous as informal street trading), household dynamics may be transforming as well. Power relations are not static; they are connected to and based in societal change. 
Introducing human agency (the middle ring) into this framework highlights that the power relations driving traders' uneven vulnerabilities operate through changing societal structures. In addition, traders' responses, which are conditioned by the actions of institutions, could mediate the outcomes they experience from the epidemic.

Overall, Figure 5 delineates traders' vulnerabilities to HIV and AIDS as caused by a convergence of factors that, in different ways, impede their wellbeing: historical structures and rapid societal transition (the outer ring), local conditions and individual circumstances (the inner ring), and dynamic power relations and constrained response options (the middle ring). Like the seed seller's story at the start of this chapter, Figure 5 also provides a means of conceptualizing how these various processes interact, and thus builds on the four central themes:

1. Traders' vulnerabilities to the epidemic are enmeshed in their dynamic environments, and thus always exist and are always changing;

2. While these environments are affected by common macro-level processes, traders' circumstances and conditions differ at the micro level, and thus HIV/ AIDS is affecting them differently;

3. Their underlying and uneven vulnerabilities to the epidemic are driven by power relations operating through changing societal structures; and

4. Institutional interventions can mediate these power dynamics, enabling traders' responses, and thus potentially reducing the impacts they bear.

This framework is based primarily on the empirical findings and interacting themes detailed earlier in this thesis. It encapsulates the results of this vulnerability analysis and offers one empirically derived conceptualization of health vulnerability in a context of HIV/ AIDS and rapid change. 


\subsection{Extending Health Vulnerability Concepts amidst HIV/ AIDS and Rapid Change: Beyond Warwick Junction}

While grounded in the perceptions and experiences of Warwick Junction traders, the framework represented in Figure 5 has also been informed by an evolving and iterative engagement with health and vulnerability concepts within globalization, human vulnerability and HIV/ AIDS research. This section positions the framework within its broader intellectual foundations, as introduced in Chapter 2. It brings together the four themes represented in Figure 5 with concepts arising in these three fields, and thus examines the potential conceptual contributions and methodological implications of this study beyond Warwick Junction.

It begins by briefly examining how the contributing literatures-globalization, human vulnerability and HIV/ AIDS _ overlap and intersect. It then demonstrates how the findings in Warwick Junction are supported by, crosscut and could begin to bridge recent developments in these three fields. Finally, through a more detailed discussion of the four emerging themes, it begins to build toward an interdisciplinary framework that could address current limitations in conceptualizing health vulnerabilities and thus provide insights into how to intervene in the processes that underlie the spread and impacts of HIV/ AIDS.

\subsubsection{Intersecting Literatures: Extending Vulnerability Dynamics}

The vulnerability assessment undertaken in thesis has drawn on concepts at the intersection of three fields of study. Research on globalization indicates that over the past two decades, global-scale economic change - with a trend towards market 
liberalization and economic interconnectedness - has resulted in rising social and economic inequalities within and between countries (Weisbrot et al 2002). Meanwhile, human vulnerability research demonstrates that vulnerability is associated with the converging effects of social and environmental transformation ( $O^{\prime}$ Brien \& Leichenko 2000), and the capacity of individuals and communities to cope with these changing conditions (Bohle 2001). In the AIDS field, the most current social science thinking emphasizes the temporal lags between HIV infection and longer-term societal impacts; this is illustrated by Whiteside's (2004) diagram of the three epidemic curves introduced in Section 2.1 (see Figure 1). All three literatures highlight the dynamic nature of vulnerability—societal change is clearly one overlapping theme.

Indeed, the three bodies of research-globalization, human vulnerability and HIV/ AIDS - are interrelated and each provides crucial puzzle pieces for understanding health vulnerabilities in a context of generalized HIV/ AIDS and rapid change. Yet, they remain largely unconnected and the challenge is to bring them together into a coherent framework. In beginning to bridge these literatures, it is evident that, unlike earlier work in the field, Whiteside's (2004) three curves effectively illustrate the epidemic's temporal dynamics and widespread consequences (see Figure 1). His conceptualization has been foundational for this thesis and thus provides one basis from which to merge vulnerability concepts. The time lags from infection to illness to societal impacts are an important reminder that while HIV prevalence is high and continuing to rise, the full societal effects of the epidemic will only unfold in the decades after infection levels have peaked. High prevalence now means the longer-term impacts are looming. 
But while impacts loom, vulnerabilities abound. Human vulnerability research demonstrates that vulnerabilities pre-exist the impacts of external stressors (Mustafa 1998; Adger 1999); thus vulnerabilities are the processes leading up to Whiteside's three curves, while the three curves (infection, illness and impacts) are the outcomes. This literature also implies that there is significant human uncertainty in impacts projections, as outcomes depend on how humans cope with or adapt to change (Bohle 2001). Moreover, vulnerability research in relation to both environmental stresses and globalization proposes that vulnerabilities are intertwined with changing societal systems (O'Brien 2001; Mittelman 2002). Together, these findings suggest that the future outcomes of the epidemic are neither known nor pre-determined.

Intersecting these literatures, it becomes apparent that the three curves, as they are currently portrayed in Figure 1, do not capture the possibility of changes in their trajectories owing to (future) changes in underlying health vulnerabilities-the longerterm consequences of the epidemic are looming, but they not fixed. In order to redirect the epidemic's outcomes, however, we need a better understanding the processes that underpin infection, illness and impacts. As indicated in Chapter 1, we are faced with significant conceptual gaps: few studies have examined how HIV/ AIDS is converging with other societal processes, how epidemics are unevenly experienced at the community-level, how societal structures drive epidemics and their impacts, or how individuals and communities are responding. Yet, it is clearly possible (and indeed worthwhile) to draw on other disciplines in order to address some of these limitations. 


$\begin{aligned} & \text { Human Vulnerability to } \\ & \text { Environmental Stresses } \\ & \text { Research }\end{aligned}$
* Shift from impacts
assessment to understanding
drivers (Watts \& Bohle
1993; Brklacich \& Bohle
2004)
*Vulnerability understood
as exposed rather than
caused by external stress
(Mustafa 1998; Adger
1999)
*Vulnerability understood
as an interaction between
external stress and coping
capacity (Chambers 1989;
Bohle 2001)
*Vulnerability linked with
cumulative and converging
processes of change
(O'Brien \& Leichenko
2000)
*Vulnerabilities differential
\& linked with uneven
power relations and social
inequalities (Watts \& Bohle
1993; Mustafa 1998)

Human Vulnerability to Research

* Shift from impacts assessment to understanding drivers (Watts \& Bohle 2004)

* Vulnerability understood as exposed rather than caused by external stress 1999)

* Vulnerability understood external stress and coping capacity (Chambers 1989; Bohle 2001)

* Vulnerability linked with processes of change (O'Brien \& Leichenko 2000)

Vulnerabilities differential power relations and social 1993; Mustafa 1998)

\section{HIV/ AIDS \& Health Research}

* Early vulnerability studies concerned with HIV risk, based on the assumption that humans act individually and without constraint (Craddock 2004).

* Health promotion \& social psychology research contributes psychosocial power as influence on behaviour (Campbell 2003); focus in health research on individual empowerment (e.g., Wallerstein 1992).

* Small but growing social science literature positioning AIDS within societal structures (e.g., Kalipeni $\boldsymbol{e t}$ al, eds, 2004). Social and economic 'vulnerability' now common theme, but concept lacks precision (Delor \& Hubert 2000).

* AIDS impacts studies define vulnerability as likelihood of being infected or affected by epidemic (Barnett \& Whiteside 2002). Extends research to account for temporal lags between HIV infection and longerterm impacts. Also extends vulnerability beyond individual to look at effects that are society-wide (Whiteside 2004, three epidemic curves, Figure 1); focus remains on outcomes, not drivers.

\section{Globalization of Human Systems Research}

* Human health influenced by local and global processes; increasingly driven by supranational processes, yet health care provision remains responsibility of nation states, and health experienced at individual \& community levels. (McMichael et al 1999; McMichael \& Beaglehole 2000).

${ }^{*}$ Economic globalization resulting in growing socio-economic inequalities within \& between countries (Weisbrot et al 2002). * Globalization a stress for some, an opportunity for others; increasing vulnerabilities for most vulnerable groups (Mittelman 2002).
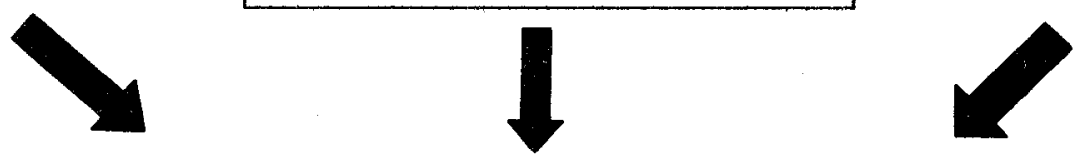

Crosscutting Concepts Arising from

Warwick Junction Research

1. Vulnerabilities are embedded in changing social systems

2. Vulnerabilities are differentiated

3. Vulnerabilities are driven by dynamic power relations

4. Vulnerabilities are negotiated

A reorientation in focus: from outcomes to processes

Figure 6: Intersecting Literatures-- An Approach to Extending Health Vulnerability Concepts 
While developing a coherent interdisciplinary framework is beyond the scope of this thesis, this task could be aided by the four central themes encapsulated in Figure 5, as these stem from empirical findings and crosscut the contributing literatures (see Figure 6). These can be summarized as follows: (1) vulnerabilities are embedded in changing social systems; (2) vulnerabilities are differentiated; (3) vulnerabilities are driven by dynamic power relations; and (4) vulnerabilities are negotiated.

The following discussion expands upon these themes to seed an amalgamation of the empirical findings of this research with concepts developed in HIV/ AIDS, human vulnerability and globalization research. In so doing, it draws together the findings from Warwick Junction with research elsewhere to begin to address current gaps in conceptualizing health vulnerabilities. It further suggests that, collectively, the four central concepts call for a re-orientation of vulnerability analysis away from its current outcomes-orientation, towards an examination of underlying processes.

\subsubsection{Vulnerabilities are embedded in changing social systems}

HIV entered traders' households and communities amidst family fracture, urbanization, institutionalized poverty, gender inequalities and rising unemployment; Chapter 3 demonstrated that these processes are the legacy of colonialism and Apartheid and a consequence of rapid transition. As a result, traders were vulnerable before HIV became part of their daily lives; they are vulnerable now, before the full impacts and outcomes have unfolded; and as the epidemic progresses, pre-existing social and economic circumstances will (if unchanged) continue to position them directly in harm's way. Traders' vulnerabilities to the epidemic are clearly embedded in their social 
systems; as such, their vulnerabilities are always in motion and conditioned by social change.

This research also shows that the epidemic is interacting with the changing political economy, globalization and increased population mobility. The consequences are not only simultaneous, but also additive and cumulative, and they feed back to influence traders' responses to new stresses. The shape of Whiteside's curves-and in particular the third curve - will thus depend on how future transition serves to mediate or perpetuate underlying vulnerabilities. Looking forward, these findings suggest that societal change that sees rising unemployment, accelerated migration and growing inequalities is likely to exacerbate AIDS impacts for traders, while transition that prioritizes social protection, public works programs, basic income grants and rural livelihood strategies may well be preventative.

Therefore, as Barnett and Whiteside (2002) attest, "epidemics and their impacts do not take place in isolation. They need to be related to other events - changes in political regimes, new ideas, global warming, the global distribution of power" (p 160). Indeed, this is reflected in recent developments in vulnerability research elsewhere (O’Brien \& Leichenko 2000). Most AIDS research does not however consider how change will influence the impacts of abrupt shocks and longer-term stresses posed by epidemics. Given the extended timeframe over which impacts occur, understanding the cumulative and linked effects of South Africa's epidemic in conjunction with other ongoing changes is crucial. 


\subsubsection{Vulnerabilities are differentiated}

Processes of change do not affect all people evenly (Mittelman 2002). Delor and Hubert (2000) explain that vulnerability assessment is ultimately an "analysis of difference"; individuals are differently vulnerable at different times in their lives and in different contexts, and there are marked differences in vulnerabilities between individuals, groups and societies.

Two levels of differentiation emerge in this study. First, among traders, vulnerabilities vary between sub-groups, and especially by age and gender; younger traders are highly vulnerable to and fearful of infection, while older women are bearing a disproportionate burden of financial, social and emotional effects. Different people and groups are thus differently vulnerable to each of Whiteside's three epidemic curves. Second, informal traders, as a group, are disproportionately vulnerable to HIV/ AIDS compared to other sectors of the population; their lack of access to ARVs alone will shorten the time lags between their three curves. What has been revealed is that the same external stressor, in this case the AIDS epidemic, manifests in different and uneven effects among different groups and sub-groups.

Moreover, O’Brien and Leichenko (2000) demonstrate that stressors tend to converge on - or "double expose"-certain places, social groups and economic sectors, and their findings are supported in this research. Just as globalization is creating opportunities for some South Africans, the traders who participated in this study do not have the skills or education to compete in the global labour market. There is a growing gap between rich and poor (Nicholson 2001), with traders facing fewer and fewer 
opportunities. At the same time, AIDS is unequally affecting South Africans by class, race and gender (Gilbert \& Walker 2002); here again, traders' social and economic conditions make them highly vulnerable. Traders and their families do not have access to adequate treatment, care or support, while others in South Africa can obtain high-quality private health care and ARV therapies. AIDS and globalization are converging on street traders - they are among those who are "double exposed".

This convergence occurs because the same underlying conditions that make traders vulnerable to the epidemic (e.g., lack of access to resources, livelihood insecurity, and displacement from their families) also make them vulnerable to other stressors. Although few intensive, place-based or ethnographic studies have been carried out to examine how HIV/ AIDS epidemics are experienced at the community level (Craddock 2004), there is a need to understand how and why vulnerabilities are differentiated and what age, gender or social characteristics underpin these differences. Identifying what causes multiple stressors to converge on certain groups has been identified as a priority elsewhere, and could assist in reducing adverse outcomes among those who are "double exposed" (O’Brien \& Leichenko 2000).

\subsubsection{Vulnerabilities are driven by dynamic power relations}

Traders' differentiated vulnerabilities are driven by uneven relations of political, economic and psychosocial power, as discussed in Chapter 5. Power relations operate through societal structures to generate stresses and limit traders' response possibilities; they also create conditions that are psychologically disempowering for many. 
Delor and Hubert $(2000)^{31}$ suggest that vulnerability to HIV and AIDS arises from the interaction of processes at three levels: (1) "identity vulnerability," which involves psychological empowerment and perceptions of self; (2) "relational vulnerability," which is generated through interactions with peer groups and sexual partners; and (3) "contextual vulnerability," which results from characteristics of the macro social environment, such as social security and cohesion. Looking at human famines, Watts and Bohle (1993) describe a "space of vulnerability" as shaped by an interaction between three sets of factors: (1) distribution of rights and resources (entitlements); (2) rights and institutions through which entitlements are defined and negotiated (empowerment/ enfranchisement); and (3) historical class and gender relations that lead to the concentration of resources within certain groups (political economy).

As in this case study, both frameworks associate vulnerability with uneven power relations. Watts and Bohle (1993) emphasize political and economic relations of power, and this is widely supported in environmental hazards research. Delor and Hubert (2000) introduce psychological dimensions of power; their findings are supported by health promotion research, which links health with perceptions of personal efficacy. However, psychological dimensions of power are absent from human vulnerability research, and very few studies examine the relationships between human health and political-economic power.

\footnotetext{
${ }^{31}$ This is one of the only empirically derived frameworks on drivers of vulnerability to HIV/ AIDS. It is based on people living with HIV in Belgium, which is not a generalized epidemic.
} 
This second point - the gap in research on structural drivers of health--is crucial. Early biomedical and epidemiological studies of HIV risk did not address issues of power (Craddock 2004). More recently, health promotion research has linked human health with psychosocial power; yet, the emphasis in health fields has remained largely on individual empowerment (e.g., Wallerstein 1992; Bandura 1995). A small number of social scientists are now investigating how AIDS epidemics are embedded in societal structures, but there is still an overriding tendency to frame HIV/ AIDS as an individual medical issue (Craddock 2004). These conceptualizations function to depoliticize AIDS, health and vulnerability.

By contrast, this thesis suggests that traders' vulnerabilities are interwoven with both dimensions of power. In line with Watts and Bohle (1993), traders' experiences result from uneven access to resources ("entitlement"), political voice ("enfranchisement/ empowerment"), and age, gender, class and race relations ("political economy"), among others. There are also clear psychological elements to traders' vulnerabilities, which supports the findings of Delor and Hubert (2000): older women feel helpless to protect their children; younger women feel unable to negotiate condom use; and younger men feel hopeless about the future.

Furthermore, traders' psychosocial vulnerabilities are largely embedded within political-economic power; for instance, young male traders feel powerless as a result of their lack of employment options. Friere (2004) contends that empowerment depends not only on psychological or motivational change at the individual level, but also on shifting structural political-economic power and raising intellectual consciousness of macro 
structures. Radically altering health vulnerabilities would, from this perspective, require interventions that move beyond individual behaviour change to a rethinking of class, race, age and gender--with meaningful education, livelihood and political opportunities created. This would also necessitate that traders become critically aware of how their collective social condition has resulted from racism, gender inequality, Apartheid, and now globalization and AIDS.

Finally, power relations, the structures through which they operate, and the social systems within which they are embedded, are dynamic, as depicted in Figure 5. Indeed, the collapse of Apartheid has brought structural changes, such as the end of restrictions on migration and the resulting change in market dynamics discussed earlier in this chapter. Social systems are not a fixed or unalterable (Gibson-Graham 2003) -and hence vulnerabilities to the epidemic could be reduced and adverse outcomes redirected. There is, however, a need to move beyond narrow conceptualizations of AIDS to understand the structural drivers of vulnerability.

\subsubsection{Vulnerabilities are negotiated}

Traders' vulnerabilities are not merely passive effects of uneven social transition, but rather negotiated processes influenced by the actions of individuals, groups and institutions. Bohle (2001) defines vulnerability as having a "double structure": as an interaction between "external" exposure to stressors and "internal" capacity to cope or adapt (Chamber 1989; Kelly \& Adger 2001). Yet, very little is known about how people and communities are responding to and coping with stresses introduced by the epidemic, 
or what macro effects will precipitate from such responses-AIDS research has not yet adequately examined the "internal" dimension.

This thesis demonstrates that although traders' actions are currently highly restricted, they continue to respond to the stresses in their lives, their responses mediate the impacts they bear, and their options can be expanded through institutional intervention. The critical finding is that institutional interventions can enable traders to mediate the stresses and impacts of the epidemic; thus the internal dimension in Warwick Junction includes individual and community responses and actions taken by governments and other institutions.

The importance of human response in shaping the epidemic's outcomes cannot be overlooked, but a caution regarding the limits to human agency is also required. 'Coping' at community and household levels, which has been a recent thrust in human vulnerability research (Kelly \& Adger 2000; Bohle 2001), can be overemphasized to justify inadequate central intervention. In Warwick Junction, a focus on 'coping' strategies could idealize traders' relative power and minimize their actual deprivation. This study suggests an emphasis on 'response options' instead, with a view that institutions shape these options and central intervention is required.

Building on Whiteside's framework, there are opportunities for institutional intervention into the processes underlying each of the three curves (see Figure 1): altering the first would require effective HIV prevention; altering the second could entail improving $A R V$ access and nutrition in order to prolong the progression from HIV to AIDS; and altering the third would mean making it easier for vulnerable populations to 
care for sick family members and orphans. The curves are linked and interventions are likely required on all three in order to decrease the gradients of each and increase the lags between them. This thesis also indicates that certain processes may underlie all three curves - such as livelihood insecurity and gender inequalities-and thus tackling these crosscutting issues could have synergistic effects.

The evidence from this study suggests that the course of South Africa's epidemic could be altered through human action but, as indicated elsewhere (Bohle 2001), the actions of those most vulnerable are disproportionately constrained. Attempts to redirect the outcomes clearly must consider how individuals and communities respond, adapt and cope and how central intervention could mediate the effects of AIDS and widen the response options available to vulnerable groups.

\subsubsection{Towards an Interdisciplinary Framework}

In bringing these four themes together, it is noteworthy that findings among the small sample of traders who participated in this research cannot be generalized to other traders or contexts, and nor were they intended to be. This thesis sought to gain an understanding of HIV/ AIDS vulnerabilities based primarily on one case study. Nevertheless, the emerging themes - that traders' vulnerabilities are embedded in their changing environments, differentiated, driven by dynamic power relations, and negotiated - are supported by, extend, and begin to merge concepts developed elsewhere. They initiate a process of bridging globalization, human vulnerability and HIV/ AIDS research, which together may provide important conceptual insights into reducing health vulnerabilities amidst HIV/ AIDS and rapid transition. Based on this discussion, the four 
themes highlighted in the development of Figure 5 could likely be extended beyond

Warwick Junction as follows (see Table 10):

1. Vulnerabilities to HIV and AIDS are likely interwoven with social systems and hence shaped by social change (Barnett \& Whiteside 2002). Given the temporal dynamics of the epidemic (Whiteside 2004), vulnerabilities need to be understood as they interact with other processes of change (O'Brien \& Leichenko 2000; Mittelman 2002).

2. HIV/ AIDS does not affect all people in the same way or to the same extent because of a differentiation in underlying vulnerabilities (Delor \& Huber 2000). As the epidemic converges with other processes, it may be that certain populations will be "double exposed" (O'Brien \& Leichenko 2000). Understanding how underlying conditions are differentiated and what factors heighten vulnerability to multiple stresses is thus crucial (O’Brien 2001).

3. Dynamic power relations, which are institutionalized in changing social systems and may be internalized as psychological attributes (Friere 2004), may drive uneven experiences of the epidemic and underpin vulnerabilities. There is a need to recognize that AIDS is not only an individual medical issue, understand its structural drivers, and examine how structures can be altered (Craddock 2004).

4. Vulnerabilities are not only structural, but also depend on individuals' and groups' capacities to respond (Bohle 2001). Institutional interventions could mediate the effects of the epidemic by enabling such responses. 
Table 10: Towards an Interdisciplinary Framework of Health Vulnerability

Core findings from Warwick Junction, as encapsulated in Figure 5

1. Traders' vulnerabilities to the epidemic are enmeshed in their dynamic environments, and thus always exist and are always changing.

2. While their environments are affected by common macro-level processes, traders' circumstances and conditions differ at the micro level, and thus HIV/ AIDS is affecting them differently.

3. Traders' underlying and uneven vulnerabilities to the epidemic are driven by political-economic and psychosocial power relations operating through changing and changeable societal structures.

4. Institutional interventions can mediate power dynamics, enabling traders' responses and thus potentially reducing the impacts they bear.
Possible conceptual extensions beyond Warwick Junction: Comprehensive health vulnerabilities in contexts of HIV/ AIDS and rapid change

1. Vulnerabilities to HIV and AIDS are likely interwoven with social systems and hence shaped by social change (Barnett \& Whiteside 2002). Given the temporal dynamics of the epidemic (Whiteside 2004), vulnerabilities need to be understood as they interact with other processes of change (O'Brien \& Leichenko 2000; Mittelman 2002).

2. HIV/ AIDS does not affect all people in the same way or to the same extent because of a differentiation in underlying vulnerabilities (Delor \& Huber 2000). As the epidemic converges with other processes of change, it may be that certain populations will be "double exposed" (O'Brien \& Leichenko 2000). Understanding how underlying conditions are differentiated and what factors heighten vulnerability to multiple stresses is thus crucial (O'Brien 2001).

3. Dynamic power relations, which are institutionalized in changing social systems and may be internalized as psychological attributes (Friere 2004), may drive uneven experiences of the epidemic and underpin vulnerabilities. There is a need to understand the structural drivers of AIDS, recognize that AIDS is not only an individual medical issue, and examine how structures can be altered (Craddock 2004).

4. Vulnerabilities are not only structural, but also depend on individuals' and groups' capacities to respond (Bohle 2001). Institutional interventions could mediate the effects of the epidemic by enabling such responses.

\subsubsection{A Reorientation from Outcomes to Processes: Methodological Implications}

The analysis above reveals that the epidemic in South Africa is young and the full impacts are yet to come, as illustrated in Whiteside's three curves (Figure 1). It also extends this thinking to suggest that the longer-term consequences are looming, but are not fixed. Indeed, among Warwick Junction traders (and with potential extensions beyond), the trajectories of the three curves depend on underlying health vulnerabilities which are embedded in social systems, influenced unevenly by change, driven by 
dynamic power relations and modifiable through human action. What we have seen is that in order to alter the impacts of the epidemic, there is a need to understand and intervene in these processes that underpin infection, illness and impacts.

This represents a significant reorientation for AIDS research, which has tended to look backward at outcomes rather than forward at how to mitigate them. Such an outcomes-focus is a characteristic of empirical research more generally: we attribute causality only to what we can clearly observe, and so we rely on measuring tangible products (or past impacts) rather than dynamic processes (or present vulnerabilities). However, studying the outcomes of a disaster post-hoc, whether the disaster is an epidemic or a tsunami, precludes prevention of human tragedies. Such a re-thinking has profound methodological implications for health vulnerability analysis.

One challenge is the dominance of biomedical conceptualizations of health and widespread reliance on measures of morbidity and mortality as health indicators. This research suggests that biomedical approaches are not adequate for capturing the complex processes that undermine human wellbeing: biomedical models reduce health to the absence of illness and measure it according to static end points (i.e., disease or death). There is a need to develop new measures that portray the systemic processes that generate health and illness, and to apply these within AIDS research.

Three further methodological implications arise from this re-orientation. First, a shift from measuring outcomes to assessing processes must consider the temporal dynamics of vulnerabilities; methodologies could include longitudinal or retrospective studies, life histories, or long-term ethnographies. Second, understanding how processes 
result in differentiated vulnerabilities requires intensive, place-based or ethnographic methods that link macro stressors with nuanced local experiences. Third, this reorientation proposes that vulnerability research itself be viewed as a process; here, the links between power and vulnerability support participatory approaches that provide opportunities for groups to analyze their collective conditions.

Chapter 1 set out the following question: what can be done so that as the wave breaks those living in low-lying areas are not carried out to sea? It suggested that providing universal access to medical treatment is one part of the solution, but the full answer is enormously complex, highly politicized and laden with unknowns. This thesis has shown that street traders are among those living in the low-lying areas, their vulnerabilities are highly complex, and interventions must extend beyond biomedical approaches. Yet, O'Brien and Vogel (2004) express that it is not sufficient for researchers to simply identify vulnerabilities; assessment should move toward identifying strategies to improve human security and wellbeing. Having discussed the implications of this study for extending health vulnerability concepts, I now return to Warwick Junction with suggestions for improving the immediate and longer-term wellbeing of street traders.

\subsection{Revisiting Warwick Junction: Potential Framework Applications}

The framework developed at the beginning of this chapter is a conceptual tool, but it may also offer insights for intervention (see Figure 5). Figure 5 highlights potential entry points for vulnerability reduction on three levels: the macro environment (outer ring), the micro context (inner ring), and the underlying power relations (middle ring). In 
line with the proposed reorientation of vulnerability concepts, these interventions are designed to move traders out of harm's way now, before further AIDS impacts unfold (see Table 11). They target processes that undermine traders' wellbeing, and many are directed at conditions described earlier as crosscutting traders' vulnerabilities to infection, illness and impacts. Given the rapidly changing systems in which traders live and the present insecurities many face, new stressors will likely continue to arise in their environments; by improving their current wellbeing and enabling their responses, these potential interventions may reduce negative outcomes not only from AIDS, but from other (perhaps unforeseen) stressors as well.

\section{Table 11: Potential Intervention Strategies at Three Levels}

\begin{tabular}{|c|c|c|}
\hline $\begin{array}{l}\text { Outer ring: } \\
\text { Macro interventions }\end{array}$ & $\begin{array}{l}\text { Inner ring: } \\
\text { Micro interventions }\end{array}$ & $\begin{array}{l}\text { Middle ring: } \\
\text { Enabling response }\end{array}$ \\
\hline $\begin{array}{l}\text { *Increasing social transfers } \\
\text { *Implementing basic income } \\
\text { grants or national welfare } \\
\text { system } \\
\text { "Establishing public sector } \\
\text { social protection } \\
\text { *Altering trade agreements to } \\
\text { allow for economic protection } \\
\text { and employment creation } \\
\text { *Supporting rural livelihood } \\
\text { strategies } \\
\text { *Implementing 'public works' } \\
\text { programs } \\
{ }^{*} \text { Creating a universal public } \\
\text { health care system and } \\
\text { dismantling two-tiered system } \\
\text { *Creating incentives for health } \\
\text { care professionals to remain in } \\
\text { South Africa and work in public } \\
\text { health care } \\
\text { *Real national leadership on } \\
\text { HIV/ AIDS } \\
\text { *Accelerating equitable ARV } \\
\text { roll out in public sector }\end{array}$ & $\begin{array}{l}\text { *Improving shelter, water, } \\
\text { toilets, waste disposal and pest } \\
\text { control at work and home } \\
\text { "Improving social housing in } \\
\text { the city } \\
\text { *Improving traders' access to } \\
\text { information-outreach } \\
\text { programs that help traders } \\
\text { apply for social transfers at } \\
\text { their sites. } \\
\text { *Outreach information on } \\
\text { HIV/ AIDS, health and social } \\
\text { services, and legal aid for } \\
\text { traders, at their sites. } \\
\text { *Improving security of trading } \\
\text { spaces for all traders, } \\
\text { including young people. } \\
\text { *Abolishing school fees in } \\
\text { urban and rural areas, and } \\
\text { establishing food programs in } \\
\text { schools } \\
\text { *Creating education and } \\
\text { training opportunities, } \\
\text { including paid } \\
\text { apprenticeships, for traders. }\end{array}$ & $\begin{array}{l}\text { *Instilling hope that the epidemic, } \\
\text { unemployment, and poverty are not } \\
\text { inevitable by meeting basic needs } \\
\text { and providing opportunities for } \\
\text { advancement. } \\
\text { *Shifting household dynamics, } \\
\text { including supporting social } \\
\text { transfers to women and children } \\
\text { *Shifting current gender dynamics; } \\
\text { facilitating community-based } \\
\text { dialogues in which men and women } \\
\text { come together to understand how } \\
\text { their conditions of disadvantage } \\
\text { have created gender norms that } \\
\text { threaten their health. } \\
\text { *Moving beyond 'ABC', 'othering' } \\
\text { and blaming, to talk about AIDS as } \\
\text { a societal issue } \\
\text { *Shifting power dynamics in } \\
\text { Warwick Junction, including } \\
\text { supporting women, youth, and } \\
\text { foreign traders to organize } \\
\text { *Creating a watchdog body for } \\
\text { trading committees and an avenue } \\
\text { for traders to voice complaints }\end{array}$ \\
\hline
\end{tabular}


At the macro level, interventions could include creating a national welfare system, instituting public works programs and supporting rural livelihoods. The 'informal economy' does not appear to be a solution to unemployment; rather, street trading remains a predominantly survivalist activity in Warwick Junction (Skinner 2004). This research suggests that secure employment and accessible social transfers could reduce traders' vulnerabilities to HIV infection and AIDS impacts. In addition, the interactive nature of the macro processes depicted on the outer ring of Figure 5 implies that addressing one change in isolation may be less effective than considering their common drivers. Shifting dominant neoliberal philosophies towards a politics of social responsibility, for instance, could address a number of overlapping challenges related to class (race and gender) inequalities: the growing rich-poor gap, the jobless growth, and the two-tiered health care system.

Just as the impacts of AIDS are not fixed, there is nothing inevitable or 'natural' about globalization, poverty, neoliberal economics or urban-rural migrancy; these processes have been set in motion by humans and could be changed (Gibson-Graham 2003). And while these are processes over which traders have very little control, addressing societal inequalities is not only a matter of equity and ethics, but could also profoundly affect future population health in South Africa (Gilbert \& Walker 2002). Macro level intervention takes time and requires a long-term perspective, but it appears to be crucial.

At the micro-level, interventions could include providing shelter, water, sanitation, housing, services, and devising outreach programs that make information 
accessible to traders at their sites. The decentralization of responsibility for the informal economy, as well as Durban's multi-sectoral urban management approach, suggest that protocols are in place for the municipal government to act: with adequate investment of resources, there is an opportunity to build on the institutional strengths of the Warwick Junction Renewal Project.

Possible interventions on the middle ring involve altering power dynamics and enabling traders' response possibilities by providing access to the resources, options and skills necessary to influence decision-making. Support could be made available to community-based initiatives aimed at opening dialogue between men and women around issues of gender inequality, sexuality, violence and AIDS. In Warwick Junction, women and youth may need support to organize and traders not represented by the ITMB a safe forum in which to voice their concerns. Enabling traders to improve their own lives could affect their immediate wellbeing and their capacities to respond to future stresses, including the coming impacts of the epidemic.

Interventions are likely required on all three levels. Yet, we have seen that the most vulnerable are the least able to affect change at home, at work and in society, while the least vulnerable have the least at stake. Altering society's macro structures may be necessary if livelihoods, resources and opportunities are to be equitably distributed; at the same time, improving micro conditions could ease the immediate struggles of traders and their families. The middle ring may offer both short and longer-term promise: assisting traders to respond to and control the stresses in their lives now could improve their current conditions, provide hope and allow them to more easily deal with future 
challenges. Finally, processes on all three rings are inter-linked, and thus an intervention on one level is likely to affect change on another. Small changes could have lasting impacts.

\subsection{Conclusion}

From the story of one seed seller, to a framework for Warwick Junction traders, and to an analysis of vulnerability concepts more widely, this chapter explores the four over-arching themes of this thesis and examines how they come together and interact: (1) vulnerabilities are embedded in changing social systems; (2) vulnerabilities are differentiated; (3) vulnerabilities are driven by dynamic power relations; and (4) vulnerabilities are negotiated. It begins a process of connecting largely separate research bodies, in order to extend current health and vulnerability concepts.

Based on these concepts, this chapter calls for a re-orientation of health vulnerability analysis away from its current outcomes-focus, towards an examination of the processes that underpin infection, illness and impacts. The key point is that this is a new epidemic-especially in South Africa--but the longer-term consequences are not fixed; a better understanding of what causes health vulnerabilities is required in order to reduce future impacts. 


\section{Chapter 7}

\section{Summary and Conclusions}

The 1994 election marked South Africa's transformation from an oppressive political regime to a democratic state with one of the most progressive constitutions in the world. This raised the hopes of millions of South Africans that a more equitable distribution of wealth would accompany political freedom. Over the past 10 years, the new government has achieved many successes, including improved access to basic services, judicial transparency and increased social transfers. Yet, just as these accomplishments are being realized, economic globalization, macro-economic 'reform', and the desegregation of urban centres have led to rising unemployment, mass urbanization and the growth of impoverished urban communities living and working in precarious 'informal' conditions.

Amidst this rapid change, HIV entered South Africa, and the ineffectual response of the old government was replaced with an equally weak response from the new. While plans had been drawn up, the new government was unprepared, unable or unwilling to take the necessary actions. The HIV epidemic has grown and AIDS is now looming insidiously in families, workplaces and public spaces. Prevalence is still rising and the impacts are beginning to be felt. Epidemiological studies are providing important data to show how many people are infected, who and where; yet, these do not explain what makes different people and groups vulnerable at different times and in different contexts, or how to best intervene. 
This study aimed to gain a more detailed understanding of vulnerabilities to HIV and AIDS: to examine the underlying conditions that result in different levels of infection, illness, impacts, and response possibilities, among different people and groups. Street traders in Warwick Junction provide a window into how converging processes have come to bear on a heterogeneous group of people living and working on South Africa's peripheries.

The research entailed critically and carefully developing a series of relationships-with the seamstress on the Berea Bridge, the trolley pusher in the taxi rank, the inyangas in the muthi market, the seed seller, the bovine head cooker, the young woman selling shoes, research assistants, a women's beading group, government officials, and beyond. I have drawn on my experiences of these relationships to tell the stories of Warwick Junction traders. These are stories of strength and struggle, of hope and tragedy; they illustrate the complexities and nuances of human vulnerability.

\subsection{Summary}

This thesis mapped out street traders' vulnerabilities to the HIV/ AIDS epidemic: the macro context, the micro context, and their uneven struggles. The analysis then formed a basis from which to extend and challenge current health and vulnerability concepts. A summary is as follows:

Chapter 2 positioned this study within HIV/ AIDS, human vulnerability, and globalization research; these literatures provide a conceptual basis from which to examine HIV/ AIDS vulnerabilities in a context of rapid change. These starting points also guided the study's interdisciplinary, participatory and ethnographic methodology. 
Chapter 2 outlined the research design and process, which included in-depth, repeated interviews with street traders, interviews with key informants and health care providers, archival research, and conceptual refinement.

Chapter 3 examined the macro context of traders' vulnerabilities and found that despite a myriad of positive changes in South Africa, many traders are struggling with rising unemployment, deepening poverty, their displacement from home, and increasing numbers of young adult deaths in their families; many are disillusioned. At the macro level, traders' struggles are shaped by the convergence of four processes: politicaleconomic transition, globalization, urbanization and the HIV/ AIDS epidemic.

Chapter 4 evaluated the micro context of traders' vulnerabilities and demonstrated that their wellbeing depends on personal factors and their interactions with local ecological, social and economic environments. At the micro level, traders' vulnerabilities are differentiated by age and gender. This chapter highlighted young traders' overwhelming fears of infections and the disproportionate care-taking burden born by older women.

Chapter 5 delved into what drives the uneven struggle and revealed that relations of psychosocial, political and economic power expose traders to different and unequal stresses. Traders' differing expressions of powerlessness and inevitability, which shape how they experience the epidemic, are based in social and economic dispossession more broadly. Their uneven power to respond is constrained by class, race, gender and age structures. 
Chapter 6 expanded the analyses from Chapters 3 through 5 to develop a framework of comprehensive health vulnerabilities. The framework illustrates how traders' vulnerabilities result from interacting macro and micro processes, experienced differently by different traders at different time. It also shows that traders' actions can mediate the stresses they face and institutions can enable their often-limited responses. Chapter 6 seeded the process of bringing together these findings with interdisciplinary themes to extend health vulnerability concepts.

\subsection{Research Contributions}

This was a first foray into research in a cross-cultural context; it was undertaken with a small sample of street traders, in one location, over a short time frame, and largely through translators. As such, further research is required to more fully map out vulnerabilities to HIV and AIDS over time, and among a larger number of people and sites. Nevertheless, the research process was beneficial to participants and the findings contribute to developing health vulnerability concepts more widely.

The approach taken in this research offered opportunities for street traders to come together and examine their own vulnerabilities. Findings were disseminated to traders, decision-makers and academics through reports, policy briefs and presentations. The project also built capacity among several local research assistants and developed institutional relationships between HEARD, local organizations and Carleton University. As a result, a longer-term research, advocacy and lobbying initiative with Warwick Junction traders is now being planned. 
This study also contributes to a broader endeavour to understand how local vulnerabilities interact with macro-level change. Most social vulnerability research has taken place in relation to natural disasters and famines; indeed, there is a long history of trying to understand how and why humans become vulnerable to these age-old stresses. However, HIV/ AIDS epidemics are new: humanity has never before experienced such slow, debilitating, pervasive and distinct 'long-wave' stresses, as the epidemics that are underway in southern Africa (Barnett \& Whiteside 2002). We have nowhere to look to understand their dynamics or their longer-term consequences.

Therefore, alongside the four months of primary research, this study engaged with human vulnerability concepts broadly in order to gain insight into what puts certain people and groups in harm's way — as a conceptual foundation from which to make sense of AIDS. Its major academic contribution is that it begins to bridge overlapping (but yet largely isolated) concepts within HIV/ AIDS, human vulnerability and globalization literatures, based on empirical field research. Through this process, it grapples not only with the immensity of HIV/ AIDS, but also with the complexities of social change, inequality and human wellbeing. It calls for a conceptual reorientation that could aid in altering the trajectories of HIV and AIDS, and ultimately contributes to a rethinking of health vulnerability assessment in contexts of rapid change.

\subsection{Conclusions}

HIV/ AIDS entered South Africa as the Apartheid era ended and at a time of transition. Gender inequalities, household fragmentation, migration and institutionalized poverty created a fertile terrain for the spread of HIV. At the same time, the globalization 
of South Africa's economy and the adoption of neoliberal macro-economic policies have led to rising levels of unemployment and a growing gap between rich and poor. This, together with the deregulation of cities, has resulted in increasing numbers living and working in sub-standard urban conditions. These processes have continued to fuel the epidemic.

Yet, societal change does not affect all people equally and vulnerabilities to HIV and AIDS are not uniformly distributed. Compared to other sectors of South African society, informal street traders are among the most vulnerable. They are disadvantaged by the past and their insecurities exacerbated by the recent political, economic and demographic transition. For most, the epidemic is serving to entrench and accelerate existing processes of marginalization and as the epidemic interacts with ongoing change, traders are becoming 'double exposed'. Globalization is creating opportunities for some, but traders do not have the skills to compete in the global labour market. Meanwhile, many South Africans can access ARVs and high-quality private health care, but traders lack medical coverage and cannot. This convergence could further polarize the very society that has just recently overcome its legislated 'separateness'.

Among traders, the epidemic is experienced differently by age and gender, with different sub-groups unevenly vulnerable to HIV infection and AIDS impacts. For young traders, it is the fear of infection that causes the greatest angst. Both young men and women feel this: young women fear for their children and are unable to negotiate safe sex, while young men's lack of livelihood options and social support generate feelings of hopelessness and shape their behaviour. Older men feel the effects as members of their 
communities die, but this research shows that it is most often older women who are bearing the greatest impacts. They care for the sick and orphaned, and many are the primary income earners in their families.

This differentiation results from underlying social and economic inequalities. At the core of traders' uneven struggles are relations of political, economic and psychosocial power, which shape their feelings of personal control and unequally limit their response possibilities. For traders as a group, their dislocation, livelihood insecurity and lack of social protection increase their likelihood of being infected or affected; for older women, it is their level of family responsibility and lack of access to family assets that make them disproportionately vulnerable to AIDS impacts.

Yet, what is most concerning about the epidemic is that it is new and HIV prevalence is still rising. It will be at least another five years before prevalence peaks, and likely another 10 before orphan numbers reach their highest levels. In the meantime, each December sees a new cohort of school leavers entering the job markets; many are ending up in the informal economy and on the pavements of Warwick Junction. We are seeing the rising burden of care, the emotional effects, the economic impacts and the loss of hope among traders, and we know that these effects are pervasive and uneven. But we do not know what is to come.

The longer-term consequences of this epidemic are menacing, but they are not pre-determined. The effects of HIV/ AIDS are interwoven with the changing society; the epidemic has arisen in change and the future effects will be linked to ongoing transition. Change that sees rising unemployment and declining social protection will likely 
accelerate the impacts of the epidemic; change that sees the creation of rural livelihood opportunities and basic income grants could soften the shocks and stresses. Human action can affect and mediate these changes: the outcomes of the epidemic on traders will depend on actions taken by individuals, communities and institutions. Firm national leadership and an accelerated, accessible ARV roll-out could help stop the mixed messages and curb the feelings of hopelessness. Improving access to information, water, housing and sanitation would allow traders to more easily care for family members who are falling ill. Traders' vulnerabilities are in motion now, before the full impacts have transpired-but these vulnerabilities can be altered.

Looking forward, HIV will spread most pervasively among impoverished, displaced and dispossessed communities, and these same communities have the least access to treatment, support and care. Nowhere is this more clearly illustrated than in the province of KwaZulu-Natal, where nearly one in three adults is infected, and in Warwick Junction, where 8000 street traders eke out a living beneath the crisscross of highway overpasses, on the Berea Railway Bridge, in the taxi ranks and on the pavements. But we do not need to stand by and await the disaster; this is a slow-breaking wave and there is time to evacuate. Small changes now could prevent human tragedies later.

This lesson most likely extends beyond Warwick Junction: in order to re-direct the adverse outcomes of HIV/ AIDS, we need to understand the processes that underpin infection, illness and cumulative impacts. This requires a reorientation of vulnerability analysis from its current outcomes-focus to an examination of underlying processes - a rethinking of AIDS research and vulnerability assessment more broadly. New measures 
of 'health' are needed to capture the complexities of human wellbeing; counting how many are sick or dead after-the-fact precludes preventing such outcomes. Methodologies must consider the dynamics and differentiation of vulnerabilities and, ultimately, provide opportunities for disadvantaged groups to gain insights into their collective social condition. This thesis calls for research that looks forward at how to prevent human tragedies, rather than backward at how to describe them. 


\section{References}

Adger, N. (1999). Social vulnerability to climate change and extremes in Coastal Vietnam. World Development. 27(2): 249-269.

Bandura, A. (1995). Exercise of personal and collective efficacy in changing societies. In Bandura, (ed.) Self-efficacy in Changing Societies. USA: Cambridge University Press, 168.

Barnett, T. \& Whiteside, A. (2002). AIDS in the Twenty-First Century: Disease and Globalization. South Africa: Interpak Books.

Brklacich, M. \& Bohle HG. (2004). Assessing human vulnerability to climatic change. In Kraft, T. \& Ehlier, E. (eds). Earth System Science \& the Anthropocene: Emerging Issues and Problems. USA: Springer Verlag.

Bohle, HG (2001). Vulnerability and criticality. Vulnerability Article 1. Newsletter of the International Human Dimensions Proagramme on Global Environmental Change. 2.

Bonnin, D. et al (1996). The struggle for Natal and KwaZulu: Workers, township dwellers and Inkatha, 1972-1985. In Morrell, R. (ed). Political Economy and Identities in KwaZulu-Natal: Historical and Social Perspectives. South Africa: Indicator Press,

Burowoy, M. (2000). Introduction: Reaching for the global. In Burawoy, M. et al. Global Ethnography: Forces, Connections, and Imaginations in a Postmodern World. USA: University of California Press, 1-40.

Campbell, C. (2003). Letting them Die: How HIV Prevention Programmes Often Fail. South Africa: Double Storey Books.

Campbell, C. (2004). Migrancy, masculine identities, and AIDS: The psychosocial context of HIV transmission on South African gold mines. In Kalipeni, E. et al (eds). HIV \& AIDS in Africa: Beyond Epidemiology. USA: Blackwell Publishing Ltd., 144-154.

Campbell, C. \& MacPhail, C. (2002). Peer education, gender and the development of consciousness: Participatory HIV prevention by South African youth. Social Science \& Medicine, 55: 331-345.

Chambers, R. (1989). Vulnerability, coping \& policy. IDS Bulletin. 20(2): 1-7.

Charmes, J. (2003). Street Traders and their Associations in South Africa. Geneva: International Labour Office. 
Craddock, S. (2004). Beyond epidemiology: Locating AIDS in Africa. In Kalipeni, E. et al (eds). HIV \& AIDS in Africa: Beyond Epidemiology. USA: Blackwell Publishing Ltd., $1-10$.

Cutter, S. et al (2000). Revealing the vulnerability of people and places: A case study in Georgetown County, South Carolina. Annals of the Association of American Geographers. 90(4): 713-737.

Deane, N. (2005). The political history of AIDS treatment. In Karim, S. \& Karim, Q. (2005). HIV/ AIDS in South Africa. USA: Cambridge University Press, 538-547.

Delor, F. \& Hubert, M. (2000). Revisiting the concept of 'vulnerability'. Social Science \& Medicine. 50: 1557-1570.

Department of Health (2003). National HIV and Syphilis Antenatal Sero-Prevalence Survey in South Africa 2003. Pretoria: Republic of South Africa, Health Systems Research, Research Coordination and Epidemiology.

Devey, R. et al (2002). The informal economy in South Africa: Who, where, what and how much?. Presented to Development Policy Research Unit Second Annual Conference on Labour Markets and Poverty in South Africa. Johannesburg: 22-24 October 2002.

Dlamini, E. (2004). Personal communication. Warwick Junction Urban Renewal Project Office, Durban: 23 Sept 2004.

Dlamini, M. (2004). Personal communication. Warwick Junction Muthi Market, Durban: 08 Oct 2004.

Dobson, R. (2004a). Personal communication. Warwick Junction Urban Renewal Project Office, Durban: 29 Sept 2004.

Dobson, R. (2004b). Personal communication. Warwick Junction Urban Renewal Project Office, Durban: 29 Nov 2004.

Erskine, S. (2005). South Africa, Provinces Map. Health Economics \& HIV/ AIDS Research Division. Durban.

Fassin, D. (2003). The embodiment of inequality: AIDS as a social condition in the historical experience in South Africa. Embo Reports. Special Issue. 4: S4-S9.

Fine. M. (1994). Working the hyphens: Reinventing Self and Other in qualitative research. In Denzin, NK. \& Lincoln, YS. (eds). Handbook of Qualitative Research. United Kingdom: Sage Publications. 
Forget, G. \& Lebel, J. (2001). An ecosystem approach to human health. International Journal of Occupational Environmental Health. 7(2): S1-S38.

Foucault, M. (1980). Two lectures. In C. Gordon (ed). Power/ Knowledge: Selected Interviews and Other Writings 1972-1977 by Michel Foucault. New York: Pantheon Books, 78-108.

Freund, B. (1996). The violence in Natal 1985-1990. In Morrell, R. (ed). Political Economy and Identities in KwaZulu-Natal: Historical and Social Perspectives. South Africa: Indicator Press.

Freund, B. \& Padayachee, V. (2002). (D)urban Vortex. South Africa: University of Natal Press.

Friere, P. (2004). Pedagogy of the Oppressed. $30^{\text {th }}$ Anniversary Edition. USA:

Continuum International.

Gibson-Graham, J.K. (2003). An Ethics of the local. Rethinking Marxism. 15(1): 49-74.

Gilbert, G. \& Walker, L. (2002). Treading the path of least resistance: HIV/ AIDS and social inequalities-A South African case study. Social Science \& Medicine. 54(7): 1093-1110.

Gouws, E. \& Karim Q. (2005). HIV infection in South Africa: An evolving epidemic. In Karim, S. \& Karim, Q. (eds.). HIV/ AIDS in South Africa. USA: Cambridge University Press, 48-66.

Grad, FP (2002). The Preamble of the constitution of the World Health Organization. Bulletin of the World Health Organization. 80 (12): 981-982.

Grest, J. (2000). Urban citizenship and legitimate governance: The case of the Greater Warwick Avenue and Grey Street Urban Renewal Project, Durban. Presented to South African Planning History Study Group Millenium Conference on Planning for Reconstruction and Transformation. Durban: 29-30 May 2000.

Grest, J. (2004). Personal communication. Department of Political Science, University of KwaZulu-Natal, Durban: 06 Oct 2004.

Hoggart, K. et al (2002). Researching Human Geography. London: Arnold.

Hosegood, V. \& Solarsh, G. (2004). Population mobility and household dynamics in rural South Africa: Implications for demographic and health research. Africa Centre for Population Studies and Reproductive Health, South Africa. 
Kalipeni, E. (2000). Health and disease in southern Africa: A comparative and vulnerability perspective. Social Science \& Medicine, 50: 965-983.

Kalipeni, E. et al, eds. (2004). HIV and AIDS in Africa: Beyond Epidemiology. USA: Blackwell Publishing Ltd.

Karim, S. (1999). Making AIDS a notifiable disease - Is it an appropriate policy for South Africa?. South African Medical Journal. 89: 609-611.

Karim, S. \& Karim, Q., eds. (2005). HIV/ AIDS in South Africa. USA: Cambridge University Press.

Kelly, M. \& Adger, N. (2000). Theory and practice in assessing vulnerability to climate change and facilitating adaptation. Climatic Change. 47: 325-352.

Lee, S. (2004a). Assessing the vulnerability of women street traders to HIV/ AIDS: a comparative analysis of Uganda and South Africa. Health Economics and HIV/ AIDS Research Division, Internet source: www.nu.ac.za/heard/papers.

Lee, S. (2004b). Personal communication. Health Economics and HIV/ AIDS Research Division, University of KwaZulu-Natal, Durban: 20 Sept 2004.

Lund, F. (2002). Social security and the changing labour market: Access for non-standard and informal workers in South Africa. Social Dynamics. 28 (2): 177-206.

McClintock, A. (1995). Imperial Leather: race, gender \& sexuality in the colonial contest. USA: Routledge.

McMichael, A. \& Beaglehole, R. (2000). The changing global context of public health. The Lancet. 356: 489-499.

McMichael, A. et al (1999). Globalization and the sustainability of human health: An ecological perspective. BioScience. 49 (3): 205-209.

Mcnube, P. (2004). Personal communication. Warwick Junction Urban Renewal Project Office, Durban: 01 Dec 2004.

Metropolitan Durban (2005). Population Indicators. Metropolitan Durban, Internet source: www. cerois.net/ reports/ durban/ drivers/ population/ indicato.

Mittelman, J. (2002). Making globalization work for the have-nots. International Journal on World Peace. 19(2): 3-25. 
Mkhize, T. (2004a). Personal communication. Warwick Junction Urban Renewal Project Office, Durban: 30 Sept 2004.

Mkhize, T. (2004b). Personal communication. EThekwini Municipality Health Department, Durban: 06 Oct 2004.

Moore, D. (2001). Neoliberal globalisation and the triple crisis of 'modernisation' in Africa: Zimbabwe, the Democratic Republic of the Congo and South Africa. Third World Quarterly. 22(6): 909-929.

Morrell, R. (1996). Preface. In Morrell, R. (ed.) Political Economy and Identities in KwaZulu-Natal: Historical and Social Perspectives. South Africa: Indicator Press.

Mustafa, D. (1998). Structural causes of vulnerability to flood hazard in Pakhistan. Economic Geography. 74(3): 289-305.

Naude, W. (2004). Post-Apartheid South Africa in the world economy: An assessment of inequality in an open developing country. Africa Insight. 34 (4): 46-53.

Nesvåg, S. (2002). The development of mass street trading in Durban: The case of muthi trading. In Freund, B. \& Padayachee, V. (D) urban Vortex. South Africa: University of Natal Press.

Nicholson, J. (2001). Measuring Change: South Africa's Economy since 1994. Trade Union Research Project, Durban: University of Natal Press.

O'Brien, K. (2001). The Dynamics of vulnerability to global change. Vulnerability Article 4. Newsletter of the International Human Dimensions Proagramme on Global Environmental Change. 2.

O'Brien, K. \& Leichenko, R. (2000). Double exposure: Assessing the impacts of climate change within the context of economic globalisation. Global Environmental Change. 10: 221-232.

O'Brien, K. \& Vogel, C (2004). Vulnerability to global environmental change: Rhetoric and reality. AVISO. Issue 13: Global Environmental Change and Human Security Project.

Oppong, J. (1998). A Vulnerability interpretation of the geography of HIV/ AIDS in Ghana, 1986-1995. Professional Geographer. 50(4): 437-448.

Skinner, C. (2004). Personal communication, Durban. School of Development Studies, University of KwaZulu-Natal, Durban: 12 Nov 2004. 
Sparks, A. (2003). Beyond the Miracle: Inside the New South Africa. USA: University of Chicago Press.

TAC (2005). Treatment Action Campaign, South Africa, Internet Source: www.tac.org.za.

UNAIDS (2003). AIDS Epidemic Update: December 2003. Geneva: Joint United Nations Programme on HIV/ AIDS and World Health Organization.

Wallerstein, N. (1992). Powerlessness, empowerment, and health: Implications for health promotion programs. American Journal of Health Promotion. 6(3): 197-205.

Watts, MJ \& Bohle HG (1993). The Space of vulnerability and the causal structure of hunger and famine. Progress in Human Geography. 17: 43-67.

Weisbrot, M. et al (2002). The scorecard on globalization 1980-2000: Its consequences for economic and social well-being. International Journal of Health Services. 32 (2): 229-253.

Welsh, F. (2000). A History of South Africa. United Kingdom: Harper Collins Publishers.

Whiteside, A. (2004). Economic and development issues around HIV/ AIDS. Presented to School of Development Studies $50^{\text {th }}$ Anniversary Conference-Reviewing the First Decade of Development and Democracy in South Africa. Durban: 21-22 October 2004.

Whiteside, A. (2005). Personal communication. Health Economics and HIV/ AIDS Research Division. University of KwaZulu-Natal, Durban: 28 June 2005.

Whiteside, A. \& Sunter, C. (2000). AIDS: The Challenge for South Africa. South Africa: Human \& Rousseau Tafelberg.

World Bank (2005). World Bank Population Data, Internet source: www.worldbank.org/ data/wdi2004/pdfs/Table3_10.pdf

World Health Organization (2003). Determinants of Health, Internet source: www.who.int/hia/evidence/doh 
Appendix A: Schedule of Key Informant and Health Care Provider Interviews I Key Informant Interviews

EThekwini Municipality

Dobson, Richard. (29 Sept 2004; 29 Nov 2004). Inner Thekwini Renewal and Urban Management Programme (iTRUMP): Joint Programme Leader

Gajee, Renu (06 Oct 2004). eThekwini Municipality Health Department: Research Committee Director.

Mcnube, Patrick. (23 Sept 2004; 1 Dec 2004). Inner Thekwini Renewal and Urban Management Programme (iTRUMP): Warwick Junction Project Area Manager

Mkhize, Tobias. (30 Sept 2004; 06 Oct 2004; 28 Nov 2004). Environmental Health Branch, eThekwini Municipality Health Department: Environmental Health Officer

Sithole, Philip (26 Nov 2004). eThekwini Municipality Department of Informal Trade: Deputy Head of Operations, Business Support

Trading Committees

Dlamini, Emmanuel. (23 Sept 2004). Informal Trade Management Board (ITMB):

President

Dlamini, Ma (08 Oct 2004). Warwick Junction Muthi Market: Muthi Market Leader, formerly with Self-Employed Women's Union (SEWU).

eThekwini Traditional Healers Council meeting (20 Oct 2004). Warwick Junction Project Centre.

Khawula, Ma/ Women's beading group (23 Sept 2004). Informal Trade Management Board: Chairwoman \& Leader of bovine head cookers

Horn, Patricia. (27 Nov 2004; 03 Dec 2004; 05 Dec 2004 all email correspondences). StreetNet International

Researchers \& Academics

Grest, Jeremy. (06 Oct 2004). Department of Political Science, University of KwaZuluNatal.

Lee, Sabrina. (20 Sept 2004). Health Economics and HIV/ AIDS Research Division, University of KwaZulu-Natal: Researcher.

Skinner, Caroline. (30 Sept 2004; 12 Nov 2004). School of Development Studies, University of KwaZulu-Natal.

Whiteside, Alan (28 June 2005). Health Economics and HIV/ AIDS Research Division, University of KwaZulu-Natal. Director. 


\section{Health Care Provider Interviews}

Dudu, Sr. (02 Nov 2004). Lifeline, Ukuba Nesibindi/ Centre of Courage, HIV Voluntary Testing and Counseling Centre (NGO): Warwick Junction Manager/ Nurse.

Liebetrau, Jeanne (06 Oct 2004; 25 Oct 2004 email correspondence; 27 Oct 2004 telephone correspondence). Prince Cyril Zulu Communicable Disease Centre (public clinic): Manager/ Nurse.

Mariemuthu, Pushpa (22 Oct 2004). Lancer's Road Primary Health Clinic (public clinic): Manager/ Nurse.

Padayatchi, Nesri (08 Nov 2004 email correspondence). Centre for the AIDS Programme of Research in South Africa (CAPRISA), Prince Cyril Zulu Communicable Disease Centre: Site Manager.

HIV/ AIDS Counsellor \#1 (02 Nov 2004/ F). Hope Worldwide, Prince Cyril Zulu Communicable Disease Centre (NGO).

HIV/ AIDS Counsellor \#2 (05 Nov 2004/ F). Hope Centre Clinic, Christian Durban Centre (NGO).

HIV/ AIDS Counsellor \#3 (09 Nov 2004/ F). Prince Cyril Zulu Communicable Disease Centre (public clinic).

HIV/ AIDS Counsellor \#4 (21 Nov 2004/ M). Lancer's Road Primary Health Clinic (public clinic)

HIV/ AIDS Counsellor \#5 (21 Nov 2004/ F). Lancer's Road Primary Health Clinic (public clinic)

Inyanga \#1 (01 Nov 2004/ M), Warwick Junction Muthi Market.

Inyanga \#2 (04 Nov 2004/ M). HIV/ AIDS Specialist, Warwick Junction Muthi Market. Inyanga \#3 (11 Nov 2004/ M). Warwick Junction Muthi Market. Inyanga \#4 (23 Nov 2004/ M). Warwick Junction Muthi Market.

Pharmacist (23 Nov 2004/ M). Scala Pharmacy, Warwick Junction.

Private doctor \#1 (02 Dec 2004/ M). Lancer's Rd, Warwick Junction.

Private doctor \#2 (23 Nov 2004/M). Berea Pharmacy, Warwick Junction.

Private doctor \#3 (23 Nov 2004/ M). Scala Surgery, Warwick Junction. 


\section{Appendix B: Stratified Sample of Core Trader Participants}

\section{(i) Female Street Traders}

\begin{tabular}{|c|c|c|c|}
\hline Trade & Age & $\begin{array}{l}\text { Inclusion (I)/ exclusion (E) status in market } \\
\text { Note: Levels of inclusion \& exclusion were not clear binary } \\
\text { categories, but rather a continuum. I/E refers to a participant } \\
\text { having characteristics of both and falling toward the centre of } \\
\text { the continuum. }\end{array}$ & $\begin{array}{l}\text { Interview } \\
\text { dates }\end{array}$ \\
\hline $\begin{array}{l}\text { Bovine head } \\
\text { cooker }\end{array}$ & 30 & $\begin{array}{l}\text { I/E: has shelter, works for mother; wants permit of own, not } \\
\text { involved with ITMB }\end{array}$ & $19-10-04$ \\
\hline $\begin{array}{l}\text { Mealie (com) } \\
\text { cooker }\end{array}$ & 21 & E: transient, no permit, no shelter, not involved with ITMB & $\begin{array}{l}26-10-04 \\
16-11-04 \\
\end{array}$ \\
\hline $\begin{array}{l}\text { Trader selling used } \\
\text { shoes }\end{array}$ & 19 & $\begin{array}{l}\text { E: no permit, running sister's business, no shelter, not } \\
\text { involved with ITMB }\end{array}$ & $\begin{array}{l}04-11-04 \\
16-11-04 \\
\end{array}$ \\
\hline Curry cooker & 20 & $\begin{array}{l}\text { E: no permit, under someone selling fruit inside the market, } \\
\text { not involved with ITMB, no shelter, police harassment }\end{array}$ & $\begin{array}{l}19-10-04 \\
23-11-04 \\
01-12-04\end{array}$ \\
\hline $\begin{array}{l}\text { Pinafore } \\
\text { seamstress }\end{array}$ & 27 & $\begin{array}{l}\text { I/E: has shelter, no permit, sells at boyfriend's site but wants } \\
\text { permit/ independence, not involved with ITMB }\end{array}$ & $\begin{array}{l}21-10-04 \\
27-11-04 \\
03-12-04\end{array}$ \\
\hline $\begin{array}{l}\text { Seed seller } \\
\text { (daughter) }\end{array}$ & 27 & $\begin{array}{l}\text { E: no shelter, not involved with ITMB, works under her } \\
\text { mother, no permit }\end{array}$ & $\begin{array}{l}8-10-04 \\
23-11-04 \\
\end{array}$ \\
\hline $\begin{array}{l}\text { Seed seller } \\
\text { (mother) }\end{array}$ & 52 & $\begin{array}{l}\text { I/E: has a permit \& } 2 \text { business operations, no shelter, not } \\
\text { involved with ITMB }\end{array}$ & $\begin{array}{l}08-10-04 \\
21-10-04 \\
22-11-04 \\
01-12 / 04\end{array}$ \\
\hline $\begin{array}{l}\text { Cardboard } \\
\text { collector }\end{array}$ & $40+$ & E: no shelter, no permit, not involved with ITMB & $\begin{array}{l}20-10-04 \\
15-11-04 \\
27-11-04 \\
\end{array}$ \\
\hline Mat seller & $40+$ & E: no shelter, no permit, transient, not involved in ITMB & $\begin{array}{l}26-10-04 \\
16-11-04 \\
\end{array}$ \\
\hline Live chicken trader & $50+$ & $\begin{array}{l}\text { I: inside market (shelter), permit, not involved with ITMB, } \\
\text { but is involved with street committee }\end{array}$ & $\begin{array}{l}26-10-04 \\
15-11-04 \\
\end{array}$ \\
\hline $\begin{array}{l}\text { Church uniform } \\
\text { seamstress }\end{array}$ & 52 & $\begin{array}{l}\text { I: on railway bridge, shelter, electricity, permit, not involved } \\
\text { with ITMB }\end{array}$ & $\begin{array}{l}28-10-04 \\
17-11-04 \\
27-11-04 \\
01-12-04 \\
\end{array}$ \\
\hline $\begin{array}{l}\text { Mpempo (incense) } \\
\text { seller }\end{array}$ & 54 & $\begin{array}{l}\text { J/ E: semi-shelter (under overpass), permit, was once part of } \\
\text { SEWU but disillusioned }\end{array}$ & $\begin{array}{l}04-11-04 \\
16-11-04 \\
27-11-04 \\
\end{array}$ \\
\hline
\end{tabular}




\section{Appendix B: Stratified Sample of Core Trader Participants}

\section{(ii) Male Street Traders}

\begin{tabular}{|c|c|c|c|}
\hline Trade & Age & $\begin{array}{l}\text { Inclusion (I)/ exclusion (E) status in market } \\
\text { (Note: Levels of inclusion \& exclusion were not clear binary } \\
\text { categories, but rather a continuum. I/E refers to a participant } \\
\text { having characteristics of both and falling toward the centre } \\
\text { of the continuum). }\end{array}$ & $\begin{array}{l}\text { Interview } \\
\text { dates }\end{array}$ \\
\hline $\begin{array}{l}\text { Trolley pusher, } \\
\text { selling chips }\end{array}$ & 19 & E: no permit, not involved with ITMB & $\begin{array}{l}22-10-04 \\
19-11-04\end{array}$ \\
\hline $\begin{array}{l}\text { Barrow boy, } \\
\text { delivering } \\
\text { produce }\end{array}$ & 25 & E: no permit, paid per load, no shelter & $\begin{array}{l}15-10-04 \\
19-11-04 \\
23-11-04\end{array}$ \\
\hline $\begin{array}{l}\text { Trolley pusher, } \\
\text { selling fruit }\end{array}$ & 21 & $\begin{array}{l}\text { E: no permit, itinerant, brother 'owns' trolley, no shelter, not } \\
\text { involved with ITMB }\end{array}$ & $\begin{array}{l}27-10-04 \\
10-11-04\end{array}$ \\
\hline Hairdresser & 35 & $\begin{array}{l}\text { E: no permit, works for 'owner' of tent, foreigner, political } \\
\text { refugee (does not speak isiZulu, interviewed in English) }\end{array}$ & $\begin{array}{l}22-10-04 \\
11-11-04 \\
02-12-04\end{array}$ \\
\hline Cigarettes seller & 31 & I: on railway bridge, permit, shelter, member of ITMB & $\begin{array}{l}27-10-04 \\
19-11-04\end{array}$ \\
\hline $\begin{array}{l}\text { Itinerant trader, } \\
\text { selling candy bars }\end{array}$ & 41 & $\begin{array}{l}\text { E: no permit, Muslim Indian (does not speak isiZulu, } \\
\text { interviewed in English), harassed by police, ITMB, Forum }\end{array}$ & $\begin{array}{l}27-10-04 \\
10-11-04 \\
\end{array}$ \\
\hline Muthi trader & 41 & $\begin{array}{l}\text { I/ E: no shelter, no space on muthi bridge, permit, member of } \\
\text { Traditional Healer's Organization (not recognized in } \\
\text { Durban), not member of ITMB }\end{array}$ & $\begin{array}{l}15-10-04 \\
12-11-04 \\
02-12-04 \\
\end{array}$ \\
\hline $\begin{array}{l}\text { Sunglasses and } \\
\text { accessories trader }\end{array}$ & 46 & $\begin{array}{l}\text { I: on railway bridge, permit, shelter, former member of } \\
\text { ITMB }\end{array}$ & $\begin{array}{l}15-10-04 \\
10-11-04 \\
02-12-04 \\
\end{array}$ \\
\hline
\end{tabular}




\section{Appendix C: Questionnaires for Interviews with Traders}

\section{(i) Questionnaire for Round 1 Interviews with Street Traders, 8 October 2004}

\section{Script for obtaining informed oral consent:}

We are doing research on the health of traders in Warwick Junction. The information we get will be given to iTrump, City Health, and the trading committees to help them understand and plan for health issues that are important to traders. We will also provide the findings in Zulu for traders in December, and we will arrange a meeting where traders can offer their comments and criticisms on the findings.

This research is part of a bigger project to understand health in the informal economy. The main researcher is May Chazan, a student from Canada who working with HEARD at the University of KwaZulu-Natal here in Durban. A summary of this research will be used for her school thesis.

Would you be interested in participating in an interview? It will take 30 to 45 minutes and we may ask if we can visit you again in a few weeks time. We will keep your name and anything that could personally identify you private in any report or presentation, but people around here might notice that you are part of our study. You can choose to not answer any of the questions or to end the interview at any time.

(If yes, then proceed) Is this a good time, or should we come back?

If you have any other questions after the interview, you may contact the supervisors of this project. (Give card with contact information)

\section{Interview Questions and Prompts}

Date of Interview:

Interviewer:

Gender of participant:

Age of participant:

Trade:

Description of location:

\section{Living situation and trading history:}

1.1 Where are you from? Where do you consider home?

1.2 Where is your house?

1.3 Who lives in your house with you (i.e. relationships to informant)?

1.4Do you have a husband/ wife/ partner?

1.5 How often do you see your partner(s)?

1.6Do you have children? How many? Who takes care of them? Where?

1.7 Why did you come to trade in this area? When?

1.8 Where do you stay when you are trading? During the week? On the week-end?

1.9lf staying away from home, how long does it take you to get here? How often do you travel? 
1.10What standard did you achieve at school?

\section{Health and well-being:}

We'd like to know about what affects the health and well-being of traders.

2.1 What do you think are the key health problems of people trading here in the market?

2.2What is the top health threat to you?

2.3Are there health threats related to your working conditions?

2.4Are there health threats related to your living conditions here, during the week?

On the week-ends?

2.5Have you been sick recently? With what illness?

2.6Did you take time off trading?

2.7When you are sick, do you have someone who can work for you here?

2.8 Who takes care of you?

2.9 When was the last time a family member was ill? What illness? Who took care of this person?

2.10Do you see a doctor or nurse when you're sick? If yes, where, which one? If no, why not?

2.11Are there other services you access? What? Where?

2.12What services are available to you here?

2.13What do you do to prevent getting sick?

2.14What do you think will affect your health most over the next 5 years?

\section{Livelihood security/social protection/ inclusion:}

Tell us a bit more about trading...

3.1Do you trade anything other than what you have here?

3.2Where do you get your supplies for trading? How often?

3.3Are you self-employed or do you work for someone else? Explain (salary, commission?).

3.4Does all of your income come from trading?

3.5What other sources of income do you have?

3.6Do you depend on anyone else for money?

3.7Do you have insurance that would pay for your expenses if you weren't able to work?

3.8Do you belong to a stokvel?

3.9Are you involved with any of the traders' unions or groups? Why or why not?

3.10Do you attend any courses or meetings here in Warwick Junction? Which ones?

How often?

3.11 Have you taken time off recently, for what reason, how long?

3.12Was it difficult to get a permit to trade here? How did you get it?

3.13 Who controls what and how you trade? Explain.

3.14Do regulations here help you trade? Do they hinder you from trading? How?

3.15Which regulations are beneficial?

3.16Has the renewal project here in Warwick affected what or how you trade? 
3.17Has it changed any of the threats to your health? Explain.

3.18 Has it changed what you do when you are sick? Explain.

3.19What could be done by the authorities to make trading or living better for you in Warwick?

3.20Do you feel like you have power to influence trading conditions? Living conditions?

\section{Crime/ Violence:}

4.1 Is crime a problem in Warwick? Is it a threat to you when you are trading?

4.2If yes, what kind of crime is a threat to you (theft, violent crime, etc)? Prioritise.

4.3How do you protect yourself?

4.4Have you been a victim recently of crime? When? What? Where?

4.5Have you witnessed a crime recently? When? What? Where?

\section{HIV/ AIDS:}

The numbers suggest that here in KwaZulu-Natal, one in every three people have HIV or AIDS.

5.1 Have you seen any signs of this among street traders?

5.2Is HIV/ AIDS something that is talked about among traders? Is it a concern?

5.3 How do you think the epidemic is affecting traders?

5.4 How are they being looked after?

5.5What could be done to make it easier for traders to deal with this epidemic?

5.6Have you ever cared for anyone sick with AIDS? Tell us about it

Do you want to add anything more about trading conditions in Warwick or threats to street traders?

Thank you so much for your time. Could we come back and speak with you again if we need to?

Would you be interested in coming to a group session to discuss the findings of this study?

(Information will be passed around in Warwick Junction in early December, or you can feel free to get in touch with May at the number on the card that you have.)

Do you have any questions?

\section{(ii) Questionnaire for Round 2 Interviews with Street Traders, 8 Nov 2004}

\section{Transition and political engagement:}

1.1 What effects have the change in government had on you?

a. On your family?

b. On where you live?

c. On where you work?

d. On your lifestyle?

1.2What have been the benefits of the change? What has not improved? 
1.3Did you vote in the first election? The second election? Do you plan to vote in future elections? Why or why not?

1.4Most traders have said that they started trading because of financial need. What were the other conditions at home that forced you to move?

\section{Urbanization:}

2.1How has leaving your farm/ being away from your family affected you? How has it affected your family?

2.2Has moving to the city changed the threats to your health? How?

2.3 Has it changed what you do when you are sick? How?

2.4Has it changed your traditions? How?

2.5 Has it changed your values? How?

2.6Has it changed what is expected of you or how you behave?

a. How are the rules different here?

b. Do traditional community and family expectations apply for people trading in the city? Is it different for men/ women? Older people/ youth?

2.7Is there anyone who could decide not to let you trade here anymore? Who?

\section{Community and social support:}

3.1 Where are the people that you feel like you can count on most?

3.2Where do you feel like you most belong? (In your farm area? Where do you stay

in the city/ township? Here at work? Elsewhere?) Why?

3.3 Who counts on you? Who do you help take care of?

3.4Do you feel that you are part of the same community as your parents/ children?

a. Do you share the same values and beliefs? Explain.

3.5Are you involved with any community groups? Where? What? Why? (i.e., church groups, neighbourhood organizations, informal get-togethers, sports, etc)

\section{Workplace cohesion:}

4.1 Who is part of your community at work (People in same trade? People in same area of market? People of same age group? Members of same committee or forum? People from same rural area (home boys)? From same township?)?

4.2Do you trust people here? Have you ever lent money to the people you work with here? Would you?

4.3What makes Warwick Junction a community? What is missing? What problems does Warwick Junction face as a community?

4.4Are you involved in any community groups here? Which ones?

4.5What causes are traders united for here? Are you included in this?

4.6Were you part of the fight to secure trading space here in the market? In what capacity?

4.7Have you ever voted for committee/ forum members or been part of the selection process? 
4.8Do the committees here represent your interests and needs? How?

a. Do they protect you? How?

b. Do they control how you work? How?

c. Have you noticed any favouritism or corruption amongst the committees? What kind? How does this affect you?

4.9When it comes to being part of the committees, going to meetings or getting space to trade, are there any

a. Age divisions? (i.e., are young people kept out of the market, on the margins?)

b. Language barriers?

c. Tensions around ethnicity or nationality?

d. Favouritism based on homeboy networks?

e. Gender issues?

Explain.

4.10Is there any intimidation of traders by police? Committees? Officials? When was the most recent example? How often does this happen?

5. Access to resources:

5.1 What do you hope to do in the next 5years in terms of work? (e.g., Continue trading? Move to a different space? Start your own business? Retire? Hand your business over to a child? Find a more formal job?)

5.2What do you need to be able to achieve this? Is there anything stopping you? What?

5.3Do you have access to educational/ training opportunities? Where? What? Why not?

5.4Are you interested in obtaining further education or training? What kind?

5.5 Have you recently taken any courses? Where? What? When?

5.6Do you have access to money, equipment, space or anything else you might need to improve your business?

a. From whom? (i.e., bank loans, loans from family members? Informal networks? Credit facilities?)

\section{Nutrition/ food security:}

6.1How many meals do you eat each day?

6.2 What have you eaten today?

6.3 What did you eat for your main meal yesterday?

6.4Do you eat fresh fruit and vegetables? How often? 
7. HIV/ AIDS:

Traders are telling us that HIV/ AIDS is affecting them and many are concerned that there is so much stigma attached to it.

We have heard that:

- Traders are noticing other traders getting sick, disappearing and dying.

- They have family members who have it, have died of it, or who they suspect have it.

- They are afraid they could have it but don't want to get tested.

- They are worried that if they get it they will have to stop trading; that they'll lose their customers.

- They are worried about their children or siblings.

- They are worried that they will have to take care of family members or orphaned children in the near future, or they already have taken care of family members with AIDS.

7.1How is the epidemic affecting you?

7.2 How is it affecting your family?

7.3Are you doing anything to deal with potential financial impacts?

7.4Do you/ can you talk about it with your partner (s)? Why or why not? What is his/ her attitude towards it?

7.5Is it to easier to talk about with friends and casual partners? Why or why not?

7.6Do you talk about it with your family, parents, children? What are their attitudes towards AIDS?

7.7How do you deal with the threat, whether to you personally or to your family? How do you protect yourself?

7.8Do you think condoms offer protection from HIV? If no, why not?

7.9Do you use condoms? Why or why not?

7.10Is your partner accepting of condoms?

7.11Have you ever suggested that a family member or friend get tested for HIV?

7.12Have you ever been tested for HIV? Why or why not?

7.13Of the people you know who have HIV, are they staying in the city once they get sick, or are they going back to their farms?

7.14If you were to get sick, where would you go to be taken care of? What treatment would you seek?

We would like to come back to you to verify that we understood all of the information you have told us. Is this alright with you? Is there a good time for us to visit?

We have set a date (December 10) for the feedback workshop. Are you still interested in attending? 
Appendix D: Traders' Perceptions of Health as Person-Environment Interactions

\begin{tabular}{|l|l|l|}
\hline & Reported Health Concerns & Trader \\
\hline $\begin{array}{l}\text { Economic } \\
\text { environment }\end{array}$ & $\begin{array}{l}\text { "Not making enough money. Not even } \\
\text { enough to make it back home..." }\end{array}$ & Bovine head cooker \\
\hline $\begin{array}{l}\text { Social } \\
\text { environment }\end{array}$ & $\begin{array}{l}\text { "The burdens and stresses of all the kids I } \\
\text { take care of. I'm more worried about the } \\
\text { children than about me, but I am also not } \\
\text { well..." }\end{array}$ & $\begin{array}{l}\text { Church uniform } \\
\text { seamstress }\end{array}$ \\
\hline $\begin{array}{l}\text { Living } \\
\text { conditions }\end{array}$ & $\begin{array}{l}\text { "I'm renting a shack in Mayville. It's } \\
\text { crowded with no toilets, no water, no } \\
\text { electricity." }\end{array}$ & Cardboard collector \\
\hline $\begin{array}{l}\text { Workplace } \\
\text { conditions }\end{array}$ & $\begin{array}{l}\text { "This place is dirty; this could give us } \\
\text { sickness in the near future." }\end{array}$ & $\begin{array}{l}\text { Trolley pusher, } \\
\text { selling fruit }\end{array}$ \\
\hline Physical self & "Sore bones" & Mat seller \\
\hline Emotional self & "Unhappy... miss being with my family" & Ma Khawula \\
\hline Spiritual self & $\begin{array}{l}\text { "Nightmares. I was sick recently because } \\
\text { the spirits rose up in me..." }\end{array}$ & Muthi trader \\
\hline
\end{tabular}


Appendix E: Core Sample of Traders Differentiated by Age and Gender

\begin{tabular}{|l|l|l|}
\hline $\begin{array}{l}\text { Life } \\
\text { context }\end{array}$ & Men & Women \\
\hline Younger & $\begin{array}{l}\text { Trolley pusher, selling chips, 19 } \\
\text { Barrow boy, delivering produce, 25 } \\
\text { Trolley pusher, selling fruit, 21 } \\
\text { Hairdresser, 34 }\end{array}$ & $\begin{array}{l}\text { Bovine head cooker, 30 } \\
\text { Mealie cooker, 21 } \\
\text { Trader selling used shoes, 19 } \\
\text { Curry cooker, 20 } \\
\text { Pinafore seamstress, 27 } \\
\text { Seed seller (daughter), 27 }\end{array}$ \\
\hline Older & $\begin{array}{l}\text { Cigarette seller, 31 } \\
\text { Itinerant trader, selling candy bars, 41 } \\
\text { Muthi trader, 41 } \\
\text { Sunglasses/ accessories trader, 46 }\end{array}$ & $\begin{array}{l}\text { Seed seller (mother), 52 } \\
\text { Cardboard collector, 40+ } \\
\text { Mat seller, 40+ } \\
\text { Live chicken trader, 50+ } \\
\text { Church uniform seamstress, 52 } \\
\text { Mpempo seller, 54 }\end{array}$ \\
\hline
\end{tabular}

Notes:

1. The age division is based more accurately on similar characteristics related to participants' life contexts and circumstances within their households than on biological age, but these characteristics do tend to group roughly according to age: younger women are those with young children (only one has no children); older women have children and grandchildren; younger men claim to have no children; and older men have children (and in one case grandchildren). Men retire from street trading younger than women, so there are very few that are over 45 years of age.

2. The 34-year-old male hairdresser fits in age-wise with the older men in the study, and he has a child back in Zanzibar; however, because he has no contact with his family and no family responsibilities, he is characteristically more similar to the men in the younger group. As he is the only foreigner in the group, his story is somewhat of an outlier. His loss of contact with his family is a source of social vulnerability to him; he reports having no access to family resources or support. He is not a South African citizen and must constantly apply for renewed refugee status. His livelihood and access to employment are very insecure. 
Appendix F: Reported Impacts of HIV/ AIDS from Interviews with Core 20 Traders, by Age and Gender

\begin{tabular}{|c|c|c|c|c|}
\hline Impacts & Younger women: 6 & Older women: 6 & Younger men: 4 & Older men: 4 \\
\hline $\begin{array}{l}\text { Impacts in } \\
\text { family }\end{array}$ & $\begin{array}{l}3 \text { lost family } \\
3 \text { worried about } \\
\text { dying of AIDS, } \\
\text { leaving children } \\
2 \text { have cared for } \\
\text { others with AIDS }\end{array}$ & $\begin{array}{l}5 \text { lost family } \\
5 \text { worried children will } \\
\text { become sick (or } \\
\text { suspect HIV+) } \\
4 \text { are/ have cared for } \\
\text { sick } \\
\text { family or neighbours } \\
\text { more than once } \\
3 \text { care for children felt } \\
\text { to be AIDS orphans }\end{array}$ & $\begin{array}{l}2 \text { lost family } \\
1 \text { cared for sick } \\
\text { relative }\end{array}$ & $\begin{array}{l}1 \text { worried about } \\
\text { own children }\end{array}$ \\
\hline $\begin{array}{l}\text { Financial } \\
\text { impacts } \\
\text { (not threats } \\
\text { to business) }\end{array}$ & $\begin{array}{l}3 \text { worried about } \\
\text { financial impacts, } \\
\text { funeral costs with } \\
\text { lack of insurance, } \\
\text { saving for AIDS }\end{array}$ & $\begin{array}{l}4 \text { feel impacts already } \\
5 \text { worried about future } \\
\text { strain } \\
3 \text { trying to save for this }\end{array}$ & $\begin{array}{l}1 \text { trying to save for } \\
\text { future impacts }\end{array}$ & $\begin{array}{l}1 \text { concerned } \\
\text { with impacts, } \\
\text { especially } \\
\text { cost of orphans } \\
\text { in community }\end{array}$ \\
\hline $\begin{array}{l}\text { Impacts on } \\
\text { community }\end{array}$ & $\begin{array}{l}2 \text { stress impacts of } \\
\text { suffering, orphans }\end{array}$ & $\begin{array}{l}5 \text { stress impacts } \\
4 \text { involved in stokvels, } \\
\text { church groups \& } \\
\text { other; } \\
\text { believe community } \\
\text { reduces impacts }\end{array}$ & $\begin{array}{l}1 \text { says homeboys } \\
\text { are getting sick, } \\
\text { dying }\end{array}$ & $\begin{array}{l}2 \text { report impact } \\
\text { in community, } \\
\text { problems with } \\
\text { orphans }\end{array}$ \\
\hline $\begin{array}{l}\text { Impacts in } \\
\text { Warwick } \\
\text { Junction }\end{array}$ & $\begin{array}{ll}44 & \text { see traders \& } \\
\text { customers dying } \\
2 & \text { feel AIDS } \\
\text { threat to business }\end{array}$ & $\begin{array}{l}4 \text { see traders dying } \\
1 \text { storing goods for } \\
\text { trader sick with AIDS }\end{array}$ & $\begin{array}{ll}4 & \begin{array}{l}\text { see traders \& } \\
\text { customers sick }\end{array} \\
2 & \begin{array}{l}\text { feel AIDS threat } \\
\text { to business }\end{array}\end{array}$ & $\begin{array}{l}3 \text { see traders \& } \\
\text { customers } \\
\text { with AIDS }\end{array}$ \\
\hline
\end{tabular}


Appendix G: Results of Focus Group, AIDS Component (10 December 2004)

\begin{tabular}{|c|c|c|}
\hline \multicolumn{3}{|c|}{ How is AIDS affecting traders? } \\
\hline Mixed group & Women & Men \\
\hline $\begin{array}{l}\text { [Very little conversation } \\
\text { about this within group } \\
\text { as a whole. } \\
\text { Uncomfortable silence] } \\
2 \text { priorities: } \\
1 . \text { We are afraid of } \\
\text { infection, it's hard to } \\
\text { talk about } \\
2 . \text { Financial } \\
\text { concerns, orphans } \\
\text { Traders believe } \\
\text { inyangas do heal } \\
\text { sick people }\end{array}$ & $\begin{array}{l}\text { - People are afraid of talking about } \\
\text { sex, especially mother to child. } \\
\text { - Need to teach children while they } \\
\text { are still young. } \\
\text { - Some don't believe AIDS exists, } \\
\text { believe it is witchcraft. } \\
\text { - Others feel it's a shame people } \\
\text { don't want to talk about AIDS. They } \\
\text { are afraid of discrimination in the } \\
\text { community. Need to talk to your } \\
\text { children. } \\
\text { - Need to be able to educate children } \\
\text { who have left school because of } \\
\text { financial problems. } \\
\text { - Money is a problem. People don't } \\
\text { trust each other in terms of saving } \\
\text { money for taking care of the sick. } \\
\text { Need to form a stokvel to save } \\
\text { money, so there is commitment. }\end{array}$ & $\begin{array}{l}\text { - People are dying, } \\
\text { both traders and } \\
\text { customers. } \\
\text { - Now there are more } \\
\text { orphans because of } \\
\text { HIV/ AIDS. } \\
\text { - Businesses are dying } \\
\text { because they don't } \\
\text { have as many } \\
\text { customers as before. } \\
\text { - Treatment is only } \\
\text { given to pregnant } \\
\text { women, where can } \\
\text { men access help? }\end{array}$ \\
\hline \multicolumn{3}{|c|}{ What are the underlying problems that make traders vulnerable? } \\
\hline Mixed group & Women & Men \\
\hline $\begin{array}{l}\quad \text { Loans, } \\
\text { need to know how } \\
\text { to access loans } \\
\text { from Business } \\
\text { Support Unit } \\
\text { Information, } \\
\text { specifically about } \\
\text { loans, grants }\end{array}$ & $\begin{array}{l}\text { - Main problem is money. } \\
\text { - Being turned away from clinics } \\
\text { because they want addresses and } \\
\text { phone numbers. } \\
\text { - Financial problems, doctors are } \\
\text { expensive } \\
\text { - AIDS education is important-need } \\
\text { time for training. } \\
\text { - Municipality should make access } \\
\text { available to traders to: } \\
\text { o Open back accounts } \\
\text { o Get loans } \\
\text { o Open accounts in stores }\end{array}$ & $\begin{array}{l}\text { - Need more } \\
\text { knowledge. } \\
\text { - Need better social } \\
\text { support, afraid to talk } \\
\text { about it. } \\
\text { - Financial insecurity } \\
\text { - Service gaps: } \\
\text { O Shelter } \\
\circ \text { Accommodation } \\
\circ \text { Money } \\
\circ \text { Infrastructure - } \\
\text { water, toilets, } \\
\text { electricity } \\
\text { Business upgrades } \\
\text { Right to borrow } \\
\text { money }\end{array}$ \\
\hline
\end{tabular}




\title{
Appendix H: Biomedical Practitioners' Messages around HIV and AIDS
}

\begin{abstract}
ABC as gender-biased:
"The big problem is that women know that when their husband says no, he means no. I had one say she can't use a condom after getting 12 cows for lobola." (Counsellor \#5)

Living positively:

"When someone is positive, we counsel about nutrition, exercise, drinking lots of water and condomizing." (Counsellor \#5)
\end{abstract}

\section{A role for traditional medicine in immune-boosting:}

"I tell people who are positive that ARV roll out is going to take a long time, they could have to wait three months. But even now they can do things... Immune boosters they can buy from the chemist: African potato, unwele, spirulina, garlic, ginger. And good nutrition... yet, being able to buy good food is a problem if they have no money...but I advise them that even in their little garden they can plant carrots, cabbage, spinach." (Counsellor \#1)

Non supportive of traditional healers:

"Of our clients, many come in the late stages because traditional healers have failed. They raise their hopes that they can cure HIV but then they fail." (Counsellor \#2) 
Appendix I: Messages about HIV and AIDS Articulated by Traditional Healers

\begin{tabular}{|c|c|}
\hline Messages & Traditional Healers' Views on HIV/ AIDS \\
\hline$\overline{\mathrm{ABC}}$ & $\begin{array}{l}\text { Pointing to } 2 \text { boxes of condoms amongst the bags of muthi, } \\
\text { "Traders collect them from me, taxi drivers come to get them... I } \\
\text { do a lot of teaching, trying to get behaviour change, prevention } \\
\text { through ABC. I emphasize ABC." (Ma Dlamini) }\end{array}$ \\
\hline AIDS as intentional & $\begin{array}{l}\text { "I've heard that HIV was given to black people by white man, } \\
\text { but I'm not sure" } \\
\text { "People say condoms get injected with infected blood. I think } \\
\text { they could have HIV on them. I don't know about it, I don't use } \\
\text { them" (Inyanga \#1) }\end{array}$ \\
\hline Fate & $\begin{array}{l}\text { "I have older people come for cures for their children who are } \\
\text { not getting better. Some die and some live. I give them muthi } \\
\text { but it's out of my hands. If god wants you then it's your time to } \\
\text { go" (Inyanga \#1) }\end{array}$ \\
\hline AIDS as curable & $\begin{array}{l}\text { "I am trying to eradicate the HIV virus. I have people come to } \\
\text { me positive and then go back to the hospital for a test and be } \\
\text { negative. I use roots and barks to make a drink." (Inyanga \#2) }\end{array}$ \\
\hline $\begin{array}{l}\text { Condoms as } \\
\text { ineffective }\end{array}$ & $\begin{array}{l}\text { "I don't believe condoms can render any help. If shoes can't } \\
\text { prevent you from getting swollen feet if someone has put muthi } \\
\text { down, then condoms can't prevent AIDS." (Inyanga \#2) }\end{array}$ \\
\hline $\begin{array}{l}\text { Muthi treats } \\
\text { symptoms }\end{array}$ & $\begin{array}{l}\text { "At the moment we are giving people muthi who are sick with } \\
\text { AIDS, but we're not sure if the illness is healed. The muthi keeps } \\
\text { the person living longer." (Inyanga \#3) }\end{array}$ \\
\hline $\begin{array}{l}\text { AIDS caused by } \\
\text { misbehaviour; youth } \\
\text { disease }\end{array}$ & $\begin{array}{l}\text { "AIDS is there and the causes are poverty and behaviour. You } \\
\text { don't get it by having sexual intercourse only, people get it when } \\
\text { they don't respect their parents, when they misbehave." (Inyanga } \\
\text { \#4) }\end{array}$ \\
\hline $\begin{array}{l}\text { Prevention through } \\
\text { traditions; abstinence }\end{array}$ & $\begin{array}{l}\text { "Traditionally, there is a big celebration at } 21 \text { if the person is } \\
\text { still a virgin... the traditional culture through this celebration is a } \\
\text { way to prevent young people from contracting HIV ... young } \\
\text { people should be promised a huge reward for keeping virginity } \\
\text { until } 21 . " \text { (Ma Dlamini) }\end{array}$ \\
\hline $\begin{array}{l}\text { Concerns with } \\
\text { intellectual property }\end{array}$ & $\begin{array}{l}\text { "Inyangas are jealous. They don't want to work together. They } \\
\text { hide treatments from each other; they are competitive." (Inyanga } \\
\text { \#4) } \\
\text { "We will not give away our secrets so that they can put a } \\
\text { trademark on them and sell them." (THC Meeting) }\end{array}$ \\
\hline
\end{tabular}


Appendix J: Uneven Vulnerabilities Differentiated by Gender and Age

\begin{tabular}{|c|c|c|}
\hline & Gender-age trends & $\begin{array}{c}\text { Evidence } \\
\text { Sample: Men: } 4 \text { younger }(\mathrm{YM}) / 4 \text { older men (OM) } \\
\text { Women: } 6 \text { younger }(\mathrm{YW}) / 6 \text { older women }(\mathrm{OW})\end{array}$ \\
\hline $\begin{array}{l}\text { Family and } \\
\text { social } \\
\text { responsibilities }\end{array}$ & $\begin{array}{l}\text { - Women experience a double } \\
\text { burden of responsibility: financial } \\
\text { and care. } \\
\text { - Family responsibility starts } \\
\text { younger for women and increases } \\
\text { with age. }\end{array}$ & $\begin{array}{l}\text { YM: All No children, little family responsibility } \\
\text { YW: All } \begin{array}{l}\text { Financial responsibilities for children, } \\
\text { siblings and/ or parents; }\end{array} \\
\begin{array}{cl}5 \text { Have children (4 are primary caregivers). } \\
\text { OM: All Financial responsibilities (none are } \\
\text { primary caregivers) }\end{array} \\
\begin{array}{cl}\text { OW: All } & \text { Financial and care responsibilities; } \\
5 & \text { Support extended families. }\end{array}\end{array}$ \\
\hline $\begin{array}{l}\text { Social security } \\
\text { and support }\end{array}$ & $\begin{array}{l}\text { - Loss of parents and strained } \\
\text { relations with older male siblings } \\
\text { over access to family home/ } \\
\text { resources may increase } \\
\text { vulnerability for younger women. } \\
\text { - For older women, house as } \\
\text { asset, symbol; building house as } \\
\text { security for family. } \\
\text { - Older men have more formal } \\
\text { insurance and savings; women } \\
\text { have informal schemes. }\end{array}$ & $\begin{array}{l}2 \text { YW have lost parents and relations with older } \\
\text { brothers in charge of family home are strained } \\
\text { over access to resources. Both feel loss of support } \\
\& \text { security. } \\
3 \text { OW feel heightened insecurity due to loss of } \\
\text { house due to political violence; } 4 \text { OW urgently } \\
\text { wish to build/ extend a home for posterity. } \\
3 \text { OM have formal insurance or savings, where no } \\
\text { other group does; lYM has stokvel. } \\
3 \text { YW \& } 4 \text { OW women have informal insurance, } \\
\text { stokvels and/ or community-oriented savings; } \\
2 \text { OW accessing social transfers. }\end{array}$ \\
\hline $\begin{array}{l}\text { Social and } \\
\text { economic } \\
\text { opportunities }\end{array}$ & $\begin{array}{l}\text { - Young men have more access to } \\
\text { family assets than young women. } \\
\text { - Men have more access to capital } \\
\text { and education. } \\
\text { - Older men accumulating most } \\
\text { profits from trading. } \\
\text { - Lack of capital /greater family } \\
\text { responsibility suggests women } \\
\text { have little chance for advancement }\end{array}$ & $\begin{array}{l}3 \text { YM could access money from family members; } \\
\text { none of YW could. } \\
\text { More than half of men could access capital to } \\
\text { uplift business or obtain training; only } 2 / 12 \\
\text { women have any access to capital \& none have } \\
\text { access to education or training. } \\
4 \text { / } 8 \text { men expressed that business is lucrative } \\
\text { enough to accumulate savings, } 3 \text { are OM; none of } \\
\text { women felt incomes were adequate to meet needs. }\end{array}$ \\
\hline $\begin{array}{l}\text { Livelihood } \\
\text { security }\end{array}$ & $\begin{array}{l}\text { - Young people \& women in least } \\
\text { secure trades. } \\
\text { - Trading committees exclude } \\
\text { itinerants \& traders without } \\
\text { permits; needs of women \& youth } \\
\text { lack adequate representation. }\end{array}$ & $\begin{array}{l}\text { All of the young people are itinerants or work for } \\
\text { other traders; none owns a permit. No older people } \\
\text { work for others, } 7 / 10 \text { have permits. Permits mean } \\
\text { less harassment, better access to storage, } \\
\text { representation. Leadership is dominated by older } \\
\text { men; some based on patronage. } \\
\text { Women more often in food trades with higher } \\
\text { potential losses. } 4 / 12 \text { women have permits. }\end{array}$ \\
\hline $\begin{array}{l}\text { Access to } \\
\text { services \& } \\
\text { information }\end{array}$ & $\begin{array}{l}\text { Women discuss barriers to } \\
\text { accessing services / information. }\end{array}$ & $\begin{array}{l}\text { Women discussed lack of access to day care, legal } \\
\text { aid, information on social transfers; men did not. } \\
6 / 12 \text { women expressed barriers to health care; } \\
\text { only } 1 \text { man expressed such concerns. }\end{array}$ \\
\hline Health $\&$ illness & $\begin{array}{l}\text { - Women report financial and } \\
\text { family stress as health concerns } \\
\text { more often than men. } \\
\text { - Older women carry an } \\
\text { excessive burden of disease } \\
\text { - Women exposed to more } \\
\text { workplace health threats. } \\
\text { - Women report missing more } \\
\text { work due to illness (self or child). }\end{array}$ & $\begin{array}{l}\text { 11 /12 women reported financial or family stress } \\
\text { among top health concerns; none of men do. } \\
4 \text { OW suffer from inconsistently treated chronic } \\
\text { diseases; } 1 \text { YW, } 1 \text { man discussed chronic diseases. } \\
9 / 12 \text { women reported workplace health threats; } \\
3 / 8 \text { men did. } \\
7 / 12 \text { women missed work during the fieldwork } \\
\text { due to illness of self or child; } 2 / 8 \text { men did. }\end{array}$ \\
\hline
\end{tabular}




\section{Appendix K: Examples of Macro-Micro Interactions Generating Vulnerabilities for Traders}

\begin{tabular}{|c|c|}
\hline Outer ring/ macro context & Impacts on inner ring (micro context) with feedbacks \\
\hline \multicolumn{2}{|l|}{ Political economy transition (Figure 5a) } \\
\hline $\begin{array}{l}\text { Historical exclusion from education and } \\
\text { employment }\end{array}$ & $\begin{array}{l}\text { Lack of employment opportunities, livelihood insecurity } \\
\text { (Figure 5iii) }\end{array}$ \\
\hline Institutionalized gender inequalities & $\begin{array}{l}\text { Shaping of gender norms (Figure 5iii), and feeds back on } \\
\text { sexual behaviours of men and women (Figure } 5 \mathrm{i} \text { ), with } \\
\text { additional feedback to spread of HIV/ AIDS (Figure } 5 \mathrm{~d} \text { ) }\end{array}$ \\
\hline Political violence & $\begin{array}{l}\text { Impacts sense of belonging and social security (Figure 5iii) } \\
\text { Destruction of land/ house (Figure 5ii), and feeds back to } \\
\text { impact migration (Figure 5c) }\end{array}$ \\
\hline Social transfers and rights & Improved social security (Figure 5iii) \\
\hline \multicolumn{2}{|l|}{$\begin{array}{l}\text { Globalization and macro-economic } \\
\text { 'reform' (Figure Sb) }\end{array}$} \\
\hline $\begin{array}{l}\text { Shift from RDP to GEAR; jobless growth, } \\
\text { workforce unable to compete in global } \\
\text { market }\end{array}$ & $\begin{array}{l}\text { Rising unemployment, lack of opportunities for street traders } \\
\text { (Figure 5iii), with feedback to urban migration (Figure 5c) } \\
\text { Livelihood insecurity, with feedback for accessing health care } \\
\text { and other services (Figure 5iii) } \\
\text { Entrenching poverty, declining school enrolment (Figure 5iii) }\end{array}$ \\
\hline Informalization of economy & $\begin{array}{l}\text { Lack of social protection (Figure 5iii), increased } \\
\text { precariousness of working conditions (Figure 5ii) }\end{array}$ \\
\hline $\begin{array}{l}\text { Decentralization, shift to local economic } \\
\text { development, state withdrawal }\end{array}$ & $\begin{array}{l}\text { Renewal project, 'outsourcing' in management, with feedback } \\
\text { to changing security threats in Warwick Junction (Figure 5iii) }\end{array}$ \\
\hline \multicolumn{2}{|l|}{ Migration (Figure 5c) } \\
\hline Increased mobility, desegregation & $\begin{array}{l}\text { Impacts sense of displacement (Figure 5i) } \\
\text { Impacts access to information (Figure 5iii) }\end{array}$ \\
\hline Urbanization & $\begin{array}{l}\text { Development of informal settlements, urban decay (Figure } \\
\text { 5ii) } \\
\text { Crime, alienation, dangerous conditions, market 'saturation' } \\
\text { (Figure 5iii), feeds back to perpetuate family fracture, gender } \\
\text { relations, constructions of masculinity (Figure 5iii), feeds } \\
\text { back to impact behaviour, sexuality, 'recklessness' (Figure } \\
\text { 5i), feeds back to impact spread of HIV/ AIDS (Figure 5d) } \\
\text { Better access to services (Figure 5iii) }\end{array}$ \\
\hline \multicolumn{2}{|l|}{ HIV/ AIDS (Figure 5d) } \\
\hline $\begin{array}{l}\text { Rising morbidity and mortality of young } \\
\text { adults }\end{array}$ & $\begin{array}{l}\text { Perpetuating financial burden, family stress, impoverishment } \\
\text { (Figure 5iii) } \\
\text { Causing emotional stress, fear (Figure 5i) } \\
\text { Perpetuating household changes (taking in sick adults and } \\
\text { orphans) (Figure 5iii), with feedback to migration (Figure 5c) }\end{array}$ \\
\hline $\begin{array}{l}\text { National government response/ lack of } \\
\text { leadership }\end{array}$ & Generating mixed messages, perpetuating stigma (Figure 5iii) \\
\hline $\begin{array}{l}\text { Uneven ARV roll-out \& two-tiered health } \\
\text { care system }\end{array}$ & $\begin{array}{l}\text { Perpetuating inequalities, lack of access to treatment (Figure } \\
\text { 5iii) }\end{array}$ \\
\hline $\begin{array}{l}\text { AIDS enters amidst rapid change (and } \\
\text { changing discourses) }\end{array}$ & $\begin{array}{l}\text { Lack of clear truth (Figure 5iii), traditional and biomedical } \\
\text { health care providers messages not matched with lived } \\
\text { impacts }\end{array}$ \\
\hline
\end{tabular}




\section{Appendix L: Examples of Inter-Ring Interactions in Figure 5}

\begin{tabular}{|c|c|}
\hline Micro/ macro conditions (inner/ outer rings) & Response capacity/ power relations (middle ring) \\
\hline $\begin{array}{l}\text { Lack of employment, livelihood insecurity, social } \\
\text { insecurity, food insecurity (Figure 5iii), } \\
\text { perpetuated by economic 'reform' and } \\
\text { globalization (Figure 5b), and rooted in historical } \\
\text { inequalities (Figure 5a) }\end{array}$ & $\begin{array}{l}\text { Generating sense of powerlessness to affect change, } \\
\text { with impacts on constructions of gender identities } \\
\text { Impeding taking time off work, accessing health } \\
\text { care, taking care of family members, recovering } \\
\text { from illnesses }\end{array}$ \\
\hline $\begin{array}{l}\text { Young people/ women excluded from employment } \\
\text { and negotiating power in Warwick Junction } \\
\text { (Figure 5iii) }\end{array}$ & $\begin{array}{l}\text { Impeding access to protection from workplace } \\
\text { hazards, ability to leave space, access to services, } \\
\text { voice }\end{array}$ \\
\hline $\begin{array}{l}\text { Poverty, including impoverished living conditions } \\
\text { (Figure 5iii) }\end{array}$ & Impeding coping with secondary illnesses \\
\hline $\begin{array}{l}\text { Lack of clear truth about HIV/ AIDS (Figure 5iii), } \\
\text { generated in part by national government response } \\
\text { to AIDS (Figure 5d) }\end{array}$ & Impeding prevention and treatment \\
\hline $\begin{array}{l}\text { AIDS (Figure 5d), impoverishing, sexually } \\
\text { transmitted/stigma (Figure 5iii) }\end{array}$ & $\begin{array}{l}\text { Impeding prevention, treatment, care } \\
\text { Impeding testing amongst youth, access to social } \\
\text { support } \\
\text { Stigma generating powerlessness among older } \\
\text { women to communicate with younger family } \\
\text { members }\end{array}$ \\
\hline $\begin{array}{l}\text { Mobility \& displacement from families (Figure 5c } \\
\text { \& Figure 5iii) }\end{array}$ & $\begin{array}{l}\text { Impeding accessing social support, caring for } \\
\text { family members }\end{array}$ \\
\hline $\begin{array}{l}\text { Lack of information, resources and services } \\
\text { (Figure 5iii), driven in part by mobility (Figure 5c) }\end{array}$ & Impeding accessing social transfers, health care \\
\hline $\begin{array}{l}\text { Gender relations (Figure 5iii), exhibited in sexual } \\
\text { practices (Figure } 5 \mathrm{i} \text { ) and household access/ control } \\
\text { over resources (Figure } 5 \text { iii), and driven by } \\
\text { historical gender inequalities (Figure } 5 \mathrm{a} \text { ) }\end{array}$ & $\begin{array}{l}\text { Impeding prevention; generating sense of } \\
\text { powerlessness among young women to use } \\
\text { condoms } \\
\text { Older \& younger women feeling a drain on earnings } \\
\text { because of division of care and control of } \\
\text { resources in households; impeding care for self } \\
\text { and family }\end{array}$ \\
\hline $\begin{array}{l}\text { Transitioning political economy (Figure 5a) } \\
\text { leading to basic services and social transfers } \\
\text { (Figure 5iii) }\end{array}$ & Enabling care of household members \\
\hline Civil society growth (Figure $5 \mathrm{a}$ ) & $\begin{array}{l}\text { Enabling access to treatment (e.g., Treatment } \\
\text { Action Campaign) }\end{array}$ \\
\hline $\begin{array}{l}\text { Decentralization (Figure 5a), of AIDS Strategy } \\
\text { and informal economy }\end{array}$ & Enabling opportunities to respond at local level \\
\hline
\end{tabular}

